Frenando la ola: el progreso hacia la resolución de las causas

de la decadencia y la aplicación de respuestas de manejo

ante la desaparición de mamíferos del norte de Australia

\title{
Stemming the tide: progress towards resolving the causes of decline and implementing management responses for the disappearing mammal fauna of northern Australia
}

\author{
Mark R. Ziembicki ${ }^{*}, 1,2$, John C. Z. Woinarski ${ }^{3,4}$, Jonathan K. Webb ${ }^{5}$, Eric Vanderduys ${ }^{6}$, Katherine Tuft ${ }^{7}$, James Smith ${ }^{4,7}$, \\ Euan G. Ritchie ${ }^{8}$, Terry B. Reardon ${ }^{9}$, lan J. Radford ${ }^{10}$, Noel Preece ${ }^{1,3,11}$, Justin Perry ${ }^{6}$, Brett P. Murphy ${ }^{12}$, Hugh \\ McGregor $^{7}{ }^{73}$, Sarah Legge ${ }^{7}$, Lily Leahy, ${ }^{73}$, Michael J. Lawes ${ }^{4}$, John Kanowski ${ }^{14}$, Chris N. Johnson ${ }^{13}$, Alex James ${ }^{7}$, \\ Anthony D. Griffiths ${ }^{15}$, Graeme Gillespie ${ }^{3,15}$, Anke S.K. Frank ${ }^{7,13}$, Alaric Fisher ${ }^{3,15}$, Andrew A. Burbidge ${ }^{16}$
}

${ }^{1}$ Centre for Tropical Environmental \& Sustainability Science, College of Marine \& Environmental Sciences, James Cook University, Queensland, 4811, Australia.

${ }^{2}$ Centre for Tropical Biodiversity and Climate Change, College of Marine \& Environmental Sciences, James Cook University, Queensland, 4811, Australia.

${ }^{3}$ NERP North Australia Hub and Threatened Species Hub of the National Environmental Science Program, Charles Darwin University, Darwin, Northern Territory, 0909, Australia.

${ }^{4}$ Research Institute for the Environment and Livelihoods, Charles Darwin University, Darwin, Northern Territory, 0909, Australia.

${ }^{5}$ School of the Environment, PO Box 123, University of Technology Sydney, Broadway, NSW, 2007, Australia.

${ }^{6} \mathrm{CSIRO}$ Land and Water, PMB PO, Aitkenvale, Queensland, 4814, Australia.

${ }^{7}$ Australian Wildlife Conservancy, Mornington Sanctuary, PMB 925, Derby, Western Australia.

${ }^{8}$ Centre for Integrative Ecology, School of Life and Environmental Sciences, Faculty of Science Engineering \& Built Environment, Deakin University, Victoria 3125, Australia.

${ }^{9}$ Evolutionary Biology Unit, South Australian Museum, North Terrace, Adelaide, 5000, South Australia .

${ }^{10}$ Division of Science and Conservation, Department of Parks and Wildlife, PO Box 942, Kununurra, 6743, Western Australia.

"Biome5 Pty Ltd, PO Box 1200 Atherton, Queensland, 4883, Australia.

${ }^{12}$ NERP Environmental Decisions Hub, School of Botany, The University of Melbourne, Victoria, 3010, Australia .

${ }^{13}$ School of Biological Sciences, University of Tasmania, Hobart, Tasmania, 7001, Australia.

${ }^{14}$ Australian Wildlife Conservancy, Malanda, Queensland, 4885, Australia.

${ }^{15}$ Flora and Fauna Division, Department of Land Resource Management, PO Box 496, Palmerston, 0810, Northern Territory, Australia. ${ }^{16}$ Western Australian Wildlife Research Centre, Department of Parks and Wildlife, PO Box 51, Wanneroo, 6946, Western Australia.

${ }^{*}$ Corresponding author:

Introduction: Recent studies at sites in northern Australia have reported severe and rapid decline of several native mammal species, notwithstanding an environmental context (small human population size, limited habitat loss, substantial reservation extent) that should provide relative conservation security. All of the more speciose taxonomic groups of mammals in northern Australia have some species for which their conservation status has been assessed as threatened, with $53 \%$ of dasyurid, $47 \%$ of macropod and potoroid, $33 \%$ of bandicoot and bilby, $33 \%$ of possum, $30 \%$ of rodent, and $24 \%$ of bat species being assessed as extinct, threatened or near threatened. However, the geographical extent and timing of declines, and their causes, remain poorly resolved, limiting the application of remedial management actions.

Material and methods: Focusing on the tropical savannas of northern Australia, this paper reviews disparate recent and ongoing studies that provide information on population trends across a broader geographic scope than the previously reported sites, and examines the conservation status and trends for mammal groups (bats, macropods) not well sampled in previous monitoring studies. It describes some diverse approaches of studies seeking to document conservation status and trends, and of the factors that may be contributing to observed patterns of decline. 
Results and Discussion: Current trends and potential causal factors for declines. The studies reported demonstrate that the extent and timing of impacts and threats have been variable across the region, although there is a general gradational pattern of earlier and more severe decline from inland lower rainfall areas to higher rainfall coastal regions. Some small isolated areas appear to have retained their mammal species, as have many islands which remain critical refuges. There is now some compelling evidence that predation by feral cats is implicated in the observed decline, with those impacts likely to be exacerbated by prevailing fire regimes (frequent, extensive and intense fire), by reduction in ground vegetation cover due to livestock and, in some areas, by 'control' of dingoes. However the impacts of dingoes may be complex, and are not yet well resolved in this area. The relative impacts of these individual factors vary spatially (with most severe impacts in higher rainfall and more rugged areas) and between different mammal species, with some species responding idiosyncratically: the most notable example is the rapid decline of the northern quoll (Dasyurus hallucatus) due to poisoning by the introduced cane toad (Rhinella marina), which continues to spread extensively across northern Australia. The impact of disease, if any, remains unresolved.

Conservation Management Responses. Recovery of the native mammal fauna may be impossible in some areas. However, there are now examples of rapid recovery following threat management. Priority conservation actions include: enhanced biosecurity for important islands, establishment of a network of feral predator exclosures, intensive fire management (aimed at increasing the extent of longer-unburnt habitat and in delivering fine scale patch burning), reduction in feral stock in conservation reserves, and acquisition for conservation purposes of some pastoral lands in areas that are significant for mammal conservation.

Key words: cane toads, conservation, disease, feral cats, fire, pastoralism, savanna, threats

\section{Introduction}

Recent papers (Fisher et al. 2014; Woinarski et al. 2010; Woinarski et al. 2011a) have identified a substantial recent and ongoing decline in many native land mammal species of the tropical savannas of northern Australia (Figure 1). This decline is occurring notwithstanding that, in a global context, the environments in this region are relatively intact, human population density is very low and the extent of conservation reserves is substantial. Indeed, much of the evidence for declines arises from monitoring studies in large and relatively well-resourced conservation reserves (Woinarski et al. 2010; Woinarski et al. 2011a).

In global comparisons, this decline is unusual, because severe biodiversity decline is usually associated with marked environmental modification and high human population density (Cardillo et al. 2004; Cincotta et al. 2000). These contemporary declines are notable in that the mammal fauna of northern Australia was previously considered resilient and largely spared the pattern of decline and extinction that has severely diminished the distinctive Australian mammal fauna, particularly those in the weight range of $35 \mathrm{~g}$ to $5.5 \mathrm{~kg}$ (the 'Critical Weight Range') in central and southern Australia (Burbidge and McKenzie 1989) (Fig. 2). Furthermore, recent global-scale predictions of future mammal decline based on estimates of latent extinction risk suggest that northern Australia should be experiencing a significant loss (Cardillo et al. 2006).

Woinarski et al. (2011a) proposed a range of possible causes for the decline of northern Australian mammals, with most relating ultimately to broad-scale but subtle environmental transformation accompanying European settlement of Australia, with particular emphasis given to predation by feral cats, changed fire regimes and vegetation change associated with livestock and feral herbivores. More recently, modelling of life history, morphological and other attributes of individual species suggested that predation by feral cats was likely to be a principal causative factor (Fisher et al. 2014; Murphy and Davies 2014; Woinarski 2015). Nonetheless, the evidence is limited, and accordingly it has been difficult to prescribe optimal responsive management, and to understand why feral cats may only now be causing such decline despite being present in the region for at least a century (Abbott 2002). However, a diverse series of recent research initiatives 
is attempting to better resolve the pattern and extent of decline and its causes, and to propose and demonstrate remedial management priorities. In this paper, we describe some of that current research and review progress since the initial description and review of the problem (Woinarski et al. 2011a).

\section{Specifically, we consider:}

(1) Spatial patterning of mammal decline in northern Australia. Although some earlier papers (Kitchener 1978; McKenzie 1981) documented historical (i.e. over a period of c. 100 years) declines in the mammal fauna of the lower rainfall southeastern and southwestern Kimberley (in northwestern Australia), much of the information on current decline arises from a substantial monitoring program at a single site, Kakadu National Park (hereafter Kakadu). The extent to which this site, and its pattern of decline, is representative of northern Australia remains poorly resolved. Here, we document recent research from a range of other sites in northeastern Australia (Cape York Peninsula in Queensland), more broadly across the 'Top End' of the Northern Territory, and in northwestern Australia, noting in particular whether these areas are also experiencing the extent and rate of declines reported currently from Kakadu.

(2) The taxonomic and ecological characterisation of declining mammals. As described above, much of the evidence for decline arises from monitoring studies in Kakadu (Woinarski et al. 2010; Woinarski et al. 2001). However, these studies were biased, because their methodology collected substantial information on small and medium-sized non-volant mammal species, but provided very little information on larger mammals (notably macropods) and no useful information on bats. Here, we complement the existing evidence concerning small and medium-sized mammals with brief reviews of the status of bats and macropods in northern Australia.

(3) A brief review of methodologies. The overall objectives of research to date have been to determine which species are declining, why, and what should be done to remedy the declines? A range of methodologies have been applied to provide complementary insights into the problem and its resolution. These approaches (which include monitoring, modelling, survey using remote cameras, experimentation, and assessment of historical decline through subfossils and ethnozoological studies), and their utility, are reviewed briefly.

Based on this information, we refine the conceptual framework of the mechanisms of decline presented by Woinarski et al. (2011a), and describe the evidence for a set of candidate causal factors, and their inter-relationships. From this basis, we consider whether there are further critical studies required to more definitively resolve the causes of mammal declines, and provide a series of management recommendations.

\section{Material and methods}

\section{STUDY AREA}

The geographic focus of this paper are the tropical savanna landscapes of northern Australia (Fig. 1), about a 1.8 million $\mathrm{km}^{2}$ area that is moderately well defined by the marked influence of a monsoonal (wet-dry) climate (Garnett et al. 2010; Woinarski et al. 2007). As defined here, this area excludes the Wet Tropics bioregion in a small section of northeastern Australia, characterised by diverse rainforest, relatively marked altitudinal variation and a very distinctive biota.

A series of loosely-linked environmental and land-use factors characterise northern Australia. By far the most extensive vegetation type is savanna woodland (featuring relatively open eucalypt forests and woodlands over a tall grassy understorey), varying in structure with annual rainfall, soils and fire regimes. Within this dominant matrix, there are smaller areas of mangroves, rainforests, 
tussock grasslands, hummock grasslands, wetlands, heathlands and Acacia woodlands, with the distribution patterns of vegetation types determined mostly by variation in soils, rainfall, geomorphology and fire regimes (Hutley et al. 2011; Russell-Smith et al. 2012; Williams et al. 1996a). Rainfall shows pronounced spatial variation, typically with highest annual rainfall in coastal areas (to c. $2000 \mathrm{~mm}$ in parts of Cape York Peninsula in northeastern Australia and parts of the Tiwi islands, and c. $1400 \mathrm{~mm}$ in the north Kimberley) and diminishing gradationally towards central Australia (to about $500 \mathrm{~mm}$ at the southern limit of the area considered here as northern Australia). Across this area, rainfall is highly seasonal, with c. 80-90 \% falling in a relatively short wet season (ca. November to April). Temperatures are typically high year-round, but peak in the wet season. The monsoonal influence has been long-standing (Bowman et al. 2010).

There are no tall mountains in northern Australia, but some regions (notably much of the Kimberley, the Arnhem Plateau and the Mcllwraith and Iron Ranges on Cape York Peninsula) are spectacularly dissected and rugged, and these regions have probably been important refugiaas they harbour many narrowly-restricted endemic mammal and other species (Crisp et al. 2001; Hitchcock et al. 2013; Pepper and Keogh 2014; Potter et al. 2012a; Potter et al. 2014b; Start et al. 2007; Woinarski et al. 2006a; Woinarski et al. 2009b). There are also many continental islands in northern Australia, ranging from ephemeral islets to some of Australia's largest islands, including Melville Island (5786 $\left.\mathrm{km}^{2}\right)$, Groote Eylandt $\left(2285 \mathrm{~km}^{2}\right)$ and Bathurst Island $\left(1693 \mathrm{~km}^{2}\right)$. Although almost all of these islands, with the exception of some remote cays, have had a long history of intermittent connection to the Australian mainland (and the broader Sahul - New Guinea land mass), mostly last broken 8000 to 6000 years ago, some of these islands support endemic mammal subspecies, and many others are now the sole refuge for species that have disappeared recently from their broader mainland ranges because of pervasive threats (Firth and Panton 2006; Gibson and McKenzie 2012; Woinarski et al. 2011 b).

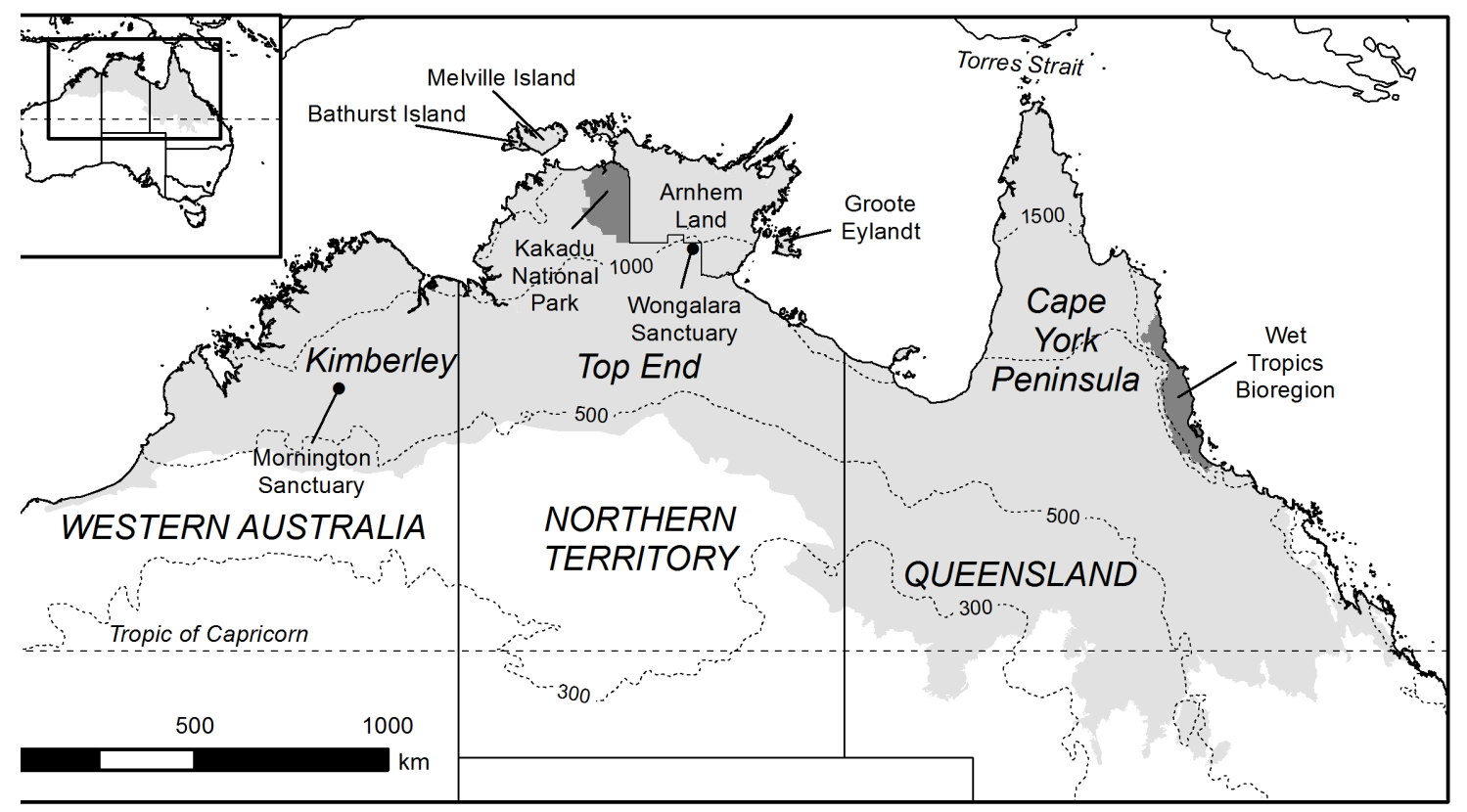

Figure 1. Map of northern Australia (pale grey shading) showing places referred to in text, state/territory boundaries and isohyets (dotted lines). Note that the inland and southern border of the region defined here as northern Australia is diffuse, but follows Fox et al. (2001). 
Northern Australia comprises three readily distinguished geographic subdivisions, coinciding with state-territory boundaries: the northwestern (Kimberley, in Western Australia), the northern ('Top End' in the Northern Territory) and the northeastern (Cape York Peninsula and the Gulf hinterland in Queensland; Figure 1). Although biota and environments are broadly similar across these regions, there is a complex series of major and minor biogeographic divides, most notably with an arid intrusion (the Carpentarian Barrier) between the northeastern and northern regions, and a less well defined intrusion between northern and northwestern regions (Eldridge et al. 2011; Ford and Johnson 2007). Many species occur across all three regions; others are represented by pairs of vicariant species. The northeastern component, particularly Cape York Peninsula, has some notable distinctions in its biota, with greater diversity of rainforest-associated species and bats, related to the region's closer proximity to New Guinea, higher rainfall and larger extent of rainforest vegetation (Hitchcock et al. 2013).

Across northern Australia, human population density is low (typically $<0.1$ person $\mathrm{km}^{-2}$ ) and Indigenous people comprise much (20-30\%) of the population and own 30-50 \% of the land. By far the most extensive land-use is pastoralism, typically based on native vegetation. Except in the south-east, there has been little intensive environmental modification, but there are pervasive and more subtle changes due to introduced animals, plants and changed fire regimes. Largely driven by the climate, fire is very frequent in this landscape, especially in higher rainfall areas, where 30 to $50 \%$ of the area is burnt annually (Russell-Smith and Edwards 2006). It is likely that this regime has changed significantly since European settlement 150 to 110 years ago (Ash et al. 1997b), in part due to changes in the demography and priorities of Indigenous land owners (Russell-Smith et al. 2003). More recently, the spread in some areas of introduced African pasture grasses, particularly gamba grass (Andropogon gayanus), has led to more destructive fires and fire regimes in weed-invaded areas, and to predictions that these will drive major environmental transformation (Grice et al. 2013; Setterfield et al. 2013; Setterfield et al. 2010).

The extant native land mammal fauna of northern Australia (Table 1) is broadly typical of Australia as a whole, with a high diversity of marsupials (about 68 spp.; note that tallies vary with different treatments of distributional limits around the diffuse border of the region here considered as northern Australia), rodents (33 spp.) and bats (55 spp.), plus two monotremes and the dingo (Canis dingo), a eutherian carnivore introduced by humans to Australia c. 4000 years ago (Ardalan et al. 2012; Savolainen et al. 2004). Fifty-five of these species (about one third of the northern Australian tally) are restricted to this region; 62 species are Australian endemics that also occur elsewhere in Australia; 30 species occur elsewhere in Australia and extralimitally; and 12 species also occur extralimitally (but not elsewhere in Australia). Three now highly restricted and threatened mammal species - bridled nailtail wallaby (Onychogalea fraenata), northern hairy-nosed wombat (Lasiorhinus krefftii) and mahogany glider (Petaurus gracilis) - occur only at a few sites in the extreme southeastern fringe of the region considered here, and are not a primary focus of this review (at least in part because a major threat for these species has been extensive vegetation loss, atypical of the broader region).

Some species (e.g. ghost bat (Macroderma gigas), spectacled hare-wallaby (Lagorchestes conspicillatus)) or species-groups (e.g. Conilurus, the rabbit-rats) persist in northern Australia but have declined or disappeared from their former range in other Australian regions. Although some megafauna species disappeared from northern Australia in the last tens of thousands of years, until recently it was considered that no mammal species had disappeared from northern Australia since European settlement, a markedly different and better fate than that for Australian mammals more generally (Woinarski et al. 2014; Figure 2).

All native mammals in northern Australia are protected under state/territory legislation, other than, a) some instances where dingoes are subject to broad-scale 'control' (poison-baiting and trapping) due to perceived detrimental impacts on pastoralism, b) some more localised 'control' of 
flying-foxes due to perceived detrimental impacts on horticulture and nuisance value of colonies in urban areas, c) some culling of macropods (principally agile wallaby (Macropus agilis)) where populations are perceived to be over-abundant and detrimentally affecting pastoral profitability (Gooding and Harrison 1954), d) some commercial hunting of macropods for meat (mostly in parts of Queensland at the southeastern fringe of the region considered here), and e) ongoing and relatively small-scale hunting of a range of mammal species (but mostly macropods) in some Indigenous communities (Altman 1987; Vardon et al. 1999).

Many introduced mammals now have a far greater biomass and ecological influence in this region than do native mammals (Woinarski 2014). Large populations of feral pig (Sus scrofa), cattle (Bos spp.), water buffalo (Bubalus bubalis), horse (Equus caballus) and donkey (E. asinus) occur across much to most of mainland northern Australia. Feral camels (Camelus dromedarius) are widespread in the more arid fringes, and there are localised populations of goats (Capra hircus), sambar deer (Cervus unicolor) and banteng (Bos javanicus). Feral cats (Felis catus) are ubiquitous on the mainland and occur on some islands. However, most of northern Australia is beyond the normal range of the other main introduced predator, the European red fox (Vulpes vulpes), and another introduced mammal pest, the European rabbit (Oryctolagus cuniculus) (Smith and Quin 1996). The introduced black rat (Rattus rattus) currently has a highly localised distribution and is often associated with human settlements, but may be expanding its range.

\section{METHODS}

In this section, we review briefly the range of approaches that have been used to help refine the current status of, and the causes of decline in, the native mammal fauna of northern Australia.

\section{Inventory and taxonomic sorting}

Native mammals of northern Australia have not been thoroughly studied, and it is likely that further species remain to be discovered and that existing species concepts will need further resolution. Twenty-six species ( $18 \%$ of the north Australian mammal fauna) have been described since 1975. Most taxonomic uncertainty relates to cryptic species, the extent of taxonomic divergence across the biogeographic regions of northern Australia, and the relationship oftaxa occurring on Cape York Peninsula and in New Guinea (or, for a few bat taxa, more broadly across southeastern Asia and Indo-Papua). Detailed genetic and morphological studies for several groups have resolved many previously challenging species-groups, and highlight a previously unrecognised level of endemism and speciation in some parts of northern Australia (Moritz et al. 2013; Potter et al. 2014a; Potter et al. 2012a; Potter et al. 2012b; Reardon et al. 2014; Westerman et al. 2012). Groups requiring further taxonomic resolution include the bat genera Miniopterus, Myotis, Nyctophilus, Phoniscus, Scotorepens, Vespadelus, Rhinolophus, Rhinonicteris, Hipposideros, Taphozous, Nyctimene and Mormopterus, the marsupial genera Sminthopsis, Planigale, Phascogale, Isoodon and Petrogale and the rodent genera Pseudomys, Xeromys and Melomys.

\section{Subfossils}

Knowledge of the native mammal fauna present in northern Australia at the 'baseline' time of European settlement is limited and fragmentary, because few substantial inventories were conducted in the first few decades following that settlement. However, information from some of these very few early surveys, most notably those by Knut Dahl in northern and northwestern Australia (Dahl 1897; Dahl 1926), points to substantial changes (mostly losses) of native mammals compared to contemporary inventories (Kitchener 1978; McKenzie 1981). 
Recently, some assessments of subfossils (from owl pellets and cave deposits), albeit at few sites in northern Australia, similarly indicate that the contemporary native mammal fauna of northern Australia is notably diminished from that present at about the time of European settlement (Cramb and Hocknull 2010; Foley 1985; Start et al. 2012; White and Mason 2011). This is in contrast to the assertion of an intact fauna presented in previous accounts (e.g. Figure 2). At least four species (two Notomys species, a Pseudomys species, and the Capricorn rabbit-rat (Conilurus capricornensis)) now known from subfossils most likely post-dated European settlement, and have never been recorded as living animals. They had not been previously recognised as part of the northern Australian mammal fauna although they disappeared recently, but before we were aware of their existence (Cramb and Hocknull 2010; Start et al. 2012). Subfossils have revealed much about historical changes in this fauna, but it remains tantalising because of the very small number of locations at which they have been reported, as well as relatively few sites where subfossils may persist, and the constraints on interpretation of dating for some of this material.

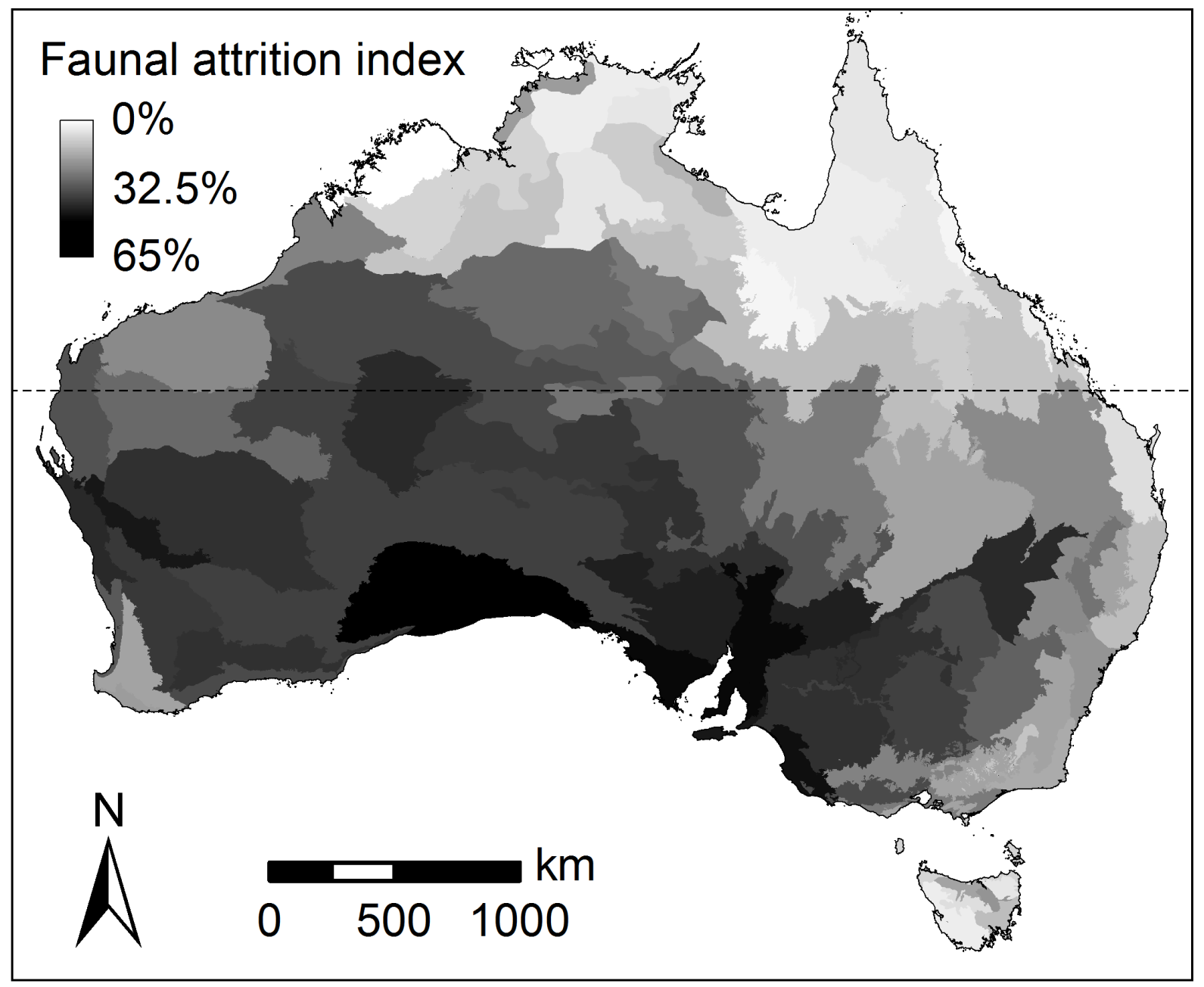

Figure 2. The extent of historical changes in the mammal fauna of continental Australia, using a Faunal Attrition Index (FAI) defined by McKenzie et al. (2007). FAl is calculated as (N+E-P)/2N, where $\mathrm{N}$ is the number of species originally in the region's fauna, $\mathrm{P}$ is the number of species still present and $\mathrm{E}$ is the number of species extirpated from the regional fauna: the Index varies from 0 (if all species have persisted) to 1 (if all species have been extirpated). Map from Murphy and Davies (2014). 


\section{Integrated distributional databases}

Interpretation of the spatial and temporal patterns of decline in mammals of northern Australia has been hampered until recently by the relative lack of integrated distributional data sets. For continental-scale analyses, Burbidge et al. (2008) and McKenzie and Burbidge (2002) compiled a broad bioregional-scale distributional matrix for Australian mammals with interpretation of historically changing distributions, but this database is too coarse for detailed examination of changes in the mammal fauna within northern Australia. More recently, a national distributional database for non-volant mammals has been collated from the separate holdings of conservation agencies and museums of Australia's states and territories (Fisher et al. 2014), with bats added and the database updated by Woinarski et al. (2014). These data sets have been used to analyse changes in conservation status of native mammals. However, compared to similar analyses for other taxa such analyses may be constrained by a lack of detailed data for mammals. For example, whereas assessments of patterns of decline of bird species in northern Australia incorporate detailed mapping of putative causal factors (Franklin et al. 2005; Reside et al. 2012), the number of distributional records in the region for birds far exceeds that for mammals, so a comparable analysis for mammals may not be so revealing. Nevertheless, improving data sets and the development of new analytical methods may offer further approaches for addressing the declining mammals issue.

\section{Monitoring}

Much of the evidence for the current decline of mammals in northern Australia arises from a small set of monitoring programs. These programs were specifically established to measure trends in abundance of mammals (and other components of biodiversity) and their responses to management actions (Russell-Smith et al. 2014; Russell-Smith et al. 2009a). To date, the most informative and substantial of these programs has been in Kakadu, with establishment in 1996 and continuation to date, mostly at five yearly intervals (Woinarski et al. 2010). Complementary, but smaller, monitoring programs (using similar sampling protocols) have been established in other nearby conservation reserves in the Northern Territory (Russell-Smith et al. 2014; RussellSmith et al. 2009a) and in the north Kimberley, Western Australia (Corey et al. 2013). More recently, monitoring programs have also commenced in some non-government conservation reserves (Kutt et al. 2012; Legge et al. 2011 a; Legge et al. 2011b), with less comprehensive monitoring also established recently in some Indigenous Protected Areas (Fitzsimons et al. 2012).

These monitoring programs have been instrumental in detecting the extent of change in the status of mammal species, and in providing some information on its causation. However, collectively they sample only a very small proportion of northern Australia, and do not represent other land tenures and management practices; they provide little information on some groups of mammals (particularly bats, larger macropods and feral mammals); they typically use relatively crude measures of abundance; mostly they rely on short-term and insecure funding; and most are not specifically designed to measure responses to particular threats or management actions.

In contrast to the recent integration of previously separate mammal distributional databases, there has been no integration of information across the limited number of monitoring programs for mammals in northern Australia. This constrains analyses of the spatio-temporal variability in population trends, and limits identification of causality and management efficacy. Existing monitoring programs should be secured, consolidated, and integrated. 


\section{Ethnozoology}

Indigenous ecological knowledge has been increasingly recognized as a valuable complement, or even alternative, for documenting and monitoring the status, distribution and life history of a range of taxa (Anadon et al. 2009; Burbidge et al. 1988; Ferguson and Messier 1997; Grech et al. 2014; Telfer and Garde 2006), and for its contribution to land and sea management and conservation efforts (Ens et al. 2012; Karadada et al. 2011; Yibarbuk et al. 2001). While there are acknowledged limitations to data based on local knowledge, information derived from such sources may be particularly valuable for species and regions that are otherwise poorly known and for which data may be otherwise unavailable. Recognising the limited documented knowledge of native mammals across much of northern Australia, a recent study in the Top End of the Northern Territory recorded Aboriginal knowledge of the changing status of terrestrial mammal species in the region (Ziembicki et al. 2013). The study's conclusions mirrored and extended findings from other sources. It found notable declines across the region, particularly in recent decades and especially for medium-sized (critical weight range $35 \mathrm{~g}$ to $5,500 \mathrm{~g}$ ) species. The study also provided valuable new information regarding the past and present range and status and aspects of the ecology of several poorly known species.

Other recent ethno-ecological studies in northern Australia that have improved our understanding of mammals, their habitats, and the threats they face, include studies of traditional fire management (Russell-Smith et al. 2009b) and the use of Indigenous knowledge (including tracking skills) in feral cat research and management in western Arnhem Land (A. Stevens, unpublished data). Such projects demonstrate the value of Indigenous knowledge in contemporary conservation practice and natural resource management, particularly on Indigenous-owned lands, which comprise over a third of northern Australia (see 'Indigenous Protected Areas' section below).

\section{Remote survey and sampling: camera trapping and other techniques}

Advances in automated remote camera technology have seen a rapid expansion of their use in wildlife research and conservation worldwide. Camera traps provide a cost effective means of studying rare and/or elusive species that may otherwise be difficult to detect. In studies of mammals in northern Australia, camera traps have been incorporated into systematic biodiversity inventory surveys and monitoring programs (e.g. G.Gillespie; B.Murphy, unpublished data), used in targeted surveys of rare or threatened species (e.g. Hohnen et al. 2013), and employed in the study of the ecology and movements of feral cats (McGregor 2014; Frank et al. 2014). Camera based methods have also been developed to estimate the density of species (e.g. northern quolls and feral cats) based on capture mark-recapture analyses where individuals can be reliably identified (Hohnen et al. 2013; McGregor 2014).

The increasing affordability, sophistication and application of other forms of technology have similarly expanded our capacity to survey and monitor cryptic and poorly known mammal species in northern Australia. Bat survey methods based on echolocation call detectors, for example, has greatly expanded the effectiveness and coverage of sampling for insectivorous bats. The continued development of call libraries in tandem with advances in software and hardware technology has significantly improved the number and accuracy of species detected, while automation, along with improved data storage capacity and battery life, has enabled long-term use of detectors at multiple sites in remote areas. Consequently, there is a rapidly improving knowledge base of the distribution and status of the region's rich bat fauna (Reardon et al. 2010). It is now possible to plan ambitious survey and monitoring projects employing many hundreds of passive bat detectors across large geographic areas recording for months at a time.

Scat surveys and faecal DNA analyses have been a useful adjunct to some mammal surveys in the region, particularly to detect rare, cryptic, and trap-shy species. Recent advances in genetic analysis now 
allow for reliable, rapid and cost-effective identification of prey items in predator faeces, predators from prey remains (Banks et al. 2003a), herbivore species from their faeces, including north Australian macropods (Telfer et al. 2006; Wadley et al. 2013), and individuals from faeces or hair samples, which may enable the monitoring of highly threatened species (Banks et al. 2003b). Extraction and analyses of DNA extracted from leeches, carrion flies and mosquitoes, may also provide novel methods for improving monitoring of a range of mammal species (Calvignac-Spencer et al. 2013; Schnell et al. 2012).

Given the resource and logistical constraints of sampling mammals over large and sparsely settled regions of northern Australia, such advances may also allow for greater involvement of landholders and 'citizen scientists', thereby improving our capacity for inventory and monitoring studies across many more sites.

\section{Experimental manipulation}

Much of the evidence base about mammal decline and causation has come from inferential or correlative studies. However, is increasing use of experimental manipulation to determine factors contributing to the decline of native mammal fauna. Notable examples include studies of mammal responses to imposed contrasts in fire regimes (Begg et al. 1981; Corbett et al. 2003; Griffiths 2013; Leahy 2013), predator access (Frank et al. 2014), pastoralism (Kutt et al. 2012; Legge et al. 2011a; Woinarski and Ash 2002), and exposure to cane toads (Rhinella marina) (Cabrera-Guzmán et al. in press; O'Donnell et al. 2010; Webb et al. 2008; Webb et al. 2011). The results of such studies are described in more detail in sections below on threats.

\section{Modelling}

There have been many modelling and other analytical studies that aim to identify the characteristics of Australian mammal species that are most associated with propensity for decline and extinction. Some of these studies specifically or by implication also attempt to evaluate the relative impacts of putative drivers of this decline (Burbidge and McKenzie 1989; Cardillo and Bromham 2001; Chisholm and Taylor 2007; Fisher et al. 2014; Johnson and Isaac 2009; McKenzie et al. 2007). To date, only one of these studies has focused specifically on decline in the mammal fauna of northern Australia (Fisher et al. 2014). That study reported that smaller mammal species, and those in more open habitats, were most likely to have exhibited decline in northern Australia. Fisher et al. (2014) concluded from this apparent contrast that predation by feral cats acted in synergy with disturbances that reduced ground cover and simplified vegetation, exposing smaller mammals to greater risk of predation.

Narrowly focussed modelling of demographic parameters of individual species has extrapolated data from short-term studies to indicate marked impacts on population viability in response to different fire regimes (Firth et al. 2010; Griffiths 2013; Pardon et al. 2003). A constraint of this approach is the relatively limited amount of detailed life history information available for most mammal species in this region, and particularly the extent to which threatening factors and the management of them may affect those parameters.

\section{CURRENT TRENDS ACROSS NORTHERN AUSTRALIA}

Much of the evidence for decline in northern Australian mammals derives from intensive monitoring studies on small- to medium-sized $(<5.5 \mathrm{~kg}$ ) non-volant mammals in Kakadu (Woinarski et al. 2010; Woinarski et al. 2001). In this section, we assess whether such trends also apply more generally across northern Australia, and across the two mammal groups least well considered in the Kakadu studies, bats and larger macropods. 


\section{Status of small and medium-sized non-volant mammals in northern Queensland}

Land degradation in northern Australia has been unequal in extent and severity (Figure 3), limited by European settlement patterns, access to markets, human population size and legislative frameworks that have either encouraged or discouraged landscape modification and Indigenous dislocation (Bradshaw 2012). In contrast to the Northern Territory and northern Western Australia, much of Queensland has a long history of agricultural intensification and broad-scale tree clearing which generally pre-dates systematic vertebrate surveys (Fensham 2008; Kutt and Fisher 2011), and there are very few established long-term monitoring programs for mammals in northeastern Australia. Much of the survey effort and reported declines for Queensland mammals have occurred in the fragmented rainforests of the Wet Tropics (Laurance 2004; Williams et al. 1996b), not considered as a focus here, where threatening processes are less subtle and similar to processes occurring in transformed landscapes of southern Australia (Lindenmayer et al. 1990).

The most threatened assemblage of the extant fauna of northern Queensland comprises species associated with tall eucalypt forests (typically at higher elevations), and mostly adjacent to or intermingled with rainforests in the Wet Tropics region. These relictual forests support a mammal fauna with close links to southeastern Australia (Winter 1997). Prevailing threats are habitat loss and fragmentation, habitat degradation from changed fire regimes (mostly fire suppression), and predation by feral cats. Consequently, the mammals most closely associated with this habitat, such as the northern bettong (Bettongia tropica) and an undescribed subspecies of yellow-bellied glider (Petaurus australis), are declining (Woinarski et al. 2014).

Information on the pre-disturbance state of small mammal populations outside of the unusual elevated east coast is limited, but where available (Kirkpatrick and Lavery 1979; Woinarski et al. 2006b) replicates the trends of decline recorded elsewhere in northern Australia (Woinarski et al. 2011a). Furthermore, recent analyses of subfossil and other historic records suggest a previously largely undocumented broad-scale decline of many mammal species in the Queensland savannas in the decades following initial European settlement (Cramb and Hocknull 2010; Dickman et al. 2000).

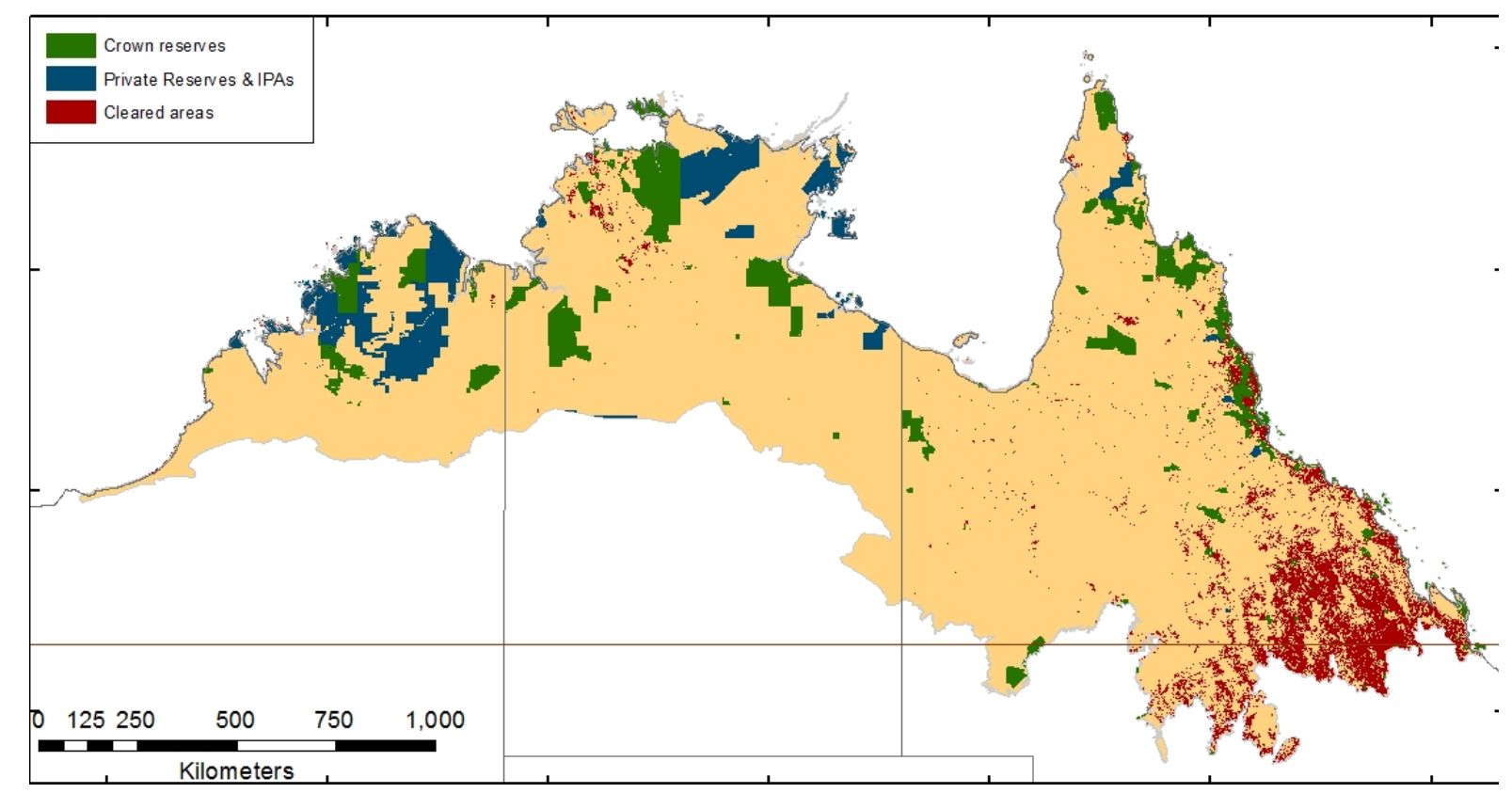

Figure 3. Extent of conservation reserves and habitat loss for savanna woodland environments in northern Australia, illustrating that most native vegetation is relatively intact, other than in the southeast part of the region. Crown reserves (National Parks and similar reserves, with protection under State, Territory or Federal legislation), private reserves (under private tenure, but not conservation protection), and Indigenous Protected Areas (secure tenure, but not necessarily for conservation). Native vegetation clearing data current to 2007 (NT), 2010 (QId), 2004/5 (WA) from SLATS data (QId), NT data and NVIS data (WA). Source: Franklin and Preece (2014). 
One anomaly may be parts of the Einasleigh Uplands region in central Queensland - an apparent refuge area for mammal populations. A recent survey in Blackbraes National Park in this region uncovered a surprising richness and abundance of mammals (Vanderduys et al. 2012). This area, embedded within the broader savanna environment, is among the highest elevation sites in the wet/dry tropics (>1000 $\mathrm{m}$ asl), has had comparatively limited disturbance and is characterized by a unique climate (being notably less seasonal than surrounding regions) (Vanderduys et al. 2012). However, the Blackbraes site may be a local exception: surveys of six other properties (36 sites) in the Einasleigh Uplands from 2009 to 2012 consistently revealed a low number of mammals, with the trap rate being at the lowest end of what was considered to be 'extremely low' (Russell-Smith et al. 2009a) in the Northern Territory (N. Preece, unpublished data).

One unusual example of recent mammal decline in northeastern Australia is the possible extinction since 2009 of the Bramble Cay melomys (Melomys rubicola), a species previously endemic to a 5 ha islet in Torres Strait (Figure 1). Its likely extinction seems to have been caused by erosion of the cay and stripping of its vegetation due to storms and rising sea levels (Woinarski et al. 2014).

\section{Status of small and medium-sized non-volant mammals in the Top End}

The timing, rate and severity of declines in the mammal fauna has varied across the Top End, with earlier and more severe declines generally in lower rainfall inland areas (Finlayson 1961; Ziembicki et al. 2013). Rapid recent declines, such as observed in Kakadu since about the 1980s (Woinarski et al. 2010; Woinarski et al. 2001), occurred later in the 1990s in nearby Litchfield National Park (Russell-Smith et al. 2014), and comparably low richness and abundance of small mammals have been recorded for sites in Nitmiluk National Park since 2005 (DLRM, unpublished data). Wildlife surveys at Fish River Station (170 km south of Darwin) in 2011/12 using conventional trapping techniques envountered low site richness and abundance of small mammals, although the subsequent deployment of remote cameras has been very valuable in revealing the persistence, albeit at low densities, of most of the expected regional complement of small mammal species (DLRM, unpublished data).

Previous studies had indicated a probable retention of relatively intact mammal faunas in part of northwestern Arnhem Land subject to ongoing traditional fire management (Yibarbuk et al. 2001). However, recent resampling of small mammals at the same sites recorded only the exotic black rat, and further sampling of a number of sites in western Arnhem Land since 2011 has indicated a much diminished small mammal fauna (DLRM, unpublished data). Curiously, some sites in peri-urban areas around Darwin have maintained high densities of several mammal species shown to be declining in more intact Top End environments (Price et al. 2005), although recent resampling of these sites indicates a decline of $75 \%$ in overall capture rates between 2001 and 2011 (DLRM, unpublished data).

Mammal faunas appear to have remained relatively intact on some islands -notably Groote Eylandt and the Tiwi islands, although more extensive sampling is required to confirm whether this pattern is consistent across all mammal taxa. Recent surveys on Bathurst Island have shown very high densities of common brushtail possum (Trichosurus vulpecula) and confirmed the persistence of brush-tailed rabbit-rat (Conilurus penicillatus) but had low reporting rates for smaller ground-active mammals (DLRM, unpublished data). Groote Eylandt is notable for continuing to support high densities of northern quoll (Woinarksi et al. 2007, J. Heiniger, pers. comm.) although a current study has had low detection rates for northern hopping mouse (Notomys aquilo) in sites where it was previously abundant (R. Diete, pers. comm.), and previously-recorded populations of brush-tailed rabbit-rat have been very rare or absent in more recent sampling. 
The localised persistence of mammal species that are declining elsewhere is likely to provide insights into causal factors and requires more systematic attention. For example, high reporting rates on camera traps have recently been reported for black-footed tree-rats (Mesembriomys gouldii) within the Gove bauxite mining lease (B. Prowse, pers. comm.), which may be linked to the relatively low frequency and low intensity fire regime maintained within the lease boundaries. Current data suggest that the most recently "intact" small mammal fauna on the Northern Territory mainland is on the Cobourg Peninsula, although systematic monitoring since 2004 shows a substantial decline for brush-tailed rabbit-rat and pale field-rat (Rattus tunneyi), and more idiosyncratic changes over time for other mammals, (including fawn antechinus (Antechinus bellus), northern brown bandicoot (Isoodon macrourus), black-footed tree-rat and common brushtail possum (DLRM, unpublished data; Firth et al. 2010; Ziembicki et al. 2013).

In contrast to some instances in the Kimberley (Legge et al. 2011a), there has been no evidence of recovery of mammal populations in the Top End of the Northern Territory following the imposition of presumed improved management of threats. Recent resampling of the long-term monitoring sites within Kakadu indicates that, while site richness and abundance of small mammals remain very low, there has at least been no further change between the 2012 to 2014 period compared to 2007 to 2009 (DLRM, unpublished data).

\section{Status of small and medium-sized non-volant mammals in the Kimberley}

Intact mammal assemblages in recent decades (1994 to 2013) have been restricted to the relatively high rainfall (mean annual rainfall $>900 \mathrm{~mm}$ ) northwestern Kimberley region adjacent to the coast (Corey et al.2013; McKenzie et al. 2007; Radford et al.2014; Start et al. 2012). Mammal groups commonly recorded during surveys in this region include all major functional groups found historically: these include marsupial predators (northern quoll, brush-tailed phascogale (Phascogale tapoatafa)), omnivores (golden bandicoot (Isoodon auratus), northern brown bandicoot, common brushtail possum) and herbivores (e.g. monjon (Petrogale burbidgei), scaly-tailed possum (Wyulda squamicaudata)); larger rodents $(>150 \mathrm{~g})$ (brush-tailed rabbit-rat, golden-backed tree-rat (Mesembriomys macrurus) and Kimberley rock-rat (Zyzomys woodwardi)); medium (35-150 g) and small rodents $(<35 \mathrm{~g})$ (e.g. northern short-tailed mouse (Leggadina lakedownensis), grassland melomys (Melomys burtoni), delicate mouse (Pseudomys delicatulus), western chestnut mouse (P. nanus), pale field-rat, common rock-rat (Zyzomys argurus)) and small insectivorous dasyurids (Pseudantechinus ningbing, Sminthopsis spp.) (Radford et al. 2014). However, some medium-sized species have uncertain status in the region. For example, the black-footed tree-rat has not been recorded in the Kimberley since last captured by Bradley et al. (1987) in 1981/82 (Corey et al. 2013; Radford et al. 2014; Start et al. 2007). The once common nabarlek (Petrogale concinna), a very small rock-wallaby has not been recorded on the Kimberley mainland since 1974, and is now confirmed in the Kimberley on four islands only (Potter et al. 2012a; Woinarski et al. 2014). The brush-tailed phascogale is another species for which few data are available since surveys in the 1980s, however recent sightings near Mitchell Falls (Woinarski et al. 2014) and at Yampi Sound in 2008 (N. Preece, unpublished data) confirm its continued presence in the region albeit at low frequency. Nevertheless, most species found historically are still present.

In contrast to the high rainfall zone, mammal assemblages of the eastern, central and southern Kimberley, with annual rainfall $<900 \mathrm{~mm}$, are in disarray and are now predominantly devoid of marsupials and rodents between $150 \mathrm{~g}$ and $2 \mathrm{~kg}$ (Legge et al. 2011a; Legge et al. 2008; McKenzie 1981; McKenzie et al. 2007; Radford et al. 2014; Start et al. 2012; Start et al. 2007). Scattered localised populations of medium-sized marsupials (e.g. northern quoll, northern brown bandicoot, scaly-tailed possum and golden-backed tree-rat) are occasionally trapped or observed in refuge habitats in the region such as in gorges, on islands or adjacent to townships where some fire protection is apparent 
(Gibson and McKenzie 2012; Legge et al. 2011 a; Potter et al. 2014; I. Radford, unpublished data). In recent years (1994-2010), smaller mammals $(<150 \mathrm{~g})$ were at relatively low abundance throughout the medium and low rainfall Kimberley (mammals captured in 2 to $9 \%$ of traps) (Radford et al. 2014), but this is still substantially higher than recent documented trap success in much of the Northern Territory and Queensland savannas (Kutt and Gordon 2012; Kutt et al. 2012; Woinarski et al. 2010). Higher mammal abundance in the medium to low rainfall Kimberley has been recorded at a few sites where careful management of fire and introduced herbivores has led to recovery (Legge et al. 2011a; Legge et al. 2011b), or where periodic irruptions have occurred in association with major rainfall events (Radford et al. 2014). The greater bilby Macrotis lagotis, a specialist arid and semi-arid zone medium-sized marsupial, is still present in the arid and semi-arid southern and western Kimberley, however data on its abundance in the region are sparse (Start et al. 2012).

Mammal assemblages in the Kimberley are now partitioned along productivity or annual rainfall gradients (McKenzie et al. 2007; Radford et al. 2014), though this was not the case historically (Johnson 2006; McKenzie 1981; Woinarski et al. 2014) with species such as golden bandicoot, northern quoll, pale field-rat and golden-backed tree-rat previously having much wider distributions into more arid areas, even into central Australia. Explanations for this change include a collapse of ecosystem productivity in more fragile arid ecosystems due to intensification of fire and cattle grazing regimes (McKenzie et al. 2007), and increased loss of vegetation cover. These changes have resulted in increased predation by introduced cats and foxes (Johnson 2006), more marked predation pressure associated with less extensive shelter (ground vegetation cover) in lower rainfall areas, and changed trophic interactions between top and introduced mesopredators (dingoes versus cats/foxes) (Johnson 2006; Letnic et al. 2012; Radford et al. 2014).

There is little evidence of declines among the very small $(<35 \mathrm{~g})$ mammals in the Kimberley region, with most small species including the small dasyurids (e.g. most Planigale spp.) still common. However, data are limited for these species due to their low capture rates using conventional trapping methods (e.g. Elliott traps and wire cage traps). Accurate assessment of the conservation status of this group is therefore problematic and will require significantly more targeted sampling effort (notably pitfall-trapping). Nevertheless, the status of at least one species, Butler's dunnart (Sminthopsis butleri), in the Kimberley is of concern. Despite numerous surveys it has not been recorded in the region since its initial discovery in the mid 1960s (Woinarski et al. 2014).

\section{Bats}

Fifty-five bat species have been recorded from mainland northern Australia (of a total of 80 extant species for the Australian mainland and Tasmania); 33 are Australian endemics. Twentynine species have their primary or entire distribution in north Australia. Overall, the group is well represented taxonomically with all eight families and 23 of the 25 genera of Australian bats present. They encompass the full trophic range for Australian bats with frugivores, nectarivores, insectivores, one specialist arachnivore, one partial piscivore and one partial carnivore (Van Dyck and Strahan 2008). Roosting preferences include tree-hollows, caves and rock crevices, open and closed foliage, abandoned bird nests and a range of human-made structures (Churchill 2008).

Only one systematic study has assessed long-term, large-scale distributional changes in bats for mainland Australia (Burbidge et al. 2008). The study found that all but one bat species had persisted in more than $50 \%$ of its pre-European settlement range in each of the 18 bioregions that comprise northern Australia. However the geographic distribution of most species is less precisely known than generally appreciated. Surprisingly few records inform the distribution maps. In reviewing the threatened status of microbats on Cape York Peninsula, Reardon et al. (2010) found only 1600 records on the best available distributional database (Queensland's 'Wildnet'). Nearly half of the 
31 species were known from fewer than 10 localities. The number of records for each species was also low with $75 \%$ of the species known from fewer than 50 records each. The sparseness of information is similar in the Northern Territory, where Milne and Pavey (2011) reported that bats comprised only $11 \%$ of all terrestrial mammal records. This percentage translates to about 3000 records from that area, a mean of about 100 records per species. These studies also highlight two important issues with the historic records: the first is that the large area encompassing southwestern Cape York Peninsula, the Gulf region and eastern Arnhem Land has been substantially under-surveyed, and secondly, that wet season records are poorly represented.

The bat fauna of the Torres Strait Islands is particularly poorly documented. Over 250 islands span the $150 \mathrm{~km}$ gap between the tip of Cape York Peninsula and New Guinea. Most of these are too small to support bat populations but at least 20 are large enough to have resident or transient bat populations. About 22 bat species are common to northern Australia and New Guinea, and a further 20 endemic species (5 from Australia and 15 from southern New Guinea) could potentially contribute to the complement for all the islands (Bonaccorso 1998; Van Dyck et al. 2013). Australia has a vital interest in biosecurity threats arriving from this northern route. For many bat species, bridging the gap between New Guinea and Australia via stepping stone islands is very plausible. Thus far the only confirmation of individual bats crossing the gap is for the large flying-fox Pteropus alecto (Breed et al. 2010). Possible threats to the bat fauna of the islands include habitat loss to agriculture, hunting (flying-foxes for food), and rising sea level. There is a substantial need for bat survey work across the straits.

Although bats make up a significant component of native mammal fauna of northern Australia, in contrast to the comparatively better defined conservation trends for non-volant mammals, relevant information is largely unavailable for most bats and they have received much less research attention than other mammal groups. Recent assessments of the conservation status of bats for the Action Plan for Australian Mammals (Woinarski et al. 2014) and Queensland's Back on Track Threatened Species Priority program, have highlighted the lack of robust information about populations for most bat species. Because occurrence records have been so patchily accumulated over time and space, they do not form an adequate basis for population size and trend analyses. Of concern is the possibility that many bat species could be suffering significant local or even widespread declines without our knowledge. At this time, there is evidence that four bat species are undergoing population declines in the north. Population monitoring of spectacled flying-fox (Pteropus conspicillatus) in parts of its range suggest a potential decline of up to 50\% in the last decade (Buettner et al. 2013; Fox 2011). Three cave-dwelling bat species have disappeared from several formerly occupied sites including the Arnhem leaf-nosed bat (Hipposideros inornatus) from Litchfield National Park, northern leaf-nosed bat (H. stenotis) from many caves across its range (Milne and Pavey 2011), and the ghost bat from sites in Boodjamulla National Park (in northwestern Queensland) and some roost sites in Kakadu (A. White, pers. comm.). There is a need for a concerted effort to establish a baseline, and improvements in technology now make this feasible.

In the absence of information on trends for bat species in northern Australia, it is difficult to identify threats, and the risk posed by putative threats, and to recommend conservation management responses. Indeed, even where declines (including extinctions) have been reported for Australian bats, it has sometimes been very difficult to identify the principal causal factors, and a decline may be due to a complex interaction of multiple threats (Lunney et al. 2011). However, some factors are recognised, or are likely, to be causing population-level declines in some bat species in northern Australia. This complement of threats is likely to differ among bat groups, and to differ between bats and other native mammals. Flying-foxes face a medley of threats, with persecution in some areas (particularly in orchards and around towns), tick paralysis, disease, and vegetation loss and change (Fox 2011). Bats that roost colonially in caves and abandoned mines are affected by disturbance and mining activity. Bats that roost in tree hollows may be affected by competition with introduced species (such as honey 
bees) and increased abundance of some other native hollow-nesting species, particularly in areas where hollow availability may be reduced because of vegetation loss or changed fire regimes. Like non-volant mammals, insectivorous bats in northern Australia may respond to pastoralism and changes in fire regimes, where these affect the abundance of their invertebrate prey. Frugivorous and nectarivorous bats may in turn respond to changed fire regimes where these affect the timing and abundance of fruit and nectar. The decline in non-volant small mammals may directly affect the abundance of the ghost bat, whose diet includes small mammals. Broad-scale decline of nonvolant small mammals may also affect bats indirectly, if predators (such as owls and raptors) are forced to prey more substantially on bats in compensation for reduced availability of non-volant mammals. Substantially more research is required to resolve the impacts of such probable threats on the population and conservation security of the bat fauna of northern Australia.

\section{Macropodids and potoroids}

Elsewhere in Australia, potoroids (bettongs, potoroos and rat-kangaroos) have suffered a very high rate of extinction and decline, and many macropods (wallabies, tree-kangaroos, rock-wallabies, pademelons and kangaroos) have also exhibited substantial declines. In contrast, in northern Australia there have been no extinctions among the diverse assemblage of macropodids, or of the two bettong species.

With a focus here on tropical savannas, we exclude from consideration a small suite of macropods restricted to, or largely associated with rainforests of the Wet Tropics: these comprise two tree kangaroos (Dendrolagus spp. ), the musky rat-kangaroo (Hypsiprymnodon moschatus) and red-legged pademelon (Thylogale stigmatica).

The bridled nailtail wallaby is arguably a component of the north Australian fauna, with a former range encompassing much of inland eastern Australia. This species has disappeared from almost all of its range except for a single remnant population, of about 100 individuals, at Taunton Scientific Reserve near the northern extremity of its former range (this population is at the southeastern edge of the north Australian region considered here). It has recently been reintroduced to three additional sites, with marked population increase at the one site at which introduced predators have been excluded by fencing. This site, Scotia Wildlife Sanctuary, now supports $>90 \%$ of individuals of the species (Woinarski et al. 2014).

With 14 species, the rock-wallabies (Petrogale spp.), are the most speciose group of macropods in northern Australia. Reflecting the highly fragmented nature of the rocky environments of northern Australia, and the rock-wallabies' limited dispersal ability, many of these species have very small and fragmented distributions (Potter et al. 2014a; Potter et al. 2012a). Although there have been no substantial and long-lasting monitoring programs, the limited available evidence suggests that many rock-wallabies in northern Australia are undergoing rapid decline, most likely associated with predation by feral cats, inappropriate fire regimes and, in some localities, habitat degradation due to livestock and feral animals (Woinarski et al. 2014). Of the 14 rockwallaby species occurring in northern Australia, four are now considered threatened and five Near Threatened (Woinarski et al. 2014).

The remaining macropodids in northern Australia include 14 species from seven genera (Aepyprymnus, Bettongia, Lagorchestes, Macropus, Onychogalea, Thylogale, and Wallabia). Of these species, only the northern bettong is considered threatened: this species occupies a narrow band of forest on the south-east margin of the study area, subject to a suite of specific threats (see above). None of the other macropodids are threatened, but two of these species (spectacled hare-wallaby and black wallaroo (M. bernardus)) are Near Threatened (Woinarski et al. 2014). As a group, macropodids are very poorly studied within the region (Ritchie 2010), and rufous bettong 
(A. rufescens), spectacled hare-wallaby and northern nailtail wallaby (O. unguifera) in particular, all appear to be good candidates for species at risk. The causes of their poor status are likely the same set of threats as for other species, given that congeners or species of similar size and ecology have shown marked declines or extinctions elsewhere in Australia. Macropodids typically occur at very low abundance across the region (Ritchie et al. 2008), especially as compared to the high abundance of some species of Macropus in southern Australia. Due to a lack of systematic historical baselines it is hard to know whether this pattern represents a natural state, perhaps in part based on low fertility soils (Ritchie et al. 2009), or if it reflects changes to savanna habitats through intensified cattle grazing, altered fire regimes and introduced pasture plants, as well as the impacts of cats and foxes on the smaller-bodied macropodids.

The most recent and extensive research work on macropodids within northern Australia examined the distribution and abundance of antilopine wallaroo (M. antilopinus), eastern grey kangaroo (M. giganteus) and euro (M. robustus) at 50 sites spanning Cape York Peninsula, the Top End of the Northern Territory, and Kimberley region of Western Australia (Ritchie et al. 2009; Ritchie et al. 2008). Fire regime, the availability of water, geology and soil type, and climate were the most important factors influencing macropodids at a broad scale. Antilopine wallaroos appear to be favoured by frequent fires whereas euros are not, and indeed frequent fires within savanna habitats that remove understorey vegetation and dry out rainforest, may reduce habitat for species such as black-striped wallaby ( $M$. dorsalis) and red-legged pademelon (in northeastern Australia). Decreasing available cover also exposes other species to increased risk of predation by feral cats and (in the southern edge of the region considered here) the introduced red fox. Climate change is expected to increase the frequency and severity of fire, as well as affecting water availability, with some species (antilopine wallaroo) predicted to suffer extensive range contractions as a result (Ritchie and Bolitho 2008).

To enhance their conservation management and security, considerably more research and monitoring is required for macropodids within the region, with the most pressing needs being for black wallaroo (Telfer and Garde 2006; Telfer et al. 2008), spectacled hare-wallaby, northern nailtail wallaby and most rock-wallaby species.

\section{Numbers and trends for threatened species}

The conservation status of all native mammal species in northern Australia, as recognised globally, under Australian legislation, and as assessed in the most recent comprehensive review is given in Table 1. For a variety of reasons, these status assessments vary markedly. Of 160 mammal species, 18 are listed by the IUCN as threatened, 23 are listed under national legislation as threatened, and 26 were assessed as threatened (with a further two species considered extinct, and another 29 species considered Near Threatened) in the most recent review (Woinarski et al. 2014).

All of the more speciose taxonomic groups of mammals in northern Australia have some species whose conservation status has been assessed as threatened by Woinarski et al. (2014), but the proportions vary among groups, with $53 \%$ of dasyurids, $47 \%$ of macropods and potoroids, 33\% of bandicoots and bilby, $33 \%$ of possums, $30 \%$ of rodents, and $24 \%$ of bats assessed as extinct, threatened or Near Threatened.

The overall conservation status of mammals endemic to northern Australia is still substantially better than for the mammal fauna elsewhere in Australia (Figsures 2,4), which suffered very severe rates of decline and extinction, mostly in the period from the 1840s to the 1960s (Woinarski et al. 2014). However, the current rate of decline for mammals in northern Australia probably now surpasses that elsewhere in Australia (Figure 4; Woinarski et al. 2014). 
Table 1. List of mammal species occurring in northern Australia at the time of European settlement. Note that this excludes the Wet Tropics area of northeastern Australia. Distribution (at the time of European settlement) is in addition to northern Australia: $\mathrm{R}=$ other parts of Australia; $\mathrm{X}=$ extralimital. Conservation status is given as for Australian national legislation (EPBCA), the IUCN Red List, and as assessed in the 2012 Action Plan for Australian Mammals (MAP) (Woinarski et al. 2014). Conservation status categories: EX extinct, $C R(P E)$ Critically Endangered (Possibly Extinct), CR Critically Endangered, EN Endangered, VU Vulnerable, NT (CD) Near Threatened (Conservation Dependent), NT Near Threatened, LC Least Concern, DD Data Deficient. Note that MAP and EPBCA status refer to Australian range only.

\begin{tabular}{|c|c|c|c|c|c|}
\hline \multirow[t]{2}{*}{ Scientific name } & \multirow[t]{2}{*}{ Common name } & \multirow[t]{2}{*}{ Distribution } & \multicolumn{3}{|c|}{ Conservation status } \\
\hline & & & EPBCA & IUCN & MAP \\
\hline \multicolumn{6}{|l|}{ TACHYGLOSSIDAE } \\
\hline Tachyglossus aculeatus & Short-beaked echidna & $\mathrm{RX}$ & & LC & LC \\
\hline Zaglossus bruijnii & Western long-beaked echidna & $x$ & & CR & EX \\
\hline \multicolumn{6}{|l|}{ ORNITHORHYNCHIDAE } \\
\hline Ornithorhynchus anatinus & Platypus & $\mathrm{R}$ & & LC & NT \\
\hline \multicolumn{6}{|l|}{ DASYURIDAE } \\
\hline Antechinomys laniger & Kultarr & $\mathrm{R}$ & & LC & LC \\
\hline Antechinus bellus & Fawn antechinus & & & LC & VU \\
\hline Antechinus leo & Cinnamon antechinus & & & LC & LC \\
\hline Pseudantechinus bilarni & Sandstone antechinus & & & NT & LC \\
\hline Pseudantechinus mimulus & Carpentarian antechinus & & VU & EN & NT \\
\hline Pseudantechinus ningbing & Ningbing antechinus & & & LC & LC \\
\hline Dasyurus hallucatus & Northern quoll & $\mathrm{R}$ & EN & EN & EN \\
\hline Phascogale pirata & Northern brush-tailed phascogale & & VU & VU & VU \\
\hline Phascogale tapoatafa & Brush-tailed phascogale & $\mathrm{R}$ & & NT & NT \\
\hline Planigale ingrami & Long-tailed planigale & $\mathrm{R}$ & & LC & LC \\
\hline Planigale maculata & Common planigale & $\mathrm{R}$ & & LC & LC \\
\hline Sminthopsis archeri & Chestnut dunnart & $x$ & & DD & NT \\
\hline Sminthopsis bindi & Kakadu dunnart & & & LC & NT \\
\hline Sminthopsis butleri & Butler's dunnart & & VU & VU & VU \\
\hline Sminthopsis douglasi & Julia Creek dunnart & & EN & NT & NT \\
\hline Sminthopsis macroura & Stripe-faced dunnart & $\mathrm{R}$ & & LC & LC \\
\hline Sminthopsis virginiae & Red-cheeked dunnart & $x$ & & LC & LC \\
\hline \multicolumn{6}{|l|}{ PERAMELIDAE } \\
\hline Echymipera rufescens & Long-nosed echymipera & $x$ & & LC & LC \\
\hline Isoodon auratus & Golden bandicoot & $\mathrm{R}$ & $\mathrm{VU}^{*}$ & VU & VU \\
\hline Isoodon macrourus & Northern brown bandicoot & $\mathrm{RX}$ & & LC & LC \\
\hline Isoodon peninsulae & Cape York brown bandicoot & & & & LC \\
\hline Perameles pallescens & Northern long-nosed bandicoot & & & & LC \\
\hline \multicolumn{6}{|l|}{ THYLACOMYIDAE } \\
\hline Macrotis lagotis & Bilby & $\mathrm{R}$ & vU & VU & VU \\
\hline \multicolumn{6}{|l|}{ PHASCOLARCTIDAE } \\
\hline Phascolarctos cinereus & Koala & $\mathrm{R}$ & $(\mathrm{VU})$ & LC & VU \\
\hline
\end{tabular}




\begin{tabular}{|c|c|c|c|c|c|}
\hline \multirow[t]{2}{*}{ Scientific name } & \multirow[t]{2}{*}{ Common name } & \multirow[t]{2}{*}{ Distribution } & \multicolumn{3}{|c|}{ Conservation status } \\
\hline & & & EPBCA & IUCN & MAP \\
\hline \multicolumn{6}{|l|}{ VOMBATIDAE } \\
\hline Lasiorhinus krefftii & Northern hairy-nosed wombat & $\mathrm{R}$ & EN & $\mathrm{CR}$ & $\mathrm{CR}$ \\
\hline \multicolumn{6}{|l|}{ PETAURIDAE } \\
\hline Dactylopsila trivirgata & Striped possum & $\mathrm{RX}$ & & LC & LC \\
\hline Petaurus australis & Yellow-bellied glider & $\mathrm{R}$ & & LC & NT \\
\hline Petaurus breviceps & Sugar glider & $\mathrm{RX}$ & & LC & LC \\
\hline Petaurus gracilis & Mahogany glider & & EN & EN & EN \\
\hline Petaurus norfolcensis & Squirrel glider & $\mathrm{R}$ & & LC & LC \\
\hline \multicolumn{6}{|l|}{ PSEUDOCHEIRIDAE } \\
\hline Petauroides volans & Greater glider & $\mathrm{R}$ & & LC & VU \\
\hline Petropseudes dahli & Rock ringtail possum & & & LC & LC \\
\hline \multicolumn{6}{|l|}{ ACROBATIDAE } \\
\hline Acrobates pygmaeus & Feathertail glider & $\mathrm{R}$ & & LC & LC \\
\hline \multicolumn{6}{|l|}{ PHALANGERIDAE } \\
\hline Spilocuscus maculatus & Common spotted cuscus & $\mathrm{RX}$ & & LC & LC \\
\hline Phalanger mimicus & Southern common cuscus & $\mathrm{RX}$ & & LC & LC \\
\hline Trichosurus vulpecula & Common brushtail possum & $\mathrm{R}$ & & LC & LC \\
\hline Wyulda squamicaudata & Scaly-tailed possum & & & DD & NT \\
\hline \multicolumn{6}{|l|}{ POTOROIDAE } \\
\hline Aepyprymnus rufescens & Rufous bettong & $\mathrm{R}$ & & LC & LC \\
\hline Bettongia lesueur & Boodie & $\mathrm{R}$ & & NT & NT (CD) \\
\hline Bettongia tropica & Northern bettong & & EN & EN & EN \\
\hline \multicolumn{6}{|l|}{ MACROPODIDAE } \\
\hline Lagorchestes conspicillatus & Spectacled hare-wallaby & $\mathrm{RX}$ & & LC & NT \\
\hline Macropus agilis & Agile wallaby & $\mathrm{RX}$ & & LC & LC \\
\hline Macropus antilopinus & Antilopine wallaroo & & & LC & LC \\
\hline Macropus bernardus & Black wallaroo & & & LC & NT \\
\hline Macropus dorsalis & Black-striped wallaby & $\mathrm{R}$ & & LC & LC \\
\hline Macropus giganteus & Eastern grey kangaroo & $\mathrm{R}$ & & LC & LC \\
\hline Macropus parryi & Whiptail wallaby & $\mathrm{R}$ & & LC & LC \\
\hline Macropus robustus & Euro & $\mathrm{R}$ & & LC & LC \\
\hline Macropus rufus & Red kangaroo & $\mathrm{R}$ & & LC & LC \\
\hline Onychogalea fraenata & Bridled nailtail wallaby & $\mathrm{R}$ & EN & EN & VU \\
\hline Onychogalea unguifera & Northern nailtail wallaby & & & LC & LC \\
\hline Petrogale assimilis & Allied rock-wallaby & & & LC & LC \\
\hline Petrogale brachyotis & Western short-eared rock-wallaby & & & LC & LC \\
\hline Petrogale burbidgei & Monjon & & & NT & NT \\
\hline Petrogale coenensis & Cape York rock-wallaby & & & NT & EN \\
\hline Petrogale concinna & Nabarlek & & & DD & NT \\
\hline
\end{tabular}




\begin{tabular}{|c|c|c|c|c|c|}
\hline \multirow[t]{2}{*}{ Scientific name } & \multirow[t]{2}{*}{ Common name } & \multirow[t]{2}{*}{ Distribution } & \multicolumn{3}{|c|}{ Conservation status } \\
\hline & & & EPBCA & IUCN & MAP \\
\hline Petrogale godmani & Godman's rock-wallaby & & & LC & NT \\
\hline Petrogale herberti & Herbert's rock-wallaby & & & LC & LC \\
\hline Petrogale inornata & Unadorned rock-wallaby & & & LC & LC \\
\hline Petrogale lateralis & Black-footed rock-wallaby & $\mathrm{R}$ & & NT & VU \\
\hline Petrogale mareeba & Mareeba rock-wallaby & & & LC & NT \\
\hline Petrogale persephone & Proserpine rock-wallaby & & EN & EN & EN \\
\hline Petrogale purpureicollis & Purple-necked rock-wallaby & & & LC & NT \\
\hline Petrogale sharmani & Mount Claro rock-wallaby & & & NT & $\mathrm{VU}$ \\
\hline Petrogale wilkinsi & Eastern short-eared rock-wallaby & & & LC & LC \\
\hline Thylogale stigmatica & Red-legged pademelon & RX & & LC & LC \\
\hline Wallabia bicolor & Swamp wallaby & $\mathrm{R}$ & & LC & LC \\
\hline \multicolumn{6}{|l|}{ NOTORYCTIDAE } \\
\hline Notoryctes caurinus & Kakarratul & $\mathrm{R}$ & EN & DD & LC \\
\hline \multicolumn{6}{|l|}{ PTEROPODIDAE } \\
\hline Dobsonia magna & Bare-backed fruit bat & $\mathrm{x}$ & & LC & LC \\
\hline Macroglossus minimus & Northern blossom bat & $\mathrm{RX}$ & & LC & LC \\
\hline Nyctimene robinsoni & Eastern tube-nosed bat & $\mathrm{R}$ & & LC & LC \\
\hline Pteropus alecto & Black flying-fox & $\mathrm{RX}$ & & LC & LC \\
\hline Pteropus conspicillatus & Spectacled flying-fox & $\mathrm{RX}$ & VU & LC & NT (CD) \\
\hline Pteropus macrotis & Large-eared flying-fox & $\mathrm{x}$ & & LC & LC \\
\hline Pteropus scapulatus & Little red flying-fox & $\mathrm{R}$ & & LC & LC \\
\hline Syconycteris australis & Eastern blossom bat & $\mathrm{RX}$ & & LC & LC \\
\hline \multicolumn{6}{|l|}{ MEGADERMATIDAE } \\
\hline Macroderma gigas & Ghost bat & $\mathrm{R}$ & & VU & VU \\
\hline \multicolumn{6}{|l|}{ RHINOLOPHIDAE } \\
\hline Rhinolophus megaphyllus & Eastern horseshoe-bat & $\mathrm{RX}$ & & LC & LC \\
\hline Rhinolophus 'intermediate' & Lesser large-eared Horseshoe-bat & & & & $\mathrm{VU}$ \\
\hline Rhinolophus robertsi & Greater large-eared Horseshoe-bat & & $\mathrm{VU}^{* *}$ & & NT \\
\hline \multicolumn{6}{|l|}{ HIPPOSIDERIDAE } \\
\hline Hipposideros ater & Dusky leaf-nosed bat & $x$ & & LC & LC \\
\hline Hipposideros cervinus & Fawn leaf-nosed bat & $\mathrm{x}$ & & LC & NT \\
\hline Hipposideros diadema & Diadem leaf-nosed bat & $\mathrm{x}$ & & LC & NT \\
\hline Hipposideros inornatus & Arnhem leaf-nosed bat & & & VU & EN \\
\hline Hipposideros semoni & Semon's leaf-nosed bat & $\mathrm{RX}$ & EN & DD & NT \\
\hline Hipposideros stenotis & Northern leaf-nosed bat & & & LC & NT \\
\hline Rhinonicteris aurantia & Orange leaf-nosed bat & $\mathrm{R}$ & & LC & LC \\
\hline \multicolumn{6}{|l|}{ EMBALLONURIDAE } \\
\hline Saccolaimus flaviventris & Yellow-bellied sheath-tailed bat & $\mathrm{R}$ & & LC & LC \\
\hline Saccolaimus mixtus & Cape York sheath-tailed bat & $x$ & & DD & NT \\
\hline Saccolaimus saccolaimus & Bare-rumped sheath-tailed bat & $x$ & & LC & NT \\
\hline
\end{tabular}




\begin{tabular}{|c|c|c|c|c|c|}
\hline \multirow[t]{2}{*}{ Scientific name } & \multirow[t]{2}{*}{ Common name } & \multirow[t]{2}{*}{ Distribution } & \multicolumn{3}{|c|}{ Conservation status } \\
\hline & & & EPBCA & IUCN & MAP \\
\hline Taphozous australis & Coastal sheath-tailed bat & $\mathrm{RX}$ & & NT & NT \\
\hline Taphozous georgianus & Common sheath-tailed bat & $\mathrm{R}$ & & LC & LC \\
\hline Taphozous kapalgensis & Arnhem sheath-tailed bat & & & LC & LC \\
\hline Taphazous troughtoni & Troughton's sheath-tailed bat & & & DD & LC \\
\hline \multicolumn{6}{|l|}{ MOLOSSIDAE } \\
\hline Austronomus australis & White-striped free-tailed bat & $\mathrm{R}$ & & LC & LC \\
\hline Chaerephon jobensis & Greater northern free-tailed bat & $\mathrm{RX}$ & & LC & LC \\
\hline Mormopterus eleryi & Bristle-faced free-tailed bat & $\mathrm{R}$ & & LC & LC \\
\hline Mormopterus lumsdenae & Northern free-tailed bat & $\mathrm{R}$ & & & LC \\
\hline Mormopterus ridei & Eastern free-tailed bat & $\mathrm{R}$ & & & LC \\
\hline Mormopterus halli & Cape York free-tailed bat & & & & DD \\
\hline Mormopterus cobourgianus & North-western free-tailed bat & $\mathrm{R}$ & & & LC \\
\hline \multicolumn{6}{|l|}{ MINIOPTERIDAE } \\
\hline Miniopterus australis & Little bent-winged bat & RX & & LC & LC \\
\hline Miniopterus orianae & Common bent-wing bat & $\mathrm{RX}$ & & NT & LC \\
\hline \multicolumn{6}{|l|}{ VESPERTILIONIDAE } \\
\hline Chalinolobus gouldii & Gould's wattled bat & $\mathrm{R}$ & & LC & LC \\
\hline Chalinolobus nigrogriseus & Hoary wattled bat & RX & & LC & LC \\
\hline Murina florium & Flute-nosed bat & RX & & LC & NT \\
\hline Myotis macropus & Large-footed myotis & $\mathrm{RX}$ & & LC & LC \\
\hline Nyctophilus arnhemensis & Northern long-eared bat & $\mathrm{R}$ & & LC & LC \\
\hline Nyctophilus bifax & Eastern long-eared bat & $\mathrm{RX}$ & & LC & LC \\
\hline Nyctophilus daedalus & Pallid long-eared bat & & & & LC \\
\hline Nyctophilus geoffroyi & Lesser long-eared bat & $\mathrm{R}$ & & LC & LC \\
\hline Nyctophilus gouldi & Gould's long-eared bat & $\mathrm{R}$ & & LC & LC \\
\hline Nyctophilus walkeri & Pygmy long-eared bat & & & LC & LC \\
\hline Phoniscus papuensis & Golden-tipped bat & $\mathrm{RX}$ & & LC & LC \\
\hline Pipistrellus adamsi & Cape York pipistrelle & & & LC & LC \\
\hline Pipistrellus westralis & Northern pipistrelle & & & LC & LC \\
\hline Scotorepens balstoni & Inland broad-nosed bat & $\mathrm{R}$ & & LC & LC \\
\hline Scotorepens greyii & Little broad-nosed bat & $\mathrm{R}$ & & LC & LC \\
\hline Scotorepens sanborni & Northern broad-nosed bat & $\mathrm{RX}$ & & LC & LC \\
\hline Vespadelus caurinus & Western cave-bat & & & LC & LC \\
\hline Vespadelus douglasorum & Yellow-lipped cave bat & & & LC & LC \\
\hline Vespadelus finlaysoni & Inland cave bat & $\mathrm{R}$ & & LC & LC \\
\hline Vespadelus troughtoni & Eastern cave bat & $\mathrm{R}$ & & LC & LC \\
\hline \multicolumn{6}{|l|}{ MURIDAE } \\
\hline Conilurus capricornensis & Capricornian rabbit-rat & $\mathrm{R}$ & & & EX \\
\hline Conilurus penicillatus & Brush-tailed rabbit-rat & $x$ & VU & NT & VU \\
\hline Hydromys chrysogaster & Water-rat & $\mathrm{RX}$ & & LC & LC \\
\hline Leggadina lakedownensis & Northern short-tailed mouse & $\mathrm{R}$ & & LC & LC \\
\hline Melomys burtoni & Grassland melomys & $\mathrm{R}$ & & LC & LC \\
\hline
\end{tabular}




\begin{tabular}{|c|c|c|c|c|c|}
\hline \multirow[t]{2}{*}{ Scientific name } & \multirow[t]{2}{*}{ Common name } & \multirow[t]{2}{*}{ Distribution } & \multicolumn{3}{|c|}{ Conservation status } \\
\hline & & & EPBCA & IUCN & MAP \\
\hline Melomys capensis & Cape York melomys & & & LC & LC \\
\hline Melomys cervinipes & Fawn-footed melomys & $\mathrm{R}$ & & LC & LC \\
\hline Melomys rubicola & Bramble Cay melomys & & EN & $\mathrm{CR}$ & CR (PE) \\
\hline Mesembriomys gouldii & Black-footed tree-rat & & & NT & VU \\
\hline Mesembriomys macrurus & Golden-backed tree-rat & & VU & LC & NT \\
\hline Notomys alexis & Spinifex hopping-mouse & $\mathrm{R}$ & & LC & LC \\
\hline Notomys aquilo & Northern hopping-mouse & & VU & EN & VU \\
\hline Pogonomys sp. & Tree mouse & $\mathrm{R}$ & & LC & $\mathrm{LC}$ \\
\hline Pseudomys calabyi & Kakadu pebble-mouse & & & VU & NT \\
\hline Pseudomys delicatulus & Delicate mouse & $\mathrm{RX}$ & & LC & LC \\
\hline Pseudomys desertor & Desert mouse & $\mathrm{R}$ & & LC & LC \\
\hline Pseudomys gracilicaudatus & Eastern chestnut mouse & $\mathrm{R}$ & & LC & LC \\
\hline Pseudomys johnsoni & Central pebble-mouse & $\mathrm{R}$ & & LC & LC \\
\hline Pseudomys nanus & Western chestnut mouse & & & LC & $\mathrm{LC}$ \\
\hline Pseudomys patrius & Eastern pebble-mouse & $\mathrm{R}$ & & LC & LC \\
\hline Rattus colletti & Dusky rat & & & LC & LC \\
\hline Rattus fuscipes & Bush rat & $\mathrm{R}$ & & LC & LC \\
\hline Rattus leucopus & Cape York rat & $\mathrm{RX}$ & & LC & LC \\
\hline Rattus lutreolus & Swamp rat & $\mathrm{R}$ & & LC & LC \\
\hline Rattus sordidus & Canefield rat & $\mathrm{R}$ & & LC & LC \\
\hline Rattus tunneyi & Pale field-rat & $\mathrm{R}$ & & $\mathrm{LC}$ & $\mathrm{LC}$ \\
\hline Rattus villosissimus & Long-haired rat & $\mathrm{R}$ & & LC & LC \\
\hline Uromys caudimaculatus & Giant white-tailed rat & $\mathrm{RX}$ & & LC & LC \\
\hline Xeromys myoides & Water mouse & $\mathrm{RX}$ & VU & VU & VU \\
\hline Zyzomys argurus & Common rock-rat & $\mathrm{R}$ & & LC & LC \\
\hline Zyzomys maini & Arnhem rock-rat & & VU & NT & Vu \\
\hline Zyzomys palatalis & Carpentarian rock-rat & & EN & CR & $\mathrm{CR}$ \\
\hline Zyzomys woodwardi & Kimberley rock-rat & & & LC & LC \\
\hline \multicolumn{6}{|l|}{ CANIDAE } \\
\hline Canis dingo & Dingo & $\mathrm{R}$ & & LC & NT \\
\hline
\end{tabular}

The number and timing of mammal extinctions following European settlement in northern Australia is not well resolved. In addition to the four recent extinctions based on subfossil records, the western long-beaked echidna (Zaglossus bruijni), formerly considered endemic to New Guinea, has been recognised recently to have occurred in Australia on the basis of a single quixotic, but apparently reliable, specimen record from the Kimberley in 1901 (Helgen et al. 2012).

\section{IDENTIFICATION OF POTENTIAL CAUSES OF DECLINES}

The important drivers of declines in north Australian mammal assemblages act in synergy and present a complex set of interactions, with varying levels of impact on mammals, that has hampered co-ordinated and focussed management and conservation actions. Here we examined the suite of drivers of change in mammal status in north Australia. 


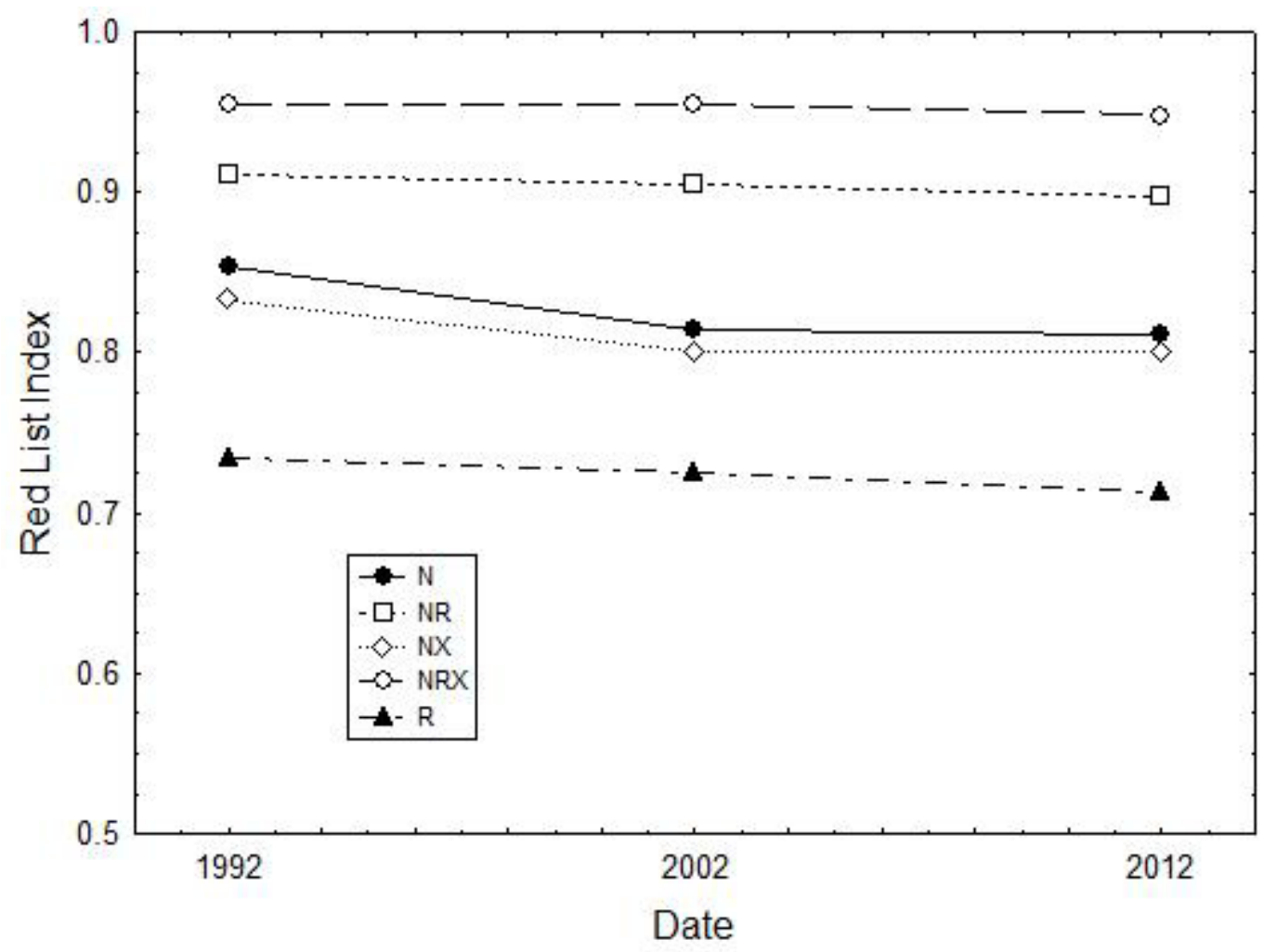

Figure 4. Change over the last 20 years in overall conservation status of geographic groupings of mammals. Note that this uses the Red List Index (Butchart et al. 2010; Hoffmann et al. 2010; Szabo et al. 2012), which varies from 0 (if all species formerly present are now recognised to be extinct) to 1 (if all species are recognised as Least Concern). Values are calculated from information in (Woinarski et al. 2014), and use a benchmark date of 1788 (the time of initial European settlement of Australia).

Groups of species: $N=$ mammal species occurring only in northern Australia $(n=53), N R=$ mammal species occurring in northern Australia and elsewhere in Australia $(n=61) ; N X=$ mammal species occurring in northern Australia (but not the rest of Australia) and extralimitally $(n=12)$; NRX=mammal species occurring in northern Australia, elsewhere in Australia, and extralimitally $(n=31)$; $R=$ mammal species endemic to Australia but not occurring in northern Australia $(n=150)$.

\section{A conceptual model}

A conceptual framework, summarised below, was recently put forward in an attempt to unify current theory on mammal declines in northern Australia (Radford et al. 2014). This schematic model is based on evidence from the Kimberley region and has not yet been tested, hence its accuracy and broader applicability remains to be determined. The framework tackles competing hypotheses and inconsistent observations within a context of limited understanding of the functional relationships between mammal assemblages and their savanna environments and processes. A simplified conceptual framework that summarises the primary factors and their interactions responsible for declines in north Australian mammal assemblages is presented in Figure 5.

This framework is a state and transition model similar to that developed for arid zone plant populations (Westoby et al. 1989) and more recently for Australian arid zone mammals (Letnic and Dickman 2010). In this framework, successive assemblage states are defined by functional composition and profile. In application of this model to the Kimberley savannas of northwestern Australia, "State 3" assemblages included all the critical weight range mammal functional groups (including slow reproducing arboreal rodents, omnivorous peramelids, predatory dasyurids, fast reproducing omnivorous rodents and low resource requiring small dasyurids); "State 2" assemblages had fewer functional groups and were dominated by omnivorous rodents, but also with small dasyurids as a minor component; and "State 0 " assemblages had very low numbers of omnivorous 
rodents and small dasyurids (Radford et al. 2014). "State 1", an assemblage dominated by small dasyurids, was seldom observed in savannas (Radford et al. 2014) and may be restricted to arid grasslands (Letnic and Dickman 2010). Transition processes causing change between states included previously identified threatening processes (e.g. fire, cat predation and cattle grazing: Woinarski et al. 2011a), or processes leading to population irruption (high rainfall: Letnic and Dickman 2010). Transitions may occur periodically in savannas, for instance, with boombust cycles caused by major rainfall events followed by drought (Letnic and Dickman 2010; Radford et al. 2014). However, longer term trends within this framework, particularly declines in assemblage functional diversity, could lead to irreversible transitions at local or national scales.

The distribution of mammal assemblage states in the Kimberley provides insights into the tenability of hypotheses raised to explain mammal declines. The importance of productivity in assemblage distributions lends support to the ecosystem productivity collapse hypothesis proposed by McKenzie et al. (2007). Under this hypothesis, loss of functional diversity is directly linked to natural productivity gradients and collapse is due to degradation through grazing and fire. Preferential loss of functional diversity in lower rainfall, lower production savannas may indicate productivity collapse in these more marginal areas for mammals. Conversely, regional assemblage patterns do not support a dominant effect of fire regime (Andersen et al. 2005; Legge et al. 2008; Woinarski et al. 2010) or cattle grazing in isolation (Legge et al. 2011a). This is because diverse mammal assemblages (State 3) in the high rainfall region of north Kimberley do not coincide with the lowest fire and cattle activity. The distribution of "State 3" assemblages in high productivity areas is also not consistent with predictions relating to the cat predation hypothesis (Johnson 2006).

Cat predation impacts should be highest under high ecosystem resource levels in the high rainfall north Kimberley because of greater and more predictable food resource availability and increased abundance of mammal 'prey', leading to larger cat populations and greater predation rates. Increases in cat populations that result in increased predation pressure have been observed in arid zone systems after major rainfall events (Letnic and Dickman 2010). Cat predation effects may however be ameliorated by interacting processes in high rainfall savannas. Predation rates by cats may be limited by increased vegetation complexity/cover for mammals in high rainfall savannas (Johnson 2006; Radford 2012). Similarly cat predation rates may be reduced by interactions with increasing numbers of the meso-predator, the dingo, in high rainfall regions (Johnson 2006; Letnic et al. 2012; Radford et al. 2014). It is difficult to predict outcomes of interactions between vegetation complexity and predators because cats also gain greater protection from dingoes in high productivity ecosystems due to their more complex vegetation. Nevertheless, cats should be more vulnerable to predation by dingoes, and small mammals should experience greater release from predation, in low production, arid and semiarid ecosystems where there is less habitat cover to protect cats. More research is needed to evaluate the relative importance of productivity-mediated predator interactions (McKenzie et al. 2007; Radford et al. 2014) versus habitat structure-mediated interactions (Johnson 2006), in determining mammal assemblage structure in northern savannas. Research of the effects of grazing and fire regimes on site productivity and predation rates will also be useful in establishing a functional link between predators and land management. Experiments are necessary to isolate the potential effects of site productivity, productivity degrading processes (e.g. cattle and fire), predator interactions and habitat simplification to disentangle the key mechanisms that are responsible for mammal declines across northern Australian savannas (Radford 2010; Williams et al. 2003a; Woinarski et al. 2011a). 


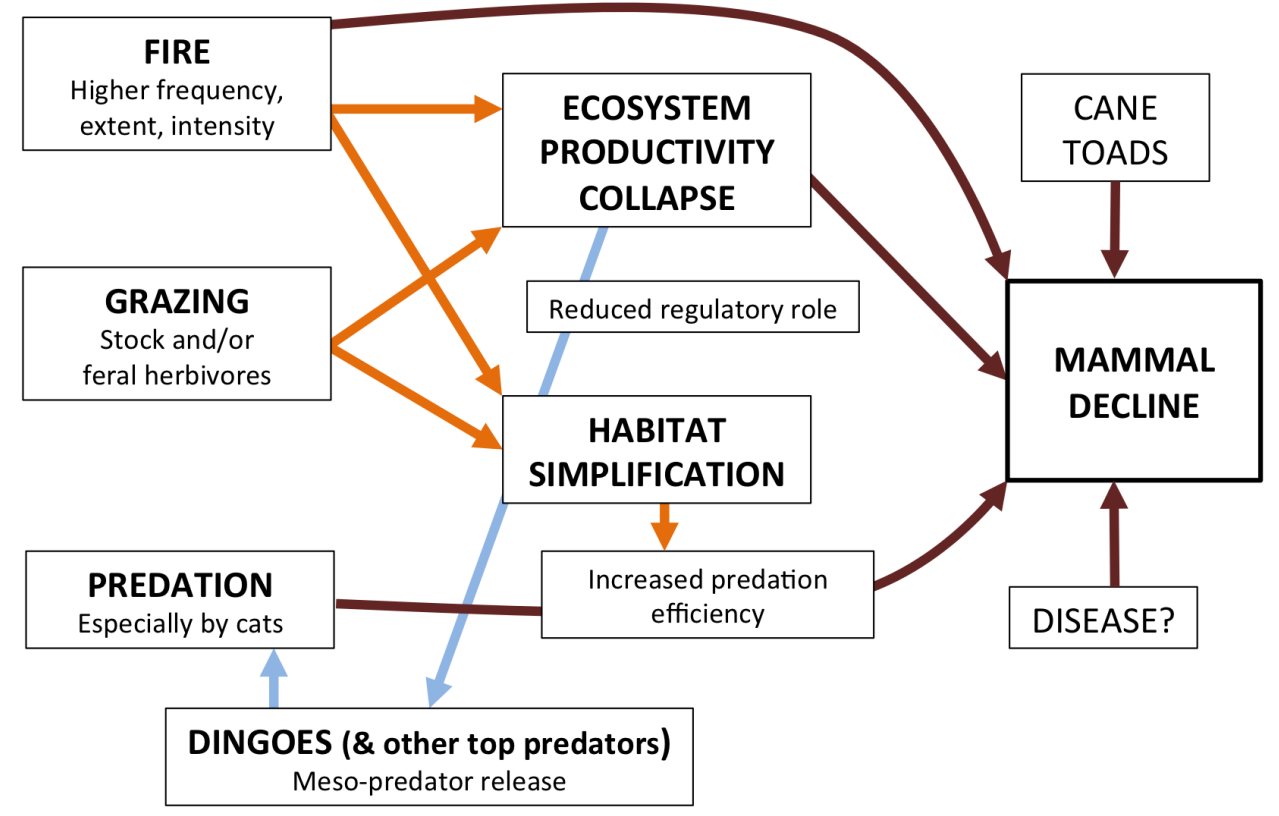

Figure 5. A conceptual framework outlining the main factors contributing to the decline of native mammals in northern Australia

\section{Predation by feral cats}

In other parts of Australia several studies have demonstrated remarkable recovery of many native mammal species to the control of feral predators, particularly through the establishment of predator-proof fencing (Moseby et al. 2009). In northern Australia, recent studies have either used relatively small-scale exclosure fencing to quantify cat predation behaviour and rates, or largerscale manipulations of fire and stock management to explore their effects on feral cat (and native mammal) behaviour and survival. Exclosure fencing has been used to explore cat impacts in two complementary studies. A recent manipulative experimental study at Wongalara about $200 \mathrm{~km}$ southeast of Kakadu (Figure 1) compared the survival of translocated long-haired rats Rattus villosissimus in two sets of matched pairs of 12.5 ha enclosures. Each pair was comprised of one enclosure that was accessible and another that was inaccessible to feral cats (Frank et al. 2014). In a first translocation of 77 individuals, rats in the cat-accessible plots were rapidly extirpated due to predation by cats, while rats in the cat-proof plots persisted (Frank et al. 2014). Rats used in this translocation were sourced from cat-free Quoin Island in the Northern Territory and captive bred to increase numbers prior to release; two factors that may have compromised the ability of these translocated rats to evade predation. A second translocation using pale field-rats was initiated in a wild-to-wild translocation, with rats sourced from an area where native mammals coexist with feral cats. A program of cat removal and deterrence was conducted around the experimental plots before and during the translocation. Similar results ensued: the pale field-rat populations in the cat-accessible plots were rapidly extirpated (Tuft et al. 2014). These experiments suggest that it may be difficult to re-establish small mammal populations in areas where the original mammal fauna has collapsed when feral cats are present. 
At Kakadu, two exclosure fences (of 64 ha each) were constructed and cleared of feral cats in late 2013 to examine whether native mammals can 'naturally' rebound in cat-free areas without translocating individuals. Intensive baseline sampling of mammals and reptiles was undertaken within the exclosures and in four unfenced control sites nearby demonstrated extremely low mammal species richness and capture rates $(<1 \%)$ across all sites (DLRM, unpublished data). Two surveys of the exclosures within the first eight months of the study failed to detect signs of mammal recovery. These are preliminary findings, however, and it may take several years for species with low baseline population sizes to exhibit an increase. This experimental approach has several limitations: the size of the enclosures potentially limits the population base size from which a treatment response can be elicited. Although the exclosures are permeable to small rodents and dasyurids, medium sized species such as adult quolls and bandicoots are excluded. Furthermore, in addition to excluding feral cats, the fences exclude dingoes/dogs, pigs, macropods and buffalo, thus limiting inference of the cause of treatment effects.

In a different approach, recent work in the Kimberley has demonstrated how changes to vegetation structure wrought by fire and introduced herbivores can substantially amplify the effect of feral cats on native mammals. The research provides a mechanistic explanation underpinning mammal declines. Cat movement and hunting behaviour were compared across large areas (tens of thousands of hectares) with varying cattle stock densities and fire treatments in the central Kimberley. This study examined the movements of thirty-two GPS-collared cats, and the novel deployment of miniature cameras on collars attached to cats to visualise very fine-scale habitat selection and hunting preferences. Grazing by introduced herbivores, and high fire intensities, both modified vegetation structure in ways that advantaged cats. The cameras showed that the likelihood of a cat making a successful kill increased nearly three fold in open habitats, compared with dense grass or complex rock habitats (McGregor 2014). GPS collar data showed that cats preferred to spend time hunting in areas of open grass cover, especially heavily grazed areas and areas burnt in high intensity fires, particularly if those habitats had a high abundance of small mammals (McGregor et al. 2014). In fact, areas burnt by intense fires were so attractive to cats that almost all cats within a $15 \mathrm{~km}$ radius of the fire edge made extra-territorial forays to visit these burnt areas. The influxes of cats to these burnt areas created localized increases in cat density that amplified up to 16-fold the predation rates by cats on resident small mammals (McGregor 2014).

In a complementary study, the movement, fecundity and survival of native rodents in contrasting experimental fire treatments were contemporaneously examined in Mornington Sanctuary. High intensity (all understorey vegetation removed) and low intensity (understorey vegetation partially removed) fire treatments were applied to adjacent areas, and resident populations of native rodents (pale field rats and western chestnut mice) were monitored by trapping and radio-tracking. Compared with the unburnt control area, post-fire mortality in the high intensity fire treatment increased 21-fold and increased 5-fold in the low intensity fire treatment. Even in the high intensity fire treatment, the direct effects of fire, post-fire starvation, emigration, and lowered breeding activity caused little or no mortality; mortality was thus directly attributable to post-fire predation by cats and dingoes. An influx of feral cats and dingoes occurred after the fire, coinciding with rodent declines, and there was direct evidence of predation by cats on the native rodents (Leahy 2013; Leahy et al. in review).

Taken together, these studies provide new insights into the mechanisms by which sparse populations of cats can have large effects on populations of small mammals at landscape scales. The collapse of the experimental populations of small mammals in the Wongalara study was due to a few individual cats who concentrated their hunting on small areas with locally high densities of small mammals, until all had been killed. The studies of the intensity of cat predation in recently burnt areas and the movement behaviour of cats, revealed the behavioural mechanisms 
responsible for their highly concentrated effect on prey populations. Cats are versatile predators that will switch their diet as their preferred prey is depleted. However, they will often continue hunting their preferred prey to much lower levels than more generalist predators (Molsher et al. 1999). This makes cats particularly dangerous to small mammal populations because not only will they continue hunting a species to local extinction, their ability to persist once small mammals have declined in an area prevents populations from recovering.

\section{Dingoes}

Dingoes (including 'stray dogs' and hybrids) may have a complex effect on native mammal assemblages in northern Australia, which may vary for different species, in different areas, and under different land management regimes. Dingoes may benefit native mammal populations where they reduce the abundance or impacts of feral cats, but may also predate and reduce mammal populations. In Kakadu, a study of a declining population of northern quolls found that predation by dingoes was a significant cause of mortality, especially in open savanna habitats that provided few structural refuges from predation (Oakwood 2000). Camp dogs or stray dogs in the vicinity of communities and Aboriginal outstations may also have an under-estimated impact on local mammal populations. These dogs supplement their diet with food from human sources, thus maintaining their numbers and their effect on mammals may be considerable (Newsome et al. 2014b; Ritchie et al. 2014). There is also evidence that similarly 'subsidised' dingoes may preferentially hunt small mammals (Newsome et al. 2014a).

However, the effect of predation by dingoes on the demography and population size of small mammals is expected be less than the effect of feral cats, for three reasons. First, dingoes tend to occur at low population densities, typically one or two individuals per $10 \mathrm{~km}^{2}$ (Fleming et al. 2001; Johnson and Ritchie 2013), while feral cats densities are often much higher than this (Denny and Dickman 2010). Second, while cats appear to prefer small mammals as prey, dingoes generally hunt larger prey and small mammals are usually only a small part of their diet (Allen and Leung 2012; Brook and Kutt 2011; Kutt 2012; Letnic et al. 2012). However, one study in Kakadu demonstrated substantial take by dingoes of small and medium-sized mammals (Corbett 1989) and a recent study in the Tanami Desert, just beyond the southern edge of the study area, also found similar results (Newsome et al. 2014a). Third, being smaller predators, cats are better able to enter small spaces that small mammals could use to evade dingoes, and they can also hunt in trees.

Consistent with the mesopredator release hypothesis (Crooks and Soule 1999), there is evidence that dingoes suppress the abundance of feral cats and enforce changes in their behaviour that reduce their impact on small mammals. Because dingoes do not prey as intensively on small mammals as cats do, by suppressing cat numbers dingoes may provide a net benefit to small mammal populations (Ritchie and Johnson 2009). Across northern Australia, cat activity tends to be higher where dingo activity is low (Brook et al. 2012; Kennedy et al. 2011). Although cats are not significant prey for dingoes, an experimental study by Moseby et al. (2012) found that dingoes killed free-ranging feral cats, leaving their bodies uneaten. Brook et al. (2012) found that in central and northern Australia, cats adjusted their daily activity patterns to avoid encounters with dingoes, being less active around dusk and in the early evening in places where dingo activity at those times was high. This might have led to reduced mortality rates of small mammals, because small mammals showed a peak in activity at dusk and in the early evening, and hunting during that period probably gives cats their best opportunity to kill small mammals. Also, simultaneous GPS tracking of coexisting dingoes and feral cats showed that cats avoid dingoes in space as well as time, adjusting their movements to avoid coming within a few hundred metres of a dingo (Brook 2013). 


\section{Fire regimes}

In the fire-prone savanna landscapes of monsoonal northern Australia, one of the ecological processes that has been most obviously disrupted at regional scales is fire. There is much evidence, though largely anecdotal, that the breakdown of traditional fire management by Aboriginal people across northern Australia by the mid- $20^{\text {th }}$ century significantly altered fire regimes (Yibarbuk et al. 2001). In the absence of purposeful Indigenous fire management, fires (ignited by people and also lightning) now tend to occur later in the dry season (c. August-November), burn with higher intensity, reach larger sizes, and recur more regularly across any one area (Russell-Smith and Edwards 2006; Russell-Smith et al. 2003). Conversely, in some pastoral areas consumption of grass by cattle has significantly reduced vegetation biomass and hence fire intensities and/ or frequencies (Russell-Smith et al. 2003). Convincing evidence of a widespread increase in fire intensities in the high rainfall savannas of the Northern Territory over the last century is the well-documented decline of the fire-sensitive northern cypress-pine (Callitris intratropica) across much of the savannas of northern Australia (Bowman and Panton 1993). High-intensity fires also tend to be larger (Yates et al. 2008), and are more likely to cross natural barriers, such as creek lines (Price et al. 2007).

The breakdown of Aboriginal fire management leading to a fire regime characterised by frequent and spatially extensive late dry season fires has been well-documented on the Arnhem Plateau in northern Australia, and has led to significant impacts on a range of plant taxa and communities, including cypress-pine, sandstone heathland and rainforest (Russell-Smith et al. 2002; Russell-Smith et al. 1998). A critical aspect of Aboriginal fire management is that it reportedly maintains a fine-scale mosaic of vegetation of varying time since fire (Bliege Bird et al. 2008; Bowman et al. 2004), and spatiotemporal heterogeneity of fire regimes - sometimes called 'pyrodiversity' (Martin and Sapsis 1992). The breakdown of Aboriginal fire management may have led to a widespread decrease in pyrodiversity, both in the high-rainfall savannas (Bowman et al. 2004) and the arid hummock grasslands at the southern fringe of the region considered here (Bliege Bird et al. 2008; Burrows et al. 2006).

Assessing the effects of changing fire regimes on northern Australia's mammals has been the focus of an increasing body of research. Unravelling the relative effects of these changes, however, is inherently complex because of the difficulty of accounting for variations in specific attributes of a fire regime (i.e. frequency, intensity, extent and timing of fires) in different landscapes, on different species and in combination with other threats and ecological and climatic processes.

The effects of fire on small mammals can be classed as either short- or long-term. Shortterm effects include killing or injuring individuals, decreasing (or sometimes increasing) food availability, and reducing understorey cover (e.g. grasses, shrubs, litter) that would otherwise provide shelter. The short-term negative impact of large hot fires on survival of small mammals has been demonstrated in a number of studies in the northern savannas (Corbett et al. 2003; Firth et al. 2010; Legge et al. 2008; Pardon et al. 2003). Recent work in the Kimberley region suggests that the reduction in understorey cover caused by spatially homogeneous hot fires significantly increases predation pressure by cats (Leahy et al. in review; McGregor et al. 2014). A similar model has been proposed by numerous other authors to explain declines of a range of mammal species (Firth et al. 2010; Fisher et al. 2014; Pardon et al. 2003; Radford 2012; Woinarski et al. 2011a), but the work by McGregor et al. (2014) and Leahy et al. (in review) provides the first direct evidence for this mechanism of decline. 
A number of studies have shown clear negative relationships between recent fire frequency and the abundance or diversity of small mammal populations within a single landscape (Corbett et al. 2003; Corey et al. 2013; Firth et al. 2006; Woinarski et al. 2010). Longer-term effects of repeated fires are likely to include indirect impacts, via reductions in habitat suitability, with frequent hot fires reportedly reducing key habitat qualities, such as a diverse layer of shrubs (Friend and Taylor 1985) and grasses (Firth et al. 2010) and abundant hollow logs. A recent systematic review of the effects of fire on small mammals globally supports this, concluding that species dependent on firesensitive habitats (e.g. requiring dense ground vegetation) have higher abundances in unburnt sites (Griffiths and Brook 2014). In addition, a recent evaluation of the relative importance of attributes of fire regimes to mammal declines in Kakadu demonstrates that large, homogeneous fires have been most closely associated with small mammal declines since the early-2000s (Lawes et al. in press). Those authors hypothesized that small mammals, with small home ranges ( $<10 \mathrm{ha})$ and limited capacity for dispersal, are particularly vulnerable to large fires that simplify habitats.

Notwithstanding the pervasiveness of fire, and the complexity associated with understanding the impacts of different types of fire, there have been relatively few experimental studies in northern Australia that have manipulated fire regimes and examined biodiversity responses (Williams et al. 2003a). The most notable is the landscape-scale (c. $670 \mathrm{~km}^{2}$ ) experimental manipulation of four different fire regimes (fire exclusion, annual fire lit in the early dry season, annual fire lit in the late dry season, and 'progressive' burning across the dry season) each replicated three times at Kapalga in Kakadu (Corbett et al. 2003). However, the experiment was sustained for only four years (19901994) and, probably as a consequence, relatively few differences in abundance of mammal species between treatments were reported (Corbett et al. 2003). Furthermore, the imposed fires - even those applied in the early dry season - were atypical, being applied at unusually high intensity and low patchiness, (G.D. Cook and J. Russell-Smith, pers. comm.). Hence it is very difficult to generalise the Kapalga results to ambient fire regimes.

Nonetheless, more recent analysis of the Kapalga data has demonstrated that high fire frequency regimes result in significantly lower rates of survival and recruitment of several species. In addition," spatially explicit population viability analyses show that increasingly frequent fires presented a substantial risk to population persistence for the four mammal species modelled, namely the northern brown bandicoot, common brushtail possum, northern quoll and grassland melomys (Griffiths 2013). Data for the northern brown bandicoot from this experimental study were also modelled by Pardon et al. (2003), who concluded that this species declined under all experimental fire treatments, suggesting that this species requires a fine-scale mix of fire regimes.

There have been few other experimental manipulations of fire to assess mammal responses. In a sandstone massif (with mixed woodlands and rainforest patches) in Kakadu, Begg et al. (1981) lit a relatively high intensity fire and compared the post-fire abundance, reproductive success, and timing of breeding of several mammal species to their pre-fire states. At Mornington Sanctuary in the Kimberley, Leahy (2013) monitored the survival of individually marked small mammals in an experimentally burnt and nearby control area.

In a more serendipitous and retrospective study near Darwin, Woinarski et al. (2004) compared the abundance of mammals (and other vertebrates, and plants) in a 120 ha savanna woodland patch from which fire had been excluded for 23 years with a comparable adjacent patch subjected to ambient (annual) fire regimes, and reported almost complete turnover in mammal species composition between the two areas. On a far briefer time scale, Legge et al. (2008) compared the abundance of mammal species in a range of areas burnt by a single high intensity late dry season fire (five weeks before sampling) with matched nearby unburnt areas, in a savanna woodland in the Kimberley, and found higher richness and a 4-fold higher abundance of mammals in the unburnt sites. 
Evidence of the effects of increased fire frequency has been fairly well established in the more intact parts of northern Australia. Yet in pyrophytic systems, such as Australia's tropical savanna, a reduction in fire frequency may also affect some components of the biota (Crowley and Garnett 1998). In the intensely grazed (pastoral) rangelands and savanna of northern Queensland there is evidence of a reduction in fire frequency over recent decades (Russell-Smith et al. 2003). Such changes may be detrimental to some native mammal species, for example by changing the phenology and diversity of plant species, and hence the availability of seed resources.

Overall, there is mounting evidence that historical increases in the frequency of extensive, hot fires have negatively impacted small mammals by both increasing mortality rates, especially via predation by cats; and reducing habitat quality (Lawes et al. in press). However, whether changes to fire regimes are a major driver of the current mammal decline in northern Australia remains uncertain. There is relatively little evidence in this region, or indeed from the few studies elsewhere in Australia (Pastro et al. 2011), relating the responses of small mammals to pyrodiversity (the mosaic grain of patches of varying fire history), and the issue remains contested (Parr and Andersen 2006). Furthermore, there is little direct evidence of a spatio-temporal association between mammal declines and the transition from Aboriginal fire management. The apparent ubiquity of the mammal decline is difficult to reconcile with spatially variable modes of fire management. For example, Yibarbuk et al. (2001) described a healthy mammal assemblage on an Aboriginal estate in central Arnhem Land, and attributed this to the maintenance of traditional management of the local fire regime (see also Whitehead et al. 2003). However, the mammal assemblage at this location has since collapsed, despite the lack of any apparent changes in fire management or the local fire regime (A. Fisher, unpublished data).

\section{Pastoralism and feral herbivores}

Studies of the role of introduced herbivores in mammal declines in northern Australia have produced variable results. A recent de-stocking study in northeastern Australia reported no benefit for native mammals, possibly because a long history of intensive grazing in that area had led to long-term declines in the population size of many native mammal species to such an extent that there was no realistic likelihood of short-term recovery after de-stocking (Kutt et al. 2012). Several opportunistic studies that have examined mammal responses at sites subjected to a longer history of contrasting livestock regimes. These have demonstrated some pastoral impacts, with significant variation in the composition of native mammal assemblages between comparable sites of varying livestock-grazing intensities (Kutt and Woinarski 2007; Woinarski and Ash 2002).

An initial landscape-scale experiment involving the removal of stock (mostly cattle) from 40,000 ha at Mornington Sanctuary in the Kimberley resulted in an immediate improvement in mammal species richness and abundance (Legge et al. 2011a). Following these early results, stocking treatment was then contrasted against fire treatments, focussing on differences between frequent, large, high intensity fires with less frequent, smaller, lower intensity fires to explore the interaction of these potential threats. Mammal recovery after stock removal was only pronounced when fires were simultaneously managed to be lower in frequency, size and intensity. When fire is not simultaneously managed (and fires were of higher frequency, larger size, and higher intensity), mammal recovery post-destocking was limited. In addition, the study suggested that fire frequencies need to be substantially reduced (or vegetation age increased) before the benefits of fire management are observed. In this relatively low rainfall area of the Kimberley (750 mm pa), fire frequencies as low as 1 in 4 years were required (from a starting frequency of 1 fire in 2 years mostly intense late dry season fires) before mammal recovery was evident (S. Legge, unpublished data). This is a lower frequency than most land managers maintain. The interacting influence 
of fire pattern on introduced herbivore impacts (and vice versa) may partly explain the confusing variation reported by some earlier studies that focussed on either fire or introduced herbivores without adequately considering their interactions. Based on the results of the Mornington research, landscape-scale manipulations of stock (involving removals from areas as large as 100,000 ha) and fire (across entire properties of 200,000-300,000 ha ) have been initiated at five other Australian Wildlife Conservancy properties across northern Australia. At three sites these manipulations are being implemented experimentally, with before-after, control-impact designs.

\section{Cane toads}

The highly toxic cane toad was deliberately introduced to Queensland in 1935, and has since spread across northern Australia. In the Northern Territory, the cane toad invasion has caused massive declines in populations of freshwater crocodiles (Crocodylus johnstoni; Letnic et al. 2008), varanid lizards (Varanus spp. ; Doody et al. 2009), blue-tongue lizards (Tiliqua spp.; Brown et al. 2011) and northern quolls (Woinarski et al. 2010). Cane toads are currently invading the Kimberley region of Western Australia, and have already caused the extirpation of northern quolls at El Questro Station (S. Doody, pers. comm.). In parts of north Queensland, however, quoll populations appear to be recovering, despite the presence of cane toads (Ujvari et al. 2013).

Cane toads clearly present a serious threat to northern quoll populations, but we know less about their effects on other native mammals. Small dasyurids such as planigales, antechinus and dunnarts do not appear to be at risk from toad poisoning. Unlike quolls that encounter and attack large, lethal toads, these smaller dasyurids encounter smaller, less toxic toads that provide learning opportunities via conditioned taste aversion (Webb et al. 2008). In laboratory trials, most planigales and dunnarts that attacked and ingested small toads became ill, and subsequently refused to attack toads for several weeks (Webb et al. 2008; Webb et al. 2011). Rodent populations are also unlikely to be affected by cane toad poisoning. Although cane toads were implicated in declines of pale field-rats in Kakadu (Woinarski et al. 2010), laboratory studies revealed that individuals of pale field-rat, grassland melomys and dusky rat (Rattus colletti) can consume cane toads without ill effects, suggesting that these species possess physiological resistance to bufotoxins (Cabrera-Guzmán et al. in press). In the wild, native rodents such as the water rat (Hydromys chrysogaster), and introduced black rats, have also been observed preying on cane toads (Fitzgerald 1990; St Cloud 1966). Nevertheless, there is still cause for concern for some native mammal species. For example, there is recent anecdotal and correlative evidence suggesting a link between cane toads and a substantial decline in the carnivorous ghost bat in parts of northern Australia (White and Madani 2014), but this link has not yet been conclusively demonstrated.

The biggest impact of cane toads on small mammal assemblages may occur via indirect pathways (Shine 2010). Cane toad invasion results in the rapid collapse of varanid lizard ('goannas') populations, which can lead to increases in the abundance of species previously preyed on by goannas. For example, in the Daly River region, green tree snakes (Dendrelaphis punctulata) increased in abundance after cane toads severely reduced populations of three species of varanid lizards (Doody et al. 2013). Likewise, increases in the abundance of some snakes at Fogg Dam probably resulted from the disappearance of yellow-spotted monitors (Varanus panoptes), which are major predators of snakes and their eggs (Brown et al. 2011). Indirect effects of cane toads on small mammals are therefore likely; for example, the removal of large varanid lizards might cause increases in the abundance of feral cats or some snakes, thereby increasing rates of predation on small mammals. Increases in raptor populations might also occur after toads invade, due to the presence of a plentiful food source (Beckmann and Shine 2011). Food-supplemented raptor populations could reduce small mammal populations, particularly in frequently burnt areas. A potential recovery of predators in the Northern 
Territory following initial collapse may provide an opportunity to study the relationships among these trophic levels in the future. At present, we know virtually nothing about the interplay of cane toads with other threatening processes (predation, fire, and grazing), making it difficult to evaluate exactly how cane toads have affected small mammal populations in northern Australia.

\section{Diseases and pathogens}

Most previous studies of disease in native mammals in northern Australia have focused on mammals as vectors for diseases that affect humans, rather than on the potential impacts of disease on the conservation of native mammals (Bell and Whelan 1993; Cook et al. 1967; Doherty et al. 1968; Plowright et al. 2008; Slack et al. 2006; Smythe et al. 2002). Many (>54 \%) emerging infectious diseases are zoonoses and are caused by bacteria or rickettsia (Jones et al. 2008), making a study of the vectors of these diseases imperative. Low reporting rates of disease in the tropics makes detecting these zoonoses difficult (Jones et al. 2008).

Disease is potentially implicated in the demise of native mammals under current changing climate and emerging infectious diseases (Cox-Witton et al. 2014; Thompson and Conlan 2011; Thompson et al. 2010a). Much of our current understanding of disease and epidemics in Australian mammals derives from anecdotal evidence (Abbott 2006). Previous research elsewhere in Australia on the effects of diseases on native mammals has identified that diseases may be implicated in the declines of some mammal species (Abbott 2006; Appelbee et al. 2005; Bettiol et al. 1997; Buettner et al. 2013; Skerratt 2005; Thompson and Conlan 2011; Thompson et al. 2010b; Warren et al. 2003; Wayne et al. 2013a; Wayne et al. 2013b; Wyatt et al. 2008). For example, in southwestern Australia, the woylie (Bettongia penicillata) experienced a sudden catastrophic decline in population abundance and distribution, and there is some suggestion that disease was a contributing factor (Smith et al. 2008; Wayne et al. 2013b), along with increased predation by feral cats.

Disease in wildlife is notoriously hard to detect, and efforts to date in northern Australia have been meagre. Sick and dying animals are rarely trapped, and it is difficult to find dead animals. Most previous studies of disease in mammals in northern Australian savannas have involved necropsies of roadside carcasses or of euthanized trapped individuals. The few previous studies in northern Australia aimed at assessment of conservation risk associated with disease have investigated just one or two potential disease causes, such as toxoplasmosis, and parasite loads, and these studies have not produced evidence that these diseases are implicated in declines (Oakwood and Pritchard 1999; Oakwood and Spratt 1999).

Introduced mammal species are likely to spread 'novel' diseases to native mammals, and the extinctions of two Christmas Island endemics, Maclear's rat (Rattus macleari) and bulldog rat ( $R$. nativitatis), has been linked to trypanosomiasis brought to the island by introduced black rats (Green 2014; Wyatt et al. 2008). One study of wild populations of the introduced black rat in the Top End of the Northern Territory investigated the presence of six'novel' diseases but found none of them (Jackson et al. 2010).

Research is currently underway in the Northern Territory to evaluate the potential role of disease as a contributing factor to mammal declines in northern Australia. Four target species have been selected (common brushtail possum, northern brown bandicoot, northern quoll and brush-tailed rabbit rat). These species represent a cross-section of ecological guilds and still have populations in various 'states' of persistence across different landforms, including on islands and the mainland. To date, over 200 individuals have been sampled across several sites in the Top End and screened for a variety of infectious diseases. In addition, indicators of health have been recorded, including body condition, reproductive status, observed health status, haematological and biochemical profiles, and ectoparasites collected (G. Gillespie, unpublished data). 


\section{Climate change}

The extent of climate change, and its likely impacts, for northern Australia are not well resolved. The most likely change is for fire regimes, with increasing severity of fires because of longer dry seasons and perhaps higher wet season rainfall (Williams et al. 2009). Such change will exacerbate the existing detrimental effects of fire regimes upon biodiversity. Whereas there are well developed predictions for catastrophic impacts of climate change (including food-plant responses to elevated atmospheric concentrations of $\mathrm{CO}_{2}$ ) upon many mammal species with sharply defined climatic thresholds and dietary specialisations in the distinctive montane environments of the Wet Tropics of northeastern Australia (Kanowski 2001; Kanowski 2004; Williams et al. 2003b), the predictions for change in the mammal fauna of the tropical savannas of northern Australia are far less settled. Nonetheless, very severe declines due to climate change have been predicted within 20 years for the small number of species modelled, including brush-tailed rabbit-rat, black wallaroo, northern brush-tailed phascogale (Phascogale pirata) and Arnhem rock-rat (Zyzomys maini). All of these are expected to decline $90 \%$ in distributions, while the northern short-tailed mouse and black-footed tree-rat are expected to decline by $60 \%$ (Kutt et al. 2009). Coastal changes due to rising sea level have also been modelled to very significantly increase the extinction risk to the water mouse (Xeromys myoides) (Traill et al. 2011).

\section{Habitat loss and fragmentation}

Habitat loss, one of the major drivers of biodiversity decline globally, is not yet a major threat across northern Australia's tropical savannas. However, there are some currently isolated cases of broadscale clearing (of the order of 100 to $500 \mathrm{~km}^{2}$ ) associated mostly with strip-mining (for example in northeastern Arnhem Land, Groote Eylandt and western Cape York Peninsula), plantation forestry (the Tiwi Islands), and intensification of agriculture (the eastern Kimberley, Darwin-Katherine area, and parts of northeastern Australia) (Woinarski 2004a), and particularly in the southeastern agricultural region of the tropical savannas (Franklin and Preece 2014) (Fig. 3). Unsurprisingly, such habitat loss has severe consequences for local native mammal assemblages (Firth et al. 2006; Woinarski 2004a; Woinarski et al. 2009a), although an exception may be where post-mining rehabilitation is intensively managed using fire exclusion (Woinarski et al. 2008).

\section{CONSERVATION MANAGEMENT}

\section{Policy responses}

There has been no coherent integrated policy or management response to the current spate of declines in the north Australian mammal fauna. In part, this reflects the fragmentation of responsibilities across different jurisdictions, and because national and Queensland, Western Australia and Northern Territory conservation agencies also have well-established conservation needs and priorities in the larger part of their jurisdictions outside monsoonal northern Australia. In addition, the declines have

been identified relatively recently, and because the evidence for causation has been weak, the main priorities for responsive management are not well defined.

The typical and sometimes successful policy response for threatened species in Australia has been the development and implementation of Recovery Plans mostly for individual threatened species across their entire range, but sometimes also for regional sets of such species. Such plans set out management priorities and responsibilities, and help coordinate research and management responses across agencies. They have some, albeit weak, foundations in national legislation. Recovery Plans have been developed for most threatened mammal species in northern Australia, including northern quoll (Hill and Ward 2010), bare-rumped sheath-tailed bat (Saccolaimus 
saccolaimus nudicluniatus; Schulz and Thomson 2007), lesser large-eared horseshoe-bat (Rhinolophus sp.'intermediate'; Thomson et al. 2001), greater large-eared horseshoe-bat (Rhinolophus robertsi (Thomson et al. 2001), Semon's leaf-nosed bat (Hipposideros semoni; Thomson et al. 2001), Troughton's sheath-tailed bat (Taphozous troughtoni; Thomson et al. 2001), Carpentarian antechinus (Pseudantechinus mimulus; Woinarski 2004b), Butler's dunnart (Woinarski 2004b), northern hoppingmouse (Woinarski 2004b), golden bandicoot (Palmer et al. 2003), golden-backed tree-rat (Palmer et al. 2003), Bramble Cay melomys (Latch 2008), bilby (Pavey 2006), northern bettong (Dennis 2002), and water mouse (Department of the Environment and Resource Management 2010). The effectiveness of most of these plans, however, has not been assessed, and it is likely that they have provided relatively little benefit, largely because their implementation has been supported by little or no funding (Bottrill et al. 2011; Woinarski et al. 2014).

The other main policy response has been directed at the management of landscape-scale threats, rather than on threatened species. National legislation allows for the recognition of Key Threatening Processes and the establishment of Threat Abatement Plans to coordinate responses to those threats. The most relevant of these to the conservation effort for mammals in northern Australia are plans for the management of feral cats (Department of Environment Water Heritage and the Arts 2008) and cane toads (Department of Sustainability Environment Water Population and Communities 2011). However, as with the Recovery Plans, these Threat Abatement Plans have been largely ineffective due to very limited resourcing.

Notwithstanding the relative ineffectiveness of these responses, the issue of decline of native mammals in northern Australia has recently received greater attention, with some increase in funding for targeted research and management. For example, the issue was identified as a priority for funding in the recent establishment of the National Environmental Research Program and the Threatened Species Recovery Hub within the programme, and is increasingly recognised as a concern in many regional natural resource management plans (www.environment.gov.au/science/ nesp). However, state and federal government policy initiatives for intensification of agriculture and mining have increased the pressure on north Australian environments (Department of Prime Minister and Cabinet 2014; Ritchie et al. 2013).

\section{Indigenous Protected Areas}

A program commencing in 1998 has seen the establishment and rapid proliferation of Indigenous Protected Areas (IPAs). These are Indigenous-owned areas of land or sea that have been identified and declared by traditional landowners and formally recognised by the Australian government as part of the country's National Reserve System. There are currently more than 50 IPAs in Australia covering more than $500,000 \mathrm{~km}^{2}$, representing more than a third of all area under formal protection. Many of these (15 IPAs, with a total area of c. $85,000 \mathrm{~km}^{2}$ ) are wholly or in part located in northern Australia, including many areas that hold substantial populations of threatened or declining mammal species. IPAs are actively managed by their Indigenous owners, often in collaboration with government and non-government organisations. Accordingly, the recent establishment and expansion of the IPA network has substantially increased the number of Indigenous rangers actively managing reserves for biodiversity outcomes. IPAs present opportunities for bringing together traditional Indigenous knowledge systems with modern science to aid management and conservation. By doing so they also help build capacity among Indigenous communities, strengthen or in some cases help re-establish cultural ties to traditional lands, and help nonIndigenous people understand what is important to traditional landowners as well as what may be learnt and applied from their knowledge and practices. 


\section{Non-government conservation reserves}

Non-government conservation organisations have a substantial presence in northern Australia. The Australian Wildlife Conservancy (AWC) owns and manages nine large reserves across the north, with a particularly strong presence in the Kimberley. AWC focuses on utilising threat management and integrated research. In particular, they manage introduced herbivores and fire at large spatial scales, embedded in an experimental paradigm, and work within and across properties that have varying histories of pressures and landscape contexts. This comparative approach may yield valuable information on when certain management actions will succeed or fail to elicit recovery. Management interventions have been ambitious, with multiple de-stocked areas of up to 100,000 ha each, and fire management programs that are regional in scope (e.g. 4 million hectares in the Kimberley) (Legge et al. 2011b). In addition, focussed research on feral cats and threatened mammals is helping to fine-tune management requirements appropriately. Another large non-government conservation organisation, Bush Heritage Australia, supports improved land management on some areas of Indigenous-owned land, with a focus on capacity-building and management planning.

\section{Islands}

Across Australia, more than 140 species of native mammals are known to occur on islands (Abbott and Burbidge 1995). Of particular importance are island populations of threatened mammal species (Burbidge 1999; Dickman 1992). Without islands, Australia's appalling record of 28 to 30 modern mammal species extinctions would be even worse, as seven species that became extinct on continental Australia have persisted on islands.

Northern Australia has many continental islands with the Kimberley having more than 2600, the Northern Territory has 973, and there are 1955 in Queensland (including some islands beyond the northern Australia area considered here). Many island groups in northern Australia have been relatively well surveyed for mammals (Firth and Panton 2006; Gibson and McKenzie 2012; Woinarski et al. 1999; Woinarski et al. $2011 \mathrm{~b})$, although this sampling is far from comprehensive and has concentrated on the larger islands. This sampling has demonstrated that many islands have significant populations of threatened mammal species, including species that have declined severely on the mainland because of pervasive threats (that may not yet occur on islands). Examples include northern quoll, Butler's dunnart, golden bandicoot, nabarlek, blackfooted tree-rat, and golden-backed tree-rat.

Probably because of their relatively recent isolation, and notwithstanding the large size of some northern Australian islands, only one endemic mammal species is restricted to a single island, or set of islands. This exceptional case (the Bramble Cay melomys) is unusual in that the species is (or, was) restricted to a very small sand cay. However, some of the larger islands (notably Bathurst and Melville Islands) have endemic subspecies of mammals (Kemper and Schmitt 1992), although subspecies differentiation on these islands is generally not well resolved.

Many to most islands of northern Australia are under Indigenous ownership or claim and the conservation management of these islands will be dependent upon the interests and capability of these owners. An increasing number of islands are now managed as Indigenous Protected Areas, or otherwise managed by Indigenous ranger groups. As elsewhere in Australia, the maintenance of the conservation values of islands in northern Australia is highly dependent upon the establishment and implementation of adequate biosecurity measures (Nias et al. 2010). Currently, only a few of the highvalue islands have active biosecurity plans.

Such biosecurity measures are required because island mammal populations are extremely vulnerable to local extirpation by invasive species, especially of introduced predators (Burbidge and Manly 2002; Woinarski et al. 2014). In northern Australia the introduction or immigration of cane 
toads is also an issue. Rafting of toads to islands has probably been responsible for at least one case of island extirpation of northern quolls in the Northern Territory, and toads have colonised another quoll-inhabited island (Augustus) in the Kimberley since 2013.

Islands have also been a focus of several translocation programs which have proven to be an effective technique for the conservation of many threatened Australian mammals (Woinarski et al. 2014). To date, however, there have been few such island translocations in northern Australia, partly because many islands in this region already hold important populations of threatened mammal species, and partly because declines in mainland areas have been relatively recent, so there has been little need to attempt translocation. A notable exception is the translocation of northern quolls to two islands off northeastern Arnhem Land. This was in response to the rapid decline of this species on the mainland due to the rapid range expansion of the introduced cane toad (Rankmore et al. 2008). The translocated populations on these (toad-free) islands increased rapidly, whereas their source populations continued to suffer severe declines (Rankmore et al. 2008; Woinarski et al. 2010). A similar effort has involved the recent translocation of small numbers of golden bandicoot from one island (its only known occurrence in the Northern Territory) to two other nearby islands (Woinarski et al. 2014).

The persistence or increased abundance of translocated populations to islands provides compelling insights into the detrimental impacts of some factors, typically introduced predators, operating elsewhere in the species' range. A contrasting 'natural' experiment on the Sir Edward Pellew island group involving the introduction of cats by landholders to some islands, and the natural colonisation of toads to many islands resulted in dramatic declines of the native mammal fauna of these islands (Woinarski et al. 2011b).

\section{Captive breeding, ex situ conservation, and translocations}

Ex situ conservation is an important part of the conservation response for many highly imperilled species across the globe, particularly for those species confronted with extreme habitat loss or severe hunting pressure. Major and sustained captive breeding programs have been established for some threatened Australian mammal species, extending over several decades (Ford and Hogg 2012; Serena 1994). Most have used captive breeding as a stage towards attempted reintroduction or other translocation programs, with particular emphasis on release into intensively-managed sites within their former range or to predator-free islands. Some of these programs have been extraordinarily successful, and have been responsible for preventing extinctions (Langford and Burbidge 2001; Moseby et al. 2011).

However, there have been few cases of ex situ conservation and no examples of the establishment of large-scale predator-proof exclosures for the mammal fauna of northern Australia. This may be because of the very recent recognition of the conservation problem in this area, and because declines in other parts of Australia have been recognised for appreciably longer periods. Captive breeding may have prevented the extinction of the Bramble Cay melomys sometime in the last decade (Latch 2008).

There is scope and probably a need for a substantial increase in the use of captive breeding and translocation in conservation management of the current decline of north Australian mammals. This should include strategic consideration of the establishment of insurance populations for some of the most imperilled species, the establishment and use of large-scale predator-proof exclosures, and the careful use of predator-free (and toad-free) islands as translocation sites. 


\section{Priority actions for species, threats, and management}

To date, much investment in conservation management in northern Australia has been ad hoc, localised and short-term, often driven by conventional wisdom and current practice, by the preferences and outlook of individuals, or by the shifting fashion of available government funding streams.

The most strategic attempt to prioritise management responses for the conservation of mammals, and other vertebrate species, in northern Australia is a recent approach in the Kimberley (Carwardine et al. 2011; Carwardine et al. 2012). This used expert testimony to evaluate the relative benefits (in terms of increase in the predicted persistence of individual species over a 20 year time period) of a prescribed set of alternative management actions, with each action carefully costed and its feasibility of implementation estimated. From these estimates, the overall benefit per unit cost of each action was calculated, along with the expenditure required to ensure all species persisted in the region, and the optimal combination of management responses under a range of available management funds. The study concluded that the wildlife of the Kimberley could be secured over a 20-year period with an initial investment of $\$ A 95$ million, followed by annual investment of $\$ A 40$ million. This figure compares with the current annual investment of $\$ A 20$ million for biodiversity conservation in the area, an amount that is larger than that provided to other northern Australian regions. The single most costeffective management action related to the control of feral cats, even though the study concluded that the likelihood of eradication of feral cats was low. The next most cost-effective response was a combination of enhanced fire management and control of introduced herbivores, and this combined response was considered to have a high likelihood of success. To date, this program has not yet been fully implemented.

Recently a similar approach was adopted for optimising management actions in Kakadu (Woinarski and Winderlich 2014), and comparative analyses are currently underway for several other regions in northern Australia, including the Fitzroy River in the Kimberley, the Daly River in the Northern Territory and the Northern Gulf region in Queensland (J. Alvarez-Romero, pers. comm.).

A different approach, namely that of prioritising species rather than of management efficiency has been applied in Queensland (the'Back on Track'process: Marsh et al. (2007)) and the Northern Territory (S. Ward, unpublished data). This approach aims to identify and prioritise not only which species are most threatened but also which have the greatest potential for recovery, thereby informing the strategic allocation of limited conservation resources. However, these approaches have not yet been substantially implemented or resourced.

\section{Management responses to specific threats}

\section{Feral cats}

There are currently no viable options for the direct control of feral cats over large landscapes. Cats are extremely cautious, live-prey specialists, making them unlikely to enter traps, or take standard poison-baits. Small-scale intensive control efforts appear ineffective due to rapid reinvasion by other cats (McGregor, unpublished data). In addition, any control method with a collateral negative impact on dingoes (including poison-baiting) is likely to be counter-productive given that dingoes suppress cat populations (Brook et al. 2012; Kennedy et al. 2011) and may not recieve landowner approval on Indigenous-owned land. The results of AWC's Kimberley research suggests that by reducing the frequency of high intensity fires and by removing introduced herbivores from mammal-rich areas (including riparian zones and wetlands), cat impacts can be reduced sufficiently to allow some recovery for at least some mammal species (e.g. small-medium sized rodents). Whether such interventions are enough to enable the recovery of more sensitive species such as the larger rodents and some marsupials, and whether such results can be repeated across other parts of northern Australia with a longer and deeper history of small mammal decline remains to be determined. 
One management response that may be practically implemented for part of northern Australia is the regulation of, or greater education about, the risks associated with the deliberate movement of 'pet' cats to north Australian islands, which are currently cat-free and contain important populations of native mammals. Most of these islands are Indigenous-owned, and some Indigenous agencies (such as Anindilyakwa Land Council on Groote Eylandt) have been proactive in implementing such controls.

\section{Dingoes}

With some exceptions, the available research suggests that the best conservation management approach for dingoes in northern Australia is to leave them alone, because management that reduces their numbers is likely to lead to increased predation pressure on native mammals from feral cats. This approach conflicts with the concerns of pastoralists in some northern Australia regions, who control dogs and dingoes because they are held responsible for significant levels of stock losses (WoolProducers Australia 2014), although it has also been argued that their impacts have been overstated (Forsyth et al. 2014). Three mechanisms are needed to resolve this possible conflict: (i) the development and implementation of broad-scale integrated pest management, that considers the interactions among different pest species and the consequences of such interactions for biodiversity (Ritchie et al. 2012; Ritchie and Johnson 2009); (ii) a clearer understanding and quantification of the costs (to pastoral production and potentially also to biodiversity) and benefits of a range of dingo management options (Prowse et al. 2014); and (iii) the development of alternative dingo control mechanisms that minimise impacts upon trophic interactions and biodiversity. There is increasing evidence that stock guardian animals may be a practical alternative to broad-scale persecution of dingoes, and this method of dingo control is being applied in some pastoral areas (Van Bommel and Johnson 2012).

\section{Fire}

Given the strong evidence that frequent and extensive hot fires have a negative impact on small mammals (Lawes et al. in press)- most likely by increasing predation pressure and decreasing habitat quality - fire management represents an important tool for maintaining mammal populations. Ideally, the frequency of large, hot fires should be minimised. This can be achieved using strategic prescribed burning early in the dry season, under mild fire weather conditions (Corey et al. 2013; Legge et al. 2011a; Russell-Smith et al. 2013).

However, there is also a conservation case to increase the proportion of savanna landscapes that remain unburnt for at least 5 years in the mesic savannas of northern Australia (Andersen et al. 2005; Andersen et al. 2012). Anderson et al. (2005)> have proposed that this can be best achieved by reducing the 'randomness' of burning, where prescribed burning strongly targets recently burnt areas, and avoids long unburnt areas. Indeed, a recent evaluation of fire management on the Arnhem Plateau within Kakadu suggests that this approach is highly effective at increasing the proportion of the landscape that is long unburnt (Murphy et al. in review). Similar results have been obtained in the Kimberley region (S. Legge, unpublished data). It is clear that highly strategic prescribed burning is an effective means of imposing fire regimes that are more favourable to the persistence of small mammals, but care must be taken to avoid indiscriminate application of fire throughout the landscape. Attempts at fire management interventions should take place within an 'adaptive management' framework, with adequate monitoring of the response of small mammals to management actions (Corey et al. 2013; Legge et al. 2011a). 
For such adaptive management to be effective, it is crucial that knowledge gained from ongoing monitoring is incorporated into fire planning, and that land managers are accountable for, and responsive to, biodiversity outcomes. Until recent improvements, an example of an ineffective fire management program is from Kakadu, where monitoring and research results have not been incorporatedsuccessfully into ongoing fire management (Parr and Andersen 2006; Parr et al. 2009). This failure has been in spite of the local collapse of mammal populations (Woinarski et al. 2010), and recognition extending back decades that many mammal species in the area required longer-unburnt habitat which was disappearing under prevailing fire management practices (Friend 1987; Friend and Taylor 1985; Kerle 1985).

\section{Pastoralism and feral stock}

Pastoralism is the most extensive land use across northern Australia. There is increasing evidence that this land use can have significant detrimental impacts upon biodiversity, including native mammals. In general, these impacts are greater as stocking rates increase and the environment is modified for pastoral purposes (including through the introduction and spread of invasive pasture grasses and the control of dingoes) (Legge et al. 2011 a; Woinarski and Ash 2002; Woinarski and Fisher 2003; Woinarski et al. 2013). High densities of feral stock (including cattle, water buffalo, horses and donkeys) are likely to have comparable effects on non-pastoral lands, including within conservation reserves (Bradshaw et al. 2007). Removal of feral animals has been shown to result in increases in some native mammal fauna in the north Kimberley (Corey et al. 2013).

Management responses to these findings may be difficult and expensive, but there are some options, including: (i) the ongoing gradual reduction in the high proportion of northern Australia devoted to beef cattle production, some of which is caused by the acquisition and de-stocking of current pastoral properties for conservation purposes. We note, however, that such purposeful change may be inconsistent with the current regulatory obligations for pastoral leases; (ii) encouragement of, or regulation to enforce, pastoral practices that benefit biodiversity and discouragement of practices that are antithetical to biodiversity (such as use of introduced pasture plants, vegetation clearing, dingo persecution, increase in the spread of artificial water points, and over-stocking) (Woinarski and Fisher 2003); and (iii) the establishment and maintenance of broad-scale and long-term programs to eradicate feral ungulates, particularly from conservation reserves.

\section{Toad invasion}

Cane toads are currently invading the Kimberley region of northwestern Australia and are expected to eventually colonise the Pilbara (Kearney et al. 2008), one of the last strongholds for northern quolls. In hot, semi-arid regions, the Achilles heel for the cane toads is their dependence on water; during the late dry season, cane toads require access to standing water every $72 \mathrm{~h}$ to avoid desiccation (Florance et al. 2011). The installation of farm dams at approximately $10 \mathrm{~km}$ intervals throughout semi-arid grazing regions has allowed cane toads to penetrate into arid regions where they could not persist without the addition of artificial water sources (Letnic et al. 2014). It may be possible to slow the spread of cane toads into semi-arid landscapes by excluding their access to artificial water sources (Florance et al. 2011). Recent modelling suggests that to reach the Pilbara, cane toads will have to travel via a narrow coastal corridor where the only permanent water sources are bore fed dams. The strategic replacement of 100 earthen dams with plastic water tanks in this corridor, at relatively low cost, could prevent cane toads from reaching the Pilbara (Tingley et al. 2013). However, the potential for toads to'hitch-hike' or be otherwise introduced to the Pilbara may make their arrival there inevitable. 
Even if the spread of cane toads cannot be stopped, the extinction of northern quoll populations is preventable. One approach is to bring quolls from toad-free populations into captivity before cane toads invade. Zoos could breed the quolls, and juveniles could be trained not to eat cane toads prior to their release back into the wild (O'Donnell et al. 2010). This approach is promising as following return to the wild, 'toad smart' quolls had higher short-term survival than toad-naïve quolls (O'Donnell et al. 2010). Importantly, some 'toad smart' females survived long-term and reproduced, and some of their offspring survived and reproduced (J. Webb, unpublished data). These results suggest that each generation of quolls learns to avoid toads as food, either via social learning, or from ingesting small, non-lethal sized toads that induce a long-term aversion to toads. A second strategy worth considering is to deploy 'toad aversion baits' to train wild quolls not to eat cane toads before the toads invade. If wild quolls that consumed baits subsequently avoided live toads, then these populations might persist after toads invaded (Webb et al. 2008). A third approach worth investigating is to introduce 'toad smart' quolls, if they exist, to quoll populations ahead of the toad invasion front. For example, Ujvari et al. (2013) suggested that northern quolls have persisted in Queensland because they possess an innate avoidance to cane toads. If quolls possess genes for toad avoidance, then males from toad-infested populations could be translocated to toad-free populations.

Finally, it is worth noting that quolls are affected by other threats and there is evidence that they were declining in several regions prior to the arrival of cane toads (Ziembicki et al. 2013), most likely because of predation and inappropriate fire regimes. Radio-tracking studies in one toad-infested area of Kakadu revealed that camp dogs and dingoes were the major cause of mortality of juvenile quolls (Cremona et al. in review). These findings are not new since prior to the toad invasion, dingoes were identified as an importantcause of mortality for quolls in savanna woodlands, and quolls were most susceptible to predation in burnt areas (Oakwood 2000).

\section{DISCUSSION AND OUTLOOK}

Greater recent resolution and recognition of the plight of the mammal fauna of northern Australia has stimulated a series of research and management initiatives aimed at improving our knowledge of population trends across the region, and to ascertain the causal factors behind population changes and potential solutions to stem the declines. In this paper we bring together these disparate efforts to summarise the current state of knowledge, refine the conceptual framework for declines presented by Woinarski et al (2011), assess the efficacy of several recent conservation management interventions, and identify key priorities for further research and management.

Apart from a handful of seminal studies, understanding population trends of mammals in northern Australia and their causation has been constrained by a lack of detailed research and long term monitoring programs. Recent efforts to improve our understanding have drawn on a range of different approaches, including improving taxonomic resolution for poorly known taxa (Potter et al. 2014a; Potter et al. 2012b; Reardon et al. 2014; Westerman et al. 2012), assessment of historical and subfossil evidence (Cramb and Hocknull 2010; Start et al. 2012), documentation of Indigenous knowledge (Ziembicki et al. 2013), modelling and other analytical studies to identify characteristics of declining species (Fisher et al. 2014; Murphy and Davies 2014; Woinarski 2015), experimental manipulation to determine relative impacts of specific factors (Frank et al. 2014; Griffiths 2013; Legge et al. 2011a; Webb et al. 2011), application of new technologies to facilitate surveys and research (Hohnen et al. 2013; McGregor et al. 2014), and improved integration of regional distributional databases (Fisher et al. 2014; Woinarski et al. 2014). These 
studies demonstrate that the extent and timing of decline and impacts of threats has been variable across the region. However, a general gradational pattern of earlier and more severe decline from inland lower rainfall areas to the higher rainfall of the coastal north is evident, particularly in the Kimberley and Top End regions (Finlayson 1961; Radford et al. 2014; Start et al. 2007; Ziembicki et al. 2013). A small area of the high rainfall, rugged coastal Kimberley region remains the last mainland stronghold for several species that have disappeared elsewhere (Corey et al. 2013; McKenzie et al. 2007; Radford et al. 2014; Start et al. 2007). Islands also remain critical refuges retaining much of their original mammal faunas (Firth and Panton 2006; Gibson and McKenzie 2012; Woinarski et al. 1999). However, these populations are highly susceptible to the introduction of novel threats and several islands have rapidly lost their refugial value following the arrival of cats and/or cane toads (Woinarski et al. 2011b).

In some regions, such as parts of northeastern Australia, there has been less or no discernible change in the mammal fauna. Here, a relatively longer and more substantial history of environmental modification may have led to mammal declines that were never clearly documented (although some changes are evident from the subfossil record). Other areas, such as some parts of the Einasleigh Uplands, may have retained a relatively intact mammal fauna possibly due to minor landscape change, or unusual environmental characteristics that have facilitated the persistence of mammal populations (Vanderduys et al. 2012).

Causes of decline are likely to be a combination of interacting threats acting differently in different regions for different species. Recent research implicates predation by cats as a major cause of severe depletion of several native northern mammals (Frank et al. 2014; McGregor 2014; Woinarski et al. 2011 b). The severity and impact of cat predation is likely to be exacerbated through interactions with other environmental changes, most notably prevailing fire regimes (McGregor et al. 2014), the reduction in shelter offered by ground vegetation due to pastoralism (McGregor et al. 2014), and in some areas, the degree and nature of interaction between dingoes and cats (Brook et al. 2012; Kennedy et al. 2011). Such synergistic impacts may explain the perceived lag between the onset of specific threats and the recent rapid decline of native mammals. For example, although feral cats have been present in the region for over a century with limited discernible effects on mammals, the impacts of cat predation may have been magnified only recently by changes in other management factors. However, this general conclusion does not yet explain all observed declines, with the most notable remaining enigma being the recent broad-scale decline of many mammal species across much of Arnhem Land, despite retention there of dingo populations, maintenance in many parts of traditional Aboriginal fire regimes, and lack of pastoralism.

The demonstration of interactive factors affecting mammals gives conservation managers some options for reducing their impacts. Cat predation may be mitigated to some degree through manipulation of fire (aimed at increasing the extent of longer unburnt habitat and area of finescale patch burning), reducing the impacts of livestock and feral herbivores, and maintaining dingo populations. Some localised instances of conservation management (involving fire and reduction in livestock) in parts of the central and north Kimberley have produced relatively rapid and substantial increases in some native mammal species (Legge et al. 2011a). However, such techniques may not be effective in areas that now have severely depleted mammal assemblages, because even small numbers of feral cats may impose unsustainable predation pressure on native mammal species with very low population size. In such areas, and elsewhere, extensive predatorexclusion fencing may be required to maintain or reintroduce some threatened mammal species. A complement to such an approach may be to increase translocations of threatened species to cat-free islands, eradicate cats from islands on which they currently occur and increase biosecurity measures to reduce the risks of introduction to cat-free islands. 
The westward spread of the cane toad across northern Australia has added an idiosyncratic factor to these broad spatial patterns of decline, with documented direct impact on at least one species, the northern quoll (Woinarski et al. 2010). Indirect impacts on other mammal species through perturbation of the predator assemblage remain unresolved. Likewise, there is too little information to assess the contribution, if any, of disease in the current pattern of mammal decline in northern Australia, and research to address this information gap is a priority.

The Australian national, state and territory governments are currently actively promoting significant large-scale development in northern Australia. These developments are likely to introduce or intensify threats to which northern Australia has so far only had limited exposure but that are responsible for most biodiversity loss in other parts of the world (notably habitat loss, overexploitation and high human population density). Improved knowledge, adequate planning and effective management strategies, underpinned by integrated long-term adaptive monitoring (Lindenmayer et al. 2013), are required to better understand and limit existing threats and the introduction or intensification of new ones. Without such concerted action a significant component of the north Australian mammal fauna is destined to contribute further to Australia's already woeful record for contemporary mammal extinctions.

\section{Acknowledgements}

This paper reports on numerous studies conducted by many researchers at many institutions, and supported by many different funding sources. Specifically, these include a fellowship from the Australian Research Council to Brett Murphy (DE130100434), an ARC Linkage grant (LP100100033), funding through the Western Australia Department of Parks and Wildlife (and predecessors) through the Kimberley Science and Conservation Strategy and the Biodiversity Conservation Initiative, funding under the National Environmental Research Program, and Cape York NRM Ltd, Northern Gulf NRM Ltd, Biodiversity Fund, Caring for Our Country. Arthur White, Damian Milne, Brydie Hill, Luke Einoder, Jaime Heiniger, Rebecca Diete and Amy Shima are thanked for the provision of some information. We thank two anonymous referees whose feedback improved the manuscript.

\section{Resumen}

Introducción: En estudios recientes en sitios al norte de Australia se ha informado una rápida y severa disminución de algunas especies de mamíferos nativos, a pesar de un contexto ambiental favorable (de baja población humana, pérdida de hábitat limitado, de un grado sustancial reservas) que debe proporcionar una seguridad relativa de conservación. Todos los grupos taxonómicos con mayor riqueza de especies de mamíferos en el norte de Australia tienen algunas especies cuyo estado de conservación se ha evaluado como amenazadas, con un $53 \%$ de dasyuridae, el $47 \%$ de macropodae y potoroidae, el 33\% de bandicoot y bilby, el $33 \%$ zarigüeyas, el $30 \%$ de los roedores, y el $24 \%$ de las especies de murciélagos están evaluados como extintas, amenazadas o casi amenazadas. Sin embargo, el alcance geográfico y cronológico de las disminuciones, y sus causas, siguen estando mal resueltos, lo que limita la aplicación de medidas de gestión de recuperación.

Material y métodos: Centrándose en las sabanas tropicales del norte de Australia, en este trabajo se revisan los estudios recientes y se proporciona información sobre las tendencias de población a través de un ámbito geográfico más amplio y se proporciona información sobre el estado de conservación y las tendencias de mamífero grupos (murciélagos, macropodos) no así la muestra en los estudios de seguimiento anteriores. Se describen algunos enfoques diversos de los estudios que documentan sobre el estado de conservación, las tendencias, y de los factores que pueden estar contribuyendo a los patrones observados de declive.

Resultados y discusión: Las tendencias actuales y los posibles factores causales de caídas. Los estudios publicados demuestran que la magnitud y oportunidad de los impactos y amenazas han sido variables en toda la región, a pesar de que existe un patrón gradual general de descenso que antes, y más grave de zonas de precipitaciones inferiores a las regiones costeras de mayor precipitación. Algunas pequeñas zonas aisladas parecen haber conservado sus 
especies de mamíferos, al igual que muchas islas en las que permanecen refugios críticos. En la actualidad existe cierta evidencia convincente de que la depredación por gatos salvajes está implicada en la disminución observada, con estos impactos podrían verse agravados por los regímenes de fuego (fuego frecuente, extensa e intensa), que prevalece por la reducción de la cobertura vegetal del suelo debido a la ganadería y, en algunas áreas, por "control" de los dingos. Sin embargo, los impactos de los dingos pueden ser complejos, y sin embargo, no están bien resueltas en esta área. Los impactos relativos de estos factores individuales varían espacialmente (con la mayoría de los impactos severos en áreas de mayor precipitación y áreas escarpadas) y entre las diferentes especies de mamíferos, no obstante con algunas especies de responder idiosincrásicamente: el ejemplo más notable es la rápida disminución del quoll del norte (Dasyurus hallucatus) debido a la intoxicación por el sapo de caña introducido (Rhinella marina), que continúa propagándose ampliamente en todo el norte de Australia. El impacto de la enfermedad, en su caso, sigue sin resolverse.

Respuestas de la Administración de Conservación. La recuperación de la fauna de mamíferos nativos puede ser imposible en algunas áreas. Sin embargo, ahora hay ejemplos de una rápida recuperación siguiente a la gestión de amenazas. Acciones prioritarias de conservación incluyen: una mayor bioseguridad para las islas importantes, establecimiento de una red de exclusiones de depredadores salvajes, manejo de incendios intensivos (dirigido a aumentar la extensión del hábitat más extenso sin quemar y en el suministro de una escala fina del parche de quema), reducción de acciones salvajes en las reservas de conservación y adquisición con de algunas tierras de pastoreo en áreas que son importantes para la conservación de los mamíferos.

Palabras clave: sapos de caña, conservación, enfermedad, gatos salvajes, fuego, pastoreo, sabana, amenazas

\section{References}

Аввотт, I. 2002. Origin and spread of the cat, Felis catus, on mainland Australia, with a discussion on the magnitude of its early impact on native fauna. Wildlife Research 29:51-74.

Аввотт, I. 2006. Mammalian faunal collapse in Western Australia, 1875-1925: the hypothesised role of epizootic disease and a conceptual model of its origin, introduction, transmission and spread. Australian Zoologist 33:530-561.

Аввотt, I., And A. A. Burbidge. 1995. The occurrence of mammal species on the islands of Australia: a summary of existing knowledge. CALMScience 1:259-324.

Allen, B. L., AND L. K. P. Leung. 2012. Assessing predation risk to threatened fauna from their prevalence in predator scats: dingoes and rodents in arid Australia. PLoS ONE 7:e36426.

Altman, J. C. 1987. Hunter-gatherers today: an Aboriginal economy in northern Australia. Australian Institute of Aboriginal Studies. Canberra.

Anadon, J. D., A. Gimenez, R. Ballestar, and I. Perez. 2009. Evaluation of local ecological knowledge as a method for collecting extensive data on animal abundance. Conservation Biology 32:617-625.

Andersen, A. N., G. D. Cook, L. K. Corbett, M. M. Douglas, R. W. Eager, J. Russell-smith, S. A. Setterfield, R. J. Williams, AND J. C. Z. Woinarski. 2005. Fire frequency and biodiversity conservation in Australian tropical savannas: implications from the Kapalga fire experiment. Austral Ecology 30:155-167.

Andersen, A. N., J. C. Z. Woinarski, And C. L. Parr. 2012. Savanna burning for biodiversity: fire management for faunal conservation in Australian tropical savannas. Austral Ecology 37:658-667.

Appelbee, A. J., R. C. A. Thompson, And M. E. Olson. 2005. Giardia and Cryptosporidium in mammalian wildlife - current status and future needs. Trends in Parasitology 21:370-376.

Ardalan, A., M. Oskarsson, C. Natanaelsson, A. Wilton, A. Ahmadian, and P. Savolainen. 2012. Narrow genetic basis for the Australian dingo confirmed through analysis of paternal ancestry. Genetica 140:65-73.

Ash, A. J., J. G. Mcivor, J. J. Mott, And M. H. Andrew. 1997. Building grass castles: integrating ecology and management of Australia's tropical tallgrass rangelands. The Rangeland Journal 19:123-144.

Banks, S. C., A. Horsup, A. N. Wilton, and A. C. Taylor. 2003a. Genetic marker investigation of the source and impact of predation on a highly endangered species. Molecular Ecology 12:1663-1667.

Banks, S. C., S. D. Hoyle, A. Horsup, P. Sunnucks, and A. C. Taylor. 2003b. Demographic monitoring of an entire species by genetic analysis of non-invasively collected material. Animal Conservation 6:101-107. 
Beckmann, C., and R. Shine. 2011. Toad's tongue for breakfast: exploitation of a novel prey type, the invasive cane toad, by scavenging raptors in tropical Australia. Biological Invasions 13:1447-1455.

BegG, R. J., K. C. Martin, and N. F. Price. 1981. The small mammals of Little Nourlangie Rock, N.T. V. The effects of fire. Wildlife Research 8:515-527.

Bell, P. J., and P. I. Whelan. 1993. A scrub typhus vector Leptotrombidium deliense (Walch) (Acari: Trombiculidae) on rats in Litchfield Park, Northern Territory, Australia. Australian Journal of Entomology 32:207-208.

Bettiol, S., J. Kettlewell, N. Davies, and J. Goldsmid. 1997. Giardiasis in native marsupials of Tasmania. Journal of Wildlife Diseases 33:352-354.

Bliege bird, R., D. W. Bird, B. F. Codding, C. H. Parker, and J. H. Jones. 2008. The 'fire stick farming' hypothesis: Australian Aboriginal foraging strategies, biodiversity, and anthropogenic fire mosaics. Proceedings of the National Academy of Sciences of the United States of America 105: 1479614801.

Bonaccorso, F. J. 1998. Bats of Papua New Guinea. Conservation International. Washington D. C.

Bottrill, M. C., J. C. Walsh, J. E. M. Watson, L. N. Joseph, A. Ortega-argueta, and H. P. Possingham. 2011. Does recovery planning improve the status of threatened species? Biological Conservation 144:1595-1601.

Bowman, D., and W. J. Panton. 1993. Decline of Callitris intratropica Baker, R.T. and Smith, H.G. in the Northern Territory: implications for pre-European and post-European colonization fire regimes. Journal of Biogeography 20:373-381.

Bowman, D. M. J. S., G. K. Brown, M. F. Braby, J. R. Brown, L. G. Cook, M. D. Crisp, F. Ford, S. Haberle, J. Hughes, Y. Isagi, L. Joseph, J. Mcbride, G. Nelson, and P. Y. Ladiges. 2010. Biogeography of the Australian monsoon tropics. Journal of Biogeography 37:201-216.

Bowman, D. M. J. S., A. Walsh, ANd L. D. Prior. 2004. Landscape analysis of Aboriginal fire management in Central Arnhem Land, north Australia. Journal of Biogeography 31:207-223.

Bradley, A. J., C. M. Kemper, D. J. Kitchener, W. F. Humphreys, and R. A. How. 1987. Small mammals of the Mitchell Plateau region, Kimberley, Western Australia. Australian Wildlife Research 14:397-413.

Bradshaw, C. J. A. 2012. Little left to lose: deforestation and forest degradation in Australia since European colonization. Journal of Plant Ecology 5:109-120.

Bradshaw, C. J. A., I. C. Field, D. M. J. S. Bowman, C. Haynes, and B. W. Brook. 2007. Current and future threats from non-indigenous animal species in northern Australia: a spotlight on World Heritage Area Kakadu National Park. Wildlife Research 34:419-436.

Breed, A. C., H. E. Field, C. S. Smith, J. Edmonston ,And J. Meers. 2010. Bats without borders: long-distance movements and implications for disease risk management. EcoHealth 7:204-212.

BRook, L. A. 2013. Predator guild interactions in northern Australia: behaviour and ecology of an apex predator, the dingo Canis lupus dingo, and an introduced mesopredator, the feral cat Felis catus (PhD thesis). James Cook University. Townsville.

Brook, L. A., C. J. Johnson, And E. G. Ritchie. 2012. Effects of predator control on behaviour of an apex predator and indirect consequences for mesopredator suppression. Journal of Applied Ecology 49:1278-1286.

Brook, L. A. And A. S. Kutt. 2011. The diet of the dingo (Canis lupus dingo) in north-eastern Australia with comments on its conservation implications. The Rangeland Journal 33: 79-85.

Brown, G. P., B. L. Phillips, And R. Shine. 2011. The ecological impact of invasive cane toads on tropical snakes: field data do not support laboratory-based predictions. Ecology 92:422-431.

Buettner, P. G., D. A. Westcott, J. Maclean, L. Brown, A. Mckeown, A. Johnson, K. Wilson, D. Blair, J. Luly, AND L. Skerratt. 2013. Tick paralysis in spectacled flying-foxes (pteropus conspicillatus) in north queensland, australia: impact of a ground-dwelling ectoparasite finding an arboreal host. Plos one 8:e73078. 
Burbidge, A. A. 1999. Conservation values and management of australian islands for non-volant mammal conservation. Australian mammalogy 21 67-74.

Burbidge, A. A., K. A. Johnson, And R. I. Southgate. 1988. Aboriginal knowledge of the mammals of the central deserts of australia. Australian wildlife research 15:9-39.

Burbidge, A. A., AND B. F. J. Manty. 2002. Mammal extinctions on australian islands: causes and conservation implications. Journal of biogeography 29:465-473.

Burbidge, A. A., And N. L. Mckenzie. 1989. Patterns in the modern decline of western australia's vertebrate fauna: causes and conservation implications. Biological conservation 50:143-198.

Burbidge, A. A., N. L. Mckenzie, K. E. C. Brennan, J. C. Z. Woinarski, C. R. Dickman, A. Baynes, G. Gordon, P. W. Menkhorst, And A. C. Robinson. 2008. Conservation status and biogeography of australia's terrestrial mammals. Australian journal of zoology 56:411-422.

Burrows, N. D., A. A. Burbidge, P. J. Fuller, AND G. Behn. 2006. Evidence of altered fire regimes in the Western Desert regime of Australia. Conservation Science Western Australia 5:272-284.

Butchart, S. H. M., M. Walpole, B. Collen, A. Van strien, J. P. W. Scharlemann, R. E. A. Almond, J. E. M. Baillie, B. Bomhard, C. Brown, J. Bruno, K. E. Carpenter, G. M. Carr, J. Chanson, A. M. Chenery, J. Csirke, N. C. Davidson, F. Dentener, M. Foster, A. Galli, J. N. Galloway, P. Genovesi, R. D. Gregory, M. Hockings, V. Kapos, J. F. Lamarque, F. Leverington, J. Loh, M. A. Mcgeoch, L. Mcrae, A. Minasyan, M. H. Morcillo, T. E. E. Oldfield, D. Pauly, D. Quader, C. Revenga, J. R. Sauer, B. Skolnik, D. Spear, D. Stanwell-Smith, S. N. Stuart, A. Symes, M. Tierney, T. D. Tyrrell, J.-C. VIÉ, ANd R. Watson. 2010. Global Biodiversity: Indicators of Recent Declines. Science 328:1164-1168.

Cabrera-guzmán, E., M. R. Crossland, D. Pearson, J. K. Webb, and R. Shine. in press. Predation on invasive cane toads (Rhinella marina) by native Australian rodents. Journal of Pest Science

Calvignac-spencer, S., K. Merkel, N. Kutzener, H. Kühl, C. Boesch, P. M. Kappeler, S. Metzger, G. Schubert, and F. H. LeEnderTz. 2013. Carrion fly-derived dna as a tool for comprehensive and cost-effective assessment of mammalian biodiversity. Molecular ecology 22:915-924.

Cardillo, M., and L. Bromham. 2001. Body size and risk of extinction in australian mammals. Conservation biology 15:1435-1440.

Cardillo, M., G. M. Mace, J. L. Gittleman, and A. Purvis. 2006. Latent extinction risk and the future battlegrounds of mammal conservation. PNAS 103:4157-4161.

Cardillo, M., A. Purvis, W. Sechrest, J. L. Gittleman,J. Bielby, and G. M. Mace. 2004. Human population density and extinction risk in the world's carnivores. PLoS Biology 2:e197.

Carwardine, J., T. O'connor, S. Legge, B. Mackey, H. Possingham, and T. G. Martin. 2011. Priority threat management to protect Kimberley wildlife. CSIRO Ecosystems Sciences. Brisbane.

Carwardine, J., T. O'connor, S. Legge, B. Mackey, H. P. Possingham, and T. G. Martin. 2012. Prioritizing threat management for biodiversity conservation. Conservation Letters 5:196-204.

Chisholm, R., And R. Taylor. 2007. Null-hypothesis significance testing and the critical weight range for Australian mammals. Conservation Biology 21:1641-1645.

ChurchiLl, S. 2008. Australian Bats. Reed New Holland. Sydney.

Cincotta, R. P., J. Wisnewski, And R. Engelman. 2000. Human population in the biodiversity hotspots. Nature 404:990-992.

Соoк, I., W. Scott, ANd R. W. CAmpbell. 1967. Scrub typhus and other infections in North Queensland animals. Transactions of the Royal Society of Tropical Medicine and Hygiene 61:343-350.

Corbett, L. C., A. N. Andersen, And W. J. Müller. 2003. Terrestrial vertebrates. Pp. 126-152 in Fire in Tropical Savannas: the Kapalga Fire Experiment. (Andersen, A. N., G. D. Cook, and R. J. Williams, eds.). SpringerVerlag. New York.

Corbett, L. K. 1989. Assessing the diet of dingoes from feces: a comparison of 3 methods. Journal of Wildlife Management 53:343-346. 
Corey, B., I. Radford, K. Carnes, E. Hatherley, and S. Legge. 2013. North-Kimberley Landscape Conservation Initiative: 2010-2012 Performance Report. Department of Parks and Wildlife. Kununurra, Western Australia.

Cox-witton, K., A. Reiss, R. Woods, V. Grillo, R. T. Baker, D. J. Blyde, W. Boardman, S. Cutter, C. Lacasse, H. Mccracken, M. Pyne, I. Smith, S. Vitali, L. Vogelnest, D. Wedd, M. Phillips, C. Bunn, and L. Post. 2014. Emerging infectious diseases in free-ranging wildlife - Australian zoo based wildlife hospitals contribute to national surveillance. PLoS ONE 9:e95127.

CRAmb, J., ANd S. Hocknull. 2010. New Quaternary records of Conilurus (Rodentia: Muridae) from eastern and northern Australia with the description of a new species. Zootaxa 2634:41-56.

Cremona, T., M. S. Crowther, And J. K. Webb. in review. Predation by a subsidised apex predator prevents the recovery of an endangered mesopredator. Animal Conservation

Crisp, M. D., S. Laffan, H. P. Linder, And A. Monro. 2001. Endemism in the Australian flora. Journal of Biogeography 28:183-98.

CRooks, K. R., AND M. E. SoulÉ. 1999. Mesopredator release and avifaunal extinctions in a fragmented system. Nature 400:563-566.

Crowley, G., And S. Garnetr. 1998. Vegetation change in the grasslands and grassy woodlands of eastcentral Cape York Peninsula, Australia. Pacific Conservation Biology 4:132-148.

DAHL, K. 1897. Biological notes on on north-Australian mammals. The Zoologist 4:189-216.

DAнL, K. 1926. In savage Australia. An account of a hunting and collecting expedition to Arnhem Land and Dampier Land. Philip Allan and Co. London.

Dennis, A. J. 2002. Recovery plan for the northern bettong, Bettongia tropica 2000-2004. Report to Environment Australia. Queensland Parks and Wildlife Service. Brisbane.

Denny, E. A., And C. R. Dickman. 2010. Review of cat ecology and management strategies in Australia. Invasive Animals Cooperative Research Centre. Canberra.

Department of enVironment Water heritage and the arts. 2008. Threat abatement plan for predation by feral cats. Department of Environment Water Heritage and the Arts. Canberra.

Department Of PRIME MINISTER AND CABINEt. 2014. Green paper on developing northern Australia. Department of Prime Minister and Cabinet. Canberra.

Department of SUstainability environment WATER POPULATION AND Communities. 2011. Threat abatement plan for the biological effects, including lethal toxic ingestion, caused by cane toads. Department of Sustainability, Environment, Water, Population and Communities. Canberra.

Department of the environment AND Resource management. 2010. National recovery plan for the water mouse (false water rat) Xeromys myoides. Department of the Environment and Resource Management. Brisbane.

Dickman, C. R. 1992. Conservation of mammals in the Australasian region: the importance of islands. Pp. 175-214 in Australia and the global environmental crisis. (Coles, J. N., and J. M. Drew, eds.). Academy Press. Canberra.

Dickman, C. R., L. K.-P. LeUnG, AND S. M. VAn Dyck. 2000. Status, ecological attributes and conservation of native rodents in Queensland. Wildlife Research 27:333-346.

Doherty, R. L., H. A. Standfast, E. J. Wetters, R. H. Whitehead, G. J. Barrow, and B. M. Gorman. 1968. Virus isolation and serological studies of arthropod borne virus infections in a high rainfall area of north Queensland. Transactions of the Royal Society of Tropical Medicine and Hygiene 62:862-867.

Doody, J. S., C. M. Castellano, D. Rhind, and B. Green. 2013. Indirect facilitation of a native mesopredator by an invasive species: are cane toads re-shaping tropical riparian communities? Biological Invasions 15:559-568.

Doody, J. S., B. Green, D. Rhind, C. M. Castellano, R. Sims, and T. Robinson. 2009. Population-level declines in Australian predators caused by an invasive species. Animal Conservation 12:46-53. 
Eldridge, M. D. B., S. Potter, And S. J. B. Cooper. 2011. Biogeographic barriers in north-western Australia: an overview and standardisation of nomenclature. Australian Journal of Zoology 59:270-272.

Ens, E. J., M. Finlayson, K. Preuse, S. Jackson, and S. Halcombe. 2012. Australian approaches for managing 'country' using Indigenous and non-Indigenous knowledge. Ecological Management and Restoration 13:100-107.

Fensham, R. J. 2008. Leichhardt's maps: 100 years of change in vegetation structure in inland Queensland. Journal of Biogeography 35: 141-156.

Ferguson, M. A. D., And F. Messier. 1997. Collection and analysis of traditional ecological knowledge about a population of Arctic tundra caribou. Arctic 50:17-28.

Finlayson, H. H. 1961. A re-examination of Mesembriomys hirsutus Gould 1842 (Muridae). Transactions of the Royal Society of South Australia 84:149-165.

Firth, R. S. C., B. W. Brook, J. C. Z. Woinarski, and D. A. Fordham. 2010. Decline and likely extinction of a northern Australian native rodent, the Brush-tailed Rabbit-rat Conilurus penicillatus. Biological Conservation 143:1193-1201.

Firth, R. S. C. and W. Panton. 2006. The mammals of Croker Island, Northern Territory, Australia. Australian Mammology 28:121-123.

Firth, R. S. C., J. C. Z. Woinarski, K. G. Brennan, and C. Hempel. 2006. Environmental relationships of the brush-tailed rabbit-rat, Conilurus penicillatus, and other small mammals on the Tiwi Islands, northern Australia. Journal of Biogeography 33:1820-1837.

Fisher, D. O., C. N. Johnson, M. J. Lawes, S. A. Fritz, H. Mccallum, S. P. Blomberg, J. Vanderwal, B. Abbott, A. Frank, S. Legge, M. Letnic, C. R. Thomas, A. Fisher, I. J. Gordon, and A. Kutt. 2014. The current decline of tropical marsupials in Australia: is history repeating? Global Ecology and Biogeography 23:181-190.

FitzGerald, M. 1990. Rattus rattus: the introduced black rat, a successful predator on the introduced cane toad Bufo marinus in northern New South Wales. Herpetofauna 20:9-14.

Fitzsimons, J., J. Russell-Smith, G. James, T. Vigilante, G. Lipsett-Moore, J. Morrison, And M. Looker. 2012. Insights into the biodiversity and social benchmarking components of the Northern Australian fire management and carbon abatement programmes. Ecological Management and Restoration 13:51-57.

Fleming, P., L. Corbett, R. Harden, and P. Thomson. 2001. Managing the Impacts of Dingoes and Other Wild Dogs. Bureau of Rural Science. Canberra.

Florance, D., J. K. Webb, T. Dempster, M. R. Kearney, A. Worthing, and M. Letnic. 2011. Excluding access to invasion hubs can contain the spread of an invasive vertebrate. Proceedings of the Royal Society $B$ 278:2900-2908.

Foley, D. 1985. Faunal analysis of Anbangbang 1 and Djuwarr 1. Pp. 97-102 in Archaeological research in Kakadu National Park. (Jones, R., eds.). Australian National Parks and Wildlife Service. Canberra.

Ford, C. AND C. Hogg (EDs.). 2012. Australasian species management program: regional census and plan, 22nd Edition. Zoo and Aquarium Association. Sydney.

FoRD, F. AND C. Johnson. 2007. Eroding abodes and vanished bridges: historical biogegraphy of the substrate specialist pebble-mound mice (Pseudomys). Journal of Biogeography 34:514-523.

Forsyth, D., A. P. Woolnough, D. Nimmo, E. G. Ritchie, M. Kennedy, A. Pople, and I. Watson. 2014. A comment on the influence of dingoes on the Australian sheep flock. Australian Veterinary Journal 92:461-462.

Fox, I. D., V. J. Neldner, G. W. Wilson, P. J. Bannink, B. A. Wilson, P. S. Brocklehurst, M. J. Clark, K. J. M. Dickinson, J. S. Beard, A. J. M. Hopkins, G. R. Beeston, J. M. Harvey, E. J. Thompson, T. S. Ryan, S. L. Thompson, D. W. Butler, H. Cartan, E. P. Addicott, L. P. Bailey, R. J. Cumming, D. C. Johnson, M. Schmeider, K. M. Stephens, And A. R. Bean. 2001. The Vegetation of the Australian Tropical Savannas. Queensland Herbarium. Mareeba.

Fox, S. 2011. The Spectacled flying fox - a review of past and present knowledge. Pp. 136-145 in The biology and conservation of Australasian bats. (Law, B., P. Eby, D. Lunney, and L. Lumsden, eds.) Royal Zoological Society of New South Wales. Sydney. 
Frank, A., C. Johnson, J. Potts, A. Fisher, M. Lawes, J. Woinarski, K. Tuft, I. Radford, I. Gordon, M.-A. Collis, AND S. LeGge. 2014. Experimental evidence that feral cats cause local extirpation of small mammals in Australia's tropical savanna. Journal of Applied Ecology 51:1486-1493.

Franklin, D. C., and N. D. Preece. 2014. The Eucalypts of Northern Australia: An Assessment of the Conservation Status of Taxa and Communities. A report to Kimberley to Cape and the Environment Centre NT.

Franklin, D. C., P. J. Whitehead, G. Pardon, J. Matthews, P. Mcmahon, and D. Mcintyre. 2005. Geographic patterns and correlates of the decline of granivorous birds in northern Australia. Wildlife Research 32:399-408.

Friend, G. R. 1987. Population ecology of Mesembriomys gouldii (Rodentia: Muridae) in the wet-dry tropics of the Northern Territory. Australian Wildlife Research 14:293-303.

Friend, G. R., AND J. A. Taylor. 1985. Habitat preferences of small mammals in tropical open-forest of the Northern Territory. Australian Journal of Ecology 10:173-185.

Garnett, S. T., J. C. Z. Woinarski, G. M. Crowley, and A. S. Kutt. 2010. Biodiversity conservation in Australian tropical rangelands. Pp. 191-234 in Wild Rangelands: conserving wildlife while maintaining livestock in semi-arid ecosystems (Du Toit, J., R. Kock, and J. Deutsch, eds.). WileyBlackwell. Chichester.

Gibson, L. A., AND N. L. Mckenzie. 2012. Occurrence of non-volant mammals on islands along the Kimberley coast of Western Australia. Records of the Western Australian Museum Supplement 81:15-39.

Gooding, C. D., AND L. A. Harrison. 1954. The wallaby menace in the Kimberleys. Report on initial survey and control experiments 1952. Journal of Agriculture 3:333-340.

Government of Western Australia. 2011. Kimberley Science and Conservation Strategy. Government of Western Australia. Perth.

Grech, A., J. Parra, I. Beasley, J. Bradley, S. Johnson, S. Whiting, and H. Marsh. 2014. Local assessments of marine mammals in cross-cultural environments. Biodiversity and Conservation 23:3319-3338.

Green, P. T. 2014. Mammal extinction by introduced infectious disease on Christmas Island (Indian Ocean): The historical context. Australian Zoologist 37:1-14.

Grice, A. C., E. P. Vanderduys, J. J. Perry And G. D. Cook. 2013. Patterns and processes of invasive grass impacts on wildlife in Australia. Wildlife Society Bulletin 37:478-485.

Griffiths, A. D. 2013. Beds are burning: small mammal responses to fire in tropical savannas of northern Australia (PhD thesis). Charles Darwin University. Darwin.

Griffiths, A. D., AND B.W. BRook. 2014. Effect of fire on small mammals: a systematic review. International Journal of Wildland Fire 23:1034-1043

Helgen, K. M., R. P. Miguez, J. L. Kohen, and L. E. Helgen. 2012. Twentieth century occurrence of the LongBeaked Echidna Zaglossus bruijnii in the Kimberley region of Australia. ZooKeys 255:103-132.

Hill, B. M., AND S. J. WARD. 2010. National Recovery Plan for the northern quoll Dasyurus hallucatus. Northern Territory Department of Natural Resources, Environment, the Arts and Sport. Darwin.

Hitchcock, P., M. Kennard, B. Leaver, B. Mackey, P. Stanton, P. Valentine, E. Vanderduys, B. Wannan, W. Willmott, and J. Woinarski. 2013. The natural attributes for World Heritage nomination of Cape York Peninsula, Australia. Department of Sustainability, Environment, Water, Population and Communities. Canberra.

Hoffmann, M., C. Hilton-Taylor, A. Angulo, M. Böhm, T. M. Brooks, S. H. M. Butchart, K. E. Carpenter, J. Chanson, B. Collen, N. A. Cox, W. R. T. Darwall, N. K. Dulvy, L. R. Harrison, V. Katariya, C. M. Pollock, S. Quader, N. I. Richman, A. S. L. Rodrigues, M. F. Tognelli, J.-C. Vié, J. M. Aguiar, D. J. Allen, G. R. Allen, G. Amori, N. Ananjeva, F. Andreone, P. Andrew, A. L. Aquino Ortiz, J. E. M. Baillie, R. Baldi, B. D. Bell, S. D. Biju, J. P. Bird, P. Black-Decima, J. J. Blanc, F. Bolaños, W. Bolivar-G., I. J. Burfield, J. A. Burton, D. R. Capper, F. Castro, G. Catullo, R. D. Cavanagh, A. Channing, N. L. Chao, A. M. Chenery, F. Chiozza, V. Clausnitzer, N. J. Collar, L. C. Collett, B. B. Collette, C. F. Cortez Fernandez, M. T. Craig, 
M. J. Crosby, N. Cumberlidge, A. Cuttelod, A. E. Derocher, A. C. Diesmos, J. S. Donaldson, J. W. Duckworth, G. Dutson, S. K. Dutta, R. H. Emslie, A. Farjon, S. Fowler, J. Freyhof, D. L. Garshelis, J. Gerlach, D. J. Gower, T. D. Grant, G. A. Hammerson, R. B. Harris, L. R. Heaney, S. B. Hedges, J.-M. Hero, B. Hughes, S. A. Hussain, I. J.M., R. F. Inger, N. Ishil, D. T. Iskandar, R. K. B. Jenkins, Y. Kaneko, M. Kottelat, K. M. Kovacs, S. L. Kuzmin, E. La Marca, J. F. Lamoreux, M. W. N. Lau, E. O. Lavilla, K. Leus, R. L. Lewison, G. Lichtenstein, S. R. Livingstone, V. Lukoschek, D. P. Mallon, P. J. K. Mcgowan, A. Mcivor, P. D. Moehlman, S. Molur, A. Muñoz Alonso, J. A. Musick, K. Nowell, R. A. Nussbaum, W. Olech, N. L. Orlov, T. J. Papenfuss, G. Parra-Olea, W. F. Perrin, B. A. Polidoro, M. Pourkazemi, P. A. Racey, J. S. Ragle, M. Ram, G. Rathbun, R. P. Reynolds, A. G. J. Rhodin, S. J. Richards, L. O. Rodríguez, S. R. Ron, C. Rondinini, A. B. Rylands, Y. Sadovy De Mitcheson, J. C. Sanciangco, K. L. Sanders, G. Santos-Barrera, J. Schipper, C. Self-Sullivan, Y. Shi, A. Shoemaker, F. T. Short, C. Sillero-Zubiri, D. L. Silvano, K. G. Smith, A. T. Smith, J. Snoeks, A. J. Stattersfield, A. J. Symes, A. B. Taber, B. K. Talukdar, H. J. Temple, R. Timmins, J. A. Tobias, K. Tsytsulina, D. Tweddle, C. Ubeda, S. V. Valenti, P. P. Van Dijk, L. M. Veiga, A. Veloso, D. C. Wege, M. Wilkinson, E. A. Williamson, F. Xie, B. E. Young, H. R. Akçakaya, L. Bennun, T. M. Blackburn, L. Boitanı, H. T. Dublin, G. A. B. Da Fonseca, C. Gascon, T. E. Lacher Jr., G. M. Mace, S. A. Mainka, J. A. Mcneely, R. A. Mittermeier, G. Mcgregor Reid, J. P. Rodriguez, A. A. Rosenberg, M. J. Samways, J. Smart, B. A. Stein, and S. N. Stuart. 2010. The impact of conservation on the status of the world's vertebrates. Science 330:1503-1509.

Hohnen, R., J. Ashby, K. Tuft, And H. Mcgregor. 2013. Individual identification of northern quolls (Dasyurus hallucatus) using remote cameras. Australian Mammalogy 35:131-135.

Hutley, L. B., J. Beringer, P. R. Isaac, J. M. Hacker, and L. A. Cernusak. 2011. A sub-continental scale living laboratory: Spatial patterns of savanna vegetation over a rainfall gradient in northern Australia. Agricultural and Forest Meteorology 151:1417-1428.

Jackson, B., S. WARD, S. Young, AND J. Woinarski. 2010. Research on small mammal decline and disease: Rattus rattus as a potential disease vector. Final Report to Kakadu National Park Ref No: K2010/0030. Biodiversity Conservation Division, NRETAS. Darwin NT.

Johnson, C. 2006. Australia's mammal extinctions: a 50,000 year history. Cambridge University Press. Port Melbourne.

Johnson, C. N., AND J. L. IsaAC. 2009. Body mass and extinction risk in Australian marsupials: the 'Critical Weight Range' revisited. Austral Ecology 34:35-40.

Johnson, C. N., And E. G. Ritchie. 2013. The dingo and biodiversity conservation in Australia: response to Fleming et al. (2012). Australian Mammalogy 35:8-14.

Jones, K. E., N. G. Patel, M. A. Levy, A. Storeygard, D. Balk, J. L. Gittleman, and P. Daszak. 2008. Global trends in emerging infectious diseases. Nature 451:990-993.

Kanowski, J. 2001. Effects of elevated CO2 on the foliar chemistry of seedlings of two rainforest trees from north-east Australia: implications for folivorous marsupials. Austral Ecology 26:165-172.

Kanowskl, J. 2004. What factors control the distribution and abundance of folivorous possums inhabiting rainforests of the Atherton Tablelands in north-east Queensland? Pp. 539-548 in The biology of Australian possums and gliders (Goldingay, R. L., and S. M. Jackson, eds.). Surrey Beatty and Sons. Chipping Norton.

Karadada, J., L. Karadada, W. Goonack, G. Mangolamara, W. Bunjuck, L. Karadada, B. Djanghara, S. Mangolamara, J. Оobagooma, A. Charles, D. Williams, R. Karadada, T. Saunders, and G. Wightman. 2011. Uunguu Plants and Animals. Wunambal Gaambera Aboriginal Corporation and Department of Natural Resources, Environment The Arts and Sport. Kalumburu.

Kearney, M., B. L. Phillips, C. R. Tracy, K. A. Christian, G. Betts, and W. P. Porter. 2008. Modelling species distributions without using species distributions: the cane toad in Australia under current and future climates. Ecography 31:423-434.

Kemper, C. M., AND L. H. Schmitt. 1992. Morphological variation between populations of the Brush-tailed Tree Rat (Conilurus penicillatus) in northern Australia and New Guinea. Australian Journal of Zoology 40:437-452. 
Kennedy, M., B. L. Phillips, S. Legge, S. A. Murphy, and R. Faulkner. 2011. Do dingoes suppress the activity of feral cats in northern Australia? Austral Ecology 37:134-139.

KerLE, J. A. 1985. Habitat preference and diet of the northern brushtail possum, Trichosurus arnhemensis in the Alligator Rivers Region, N. T. Proceedings of the Ecological Society of Australia 13:171-182.

KIRKPatrick, T. H., AND H. J. Lavery. 1979. Fauna surveys in Queensland. Queensland Journal of Agriculture and Animal Science 36:181-188.

Kitchener, D. J. 1978. Mammals of the Ord River area, Kimberley, Western Australia. Records of the Western Australian Museum 6:189-217.

Kutt, A., L. Felderhof, J. Van Der Wal, P. Stone, and G. Perkins. 2009. Terrestrial ecosystems of northern Australia. Canberra.

Kutt, A. S. 2012. Feral cat (Felis catus) prey size and selectivity in north-eastern Australia: implications for mammal conservation. Journal of Zoology 287:292-300.

Kutt, A. S., AND A. Fisher. 2011. Increased grazing and dominance of an exotic pasture (Bothriochloa pertusa) affects vertebrate fauna species composition, abundance and habitat in savanna woodland. The Rangeland Journal 33:49-58.

KUTt, A.S., AND I. J. GoRdon. 2012. Variation in terrestrial mammal abundance on pastoral and conservation land tenures in north-eastern Australian tropical savannas. Animal Conservation 15:416-425.

Kutt, A. S., E. P. Vanderduys, J. J. Perry, G. C. Perkins, J. E. Kemp, B. L. Bateman, J. Kanowski, and R. Jensen. 2012. Signals of change in tropical savanna woodland vertebrate fauna 5 years after cessation of livestock grazing. Wildlife Research 39:386-396.

KUTt, A. S., AND J. C. Z. WoinaRSKI. 2007. The effects of grazing and fire on vegetation and the vertebrate assemblage in a tropical savanna woodland in north-eastern Australia. Journal of Tropical Ecology 23:95-106.

Langford, D., AND A. A. BuRbidge. 2001. Translocation of mala from the Tanami Desert, Northern Territory to Trimouille Island, Western Australia. Australian Mammalogy 23:37-46.

Latch, P. 2008. Recovery plan for the Bramble Cay Melomys Melomys rubicola. Environmental Protection Agency. Brisbane.

LaURAnCE, W. F. 2004. Forest-climate interactions in fragmented tropical landscapes. Philosophical Transactions of the Royal Society B: Biological Sciences 359:345-352.

Lawes, M. J., B. P. Murphy, A. Fisher, J. C. Z. Woinarski, A. Edwards, and J. Russell-Smith. in press. Fire ecology and Aboriginal land management in central Arnhem Land, northern Australia: a tradition of ecosystem management. International Journal of Wildland Fire

LeaHY, L. 2013. Responses of small mammals to fire in Australia's tropical savannas: a mechanistic approach. (Honours thesis). University of Tasmania. Hobart.

Leahy, L., S. M. Legge, K. Tuft, H. Mcgregor, L. Barmuta, M. Jones, and C. N. Johnson. in review. Amplified predation after fire drives declines of small mammals in Australia's tropical savannas. Wildlife Research

Legge, S., M. S. Kennedy, R. Lloyd, S. Murphy, and A. Fisher. 2011 a. Rapid recovery of mammal fauna in the central Kimberley, northern Australia, following removal of introduced herbivores. Austral Ecology 36:791-799.

Legge, S., S. Murphy, J. Heathcote, E. Flaxman, J. Augusteyn, and M. Crossman. 2008. The short-term effects of an extensive and high-intensity fire on vertebrates in the tropical savannas of the central Kimberley, northern Australia. Wildlife Research 35:33-43.

Legge, S., S. Murphy, R. Kingswood, B. Maher, and D. Swan. 2011b. EcoFire: restoring the biodiversity values of the Kimberley region by managing fire. Ecological Management and Restoration 12:8492.

Letnic, M., And C. R. Dickman. 2010. Resource pulses and mammalian dynamics: conceptual models for hummock grasslands and other Australian desert habitats. Biological Reviews 85:501-521. 
Letnic, M., E. Ritchie, And C. Dickman. 2012. Top predators as biodiversity regulators: the dingo Canis lupus dingo as a case study. Biological Reviews 87:390-413.

Letnic, M., J. K. WebB, T. S. Jessop, D. Florance, And T. Dempster. 2014. Artificial water points facilitate the spread of an invasive vertebrate in arid Australia. Journal of Applied Ecology51:795-803.

Letnic, M., J. K. WebB, And R. Shine. 2008. Invasive cane toads (Bufo marinus) cause mass mortality of freshwater crocodiles (Crocodylus johnstoni) in tropical Australia. Biological Conservation 141:17731782.

Lindenmayer, D., R. B. Cunningham, M. T. Tanton, And A. P. Smith. 1990. The conservation of arboreal marsupials in the montane ash forests of the Central Highlands of Victoria, south-east Australia: II The loss of trees with hollows and its implications for the conservation of Leadbeater's Possum Gymnobelideus leadbeateri McCoy (Marsupiala: Petauridae). Biological Conservation 54:133-145.

Lunney, D., B. Law, M. Schulz, And M. Pennay. 2011. Turning the spotlight onto the conservation of Australian bats and the extinction of the Christmas Island Pipistrelle. Pp. 485-498 in The biology and conservation of Australasian bats (Law, B., P. Eby, D. Lunney, and I. Lumsden, eds.). Royal Zoological Society of NSW. Mosman.

Marsh, H., A. Dennis, H. Hines, A. Kutt, K. Mcdonald, E. Weber, S. Williams, and J. Winter. 2007. Optimizing allocation of management resources for wildlife. Conservation Biology 21:387-399.

Martin, R. E., AND D. B. Sapsis. 1992. Fires as agents of biodiversity: pyrodiversity promotes biodiversity. Pp. 150-157 in Proceedings of the Ssymposium on Biodiversity in Northwestern California, 1991 (Kerner, H. M., ed.). Wildland Resources Centre, University of California. Berkeley.

McGReGoR, H. W. 2014. Hunting behavior of feral cats in relation to fire and grazing in northern Australia (PhD thesis). University of Tasmania. Hobart.

Mcgregor, H. W., S. LegGe, M. E. Jones, ANd C. N. Johnson. 2014. Landscape management of fire and grazing regimes alters the fine-scale habitat utilisation by feral cats. PloS ONE 9:e109097.

Mckenzie, N., And A. Burbidge. 2002. Australian Mammal Audit: A Component of the National Land and Water Resources Biodiversity Audit. Department of Conservation and Land Management, W. A. Perth.

Mckenzie, N. L. 1981. Mammals of the Phanerozoic south-west Kimberley, Western Australia: biogeography and recent changes. Journal of Biogeography 8:263-280.

Mckenzie, N. L., A. A. Burbidge, A. Baynes, R. N. Brereton, C. R. Dickman, G. Gordon, L. A. Gibson, P. W. Menkhorst, A. C. Robinson, M. R. Williams, and J. C. Z. Woinarski. 2007. Analysis of factors implicated in the recent decline of Australia's mammal fauna. Journal of Biogeography 34:597-611.

Milne, D. J., And C. R. Pavey. 2011. The status and conservation of bats in the Northern Territory. Pp. 208-225 in The biology and conservation of Australasian bats. (Law, B., P. EbyY, D. Lunney, and L. Lumsden, eds.). Royal Zoological Society of New South Wales. Sydney.

Molsher, R., A. Newsome, and C. R. Dickman. 1999. Fedding ecology and population dynamics of the feral cat (Felis catus) in relation to the availability of prey in central-eastern New South Wales. Wildlife Research 26:593-607.

Moritz, C., E. J. Ens, S. Potter, and R. A. Catullo. 2013. The Australian monsoon tropics: an opportunity to protect biodiversity and secure benefits for Aboriginal communities. Pacific Conservation Biology 19:343-355.

Moseby, K., H. Neilly, J. Read, and H. Crisp. 2012. Interactions between a top order predator and exotic mesopredators in the Australian rangelands. International Journal of Ecology e250352:

Moseby, K. E., B. M. Hill, AND J. L. Read. 2009. Arid Recovery a comparison of reptile and small mammal populations inside and outside a large rabbit, cat, and fox-proof exclosure in arid South Australia. Austral Ecology 34:156-169.

Moseby, K. E., J. L. Read, D. C. Paton, P. Copley, B. M. Hill, and H. A. CRisp. 2011. Predation determines the outcome of 10 reintroduction attempts in arid South Australia. Biological Conservation 144:2863-2872. 
Murphy, B. P., M. A. Cochrane, and J. Russell-Smith. in review. Prescribed burning protects endangered tropical heathlands of the Arnhem Plateau. Journal of Applied Ecology

Murphy, B. P., And H. F. Davies. 2014. There is a critical weight range for Australia's declining tropical mammals. Global Ecology and Biogeography 23:1058-1061.

Newsome, T. M., G.-A. Ballard, P. J. S. Fleming, R. Van De Ven, G. L. Story, and C. R. Dickman. $2014 a$. Human-resource subsidies alter the dietary preferences of a mammalian top predator. Oecologia 175:139-150.

Newsome, T. M., J. A. Dellinger, C. R. Pavey, W. J. Ripple, C. R. Shores, A. J. Wirsing, and C. R. Dickman. 2014b. The ecological effects of providing resource subsidies to predators. Global Ecology and Biogeography 24:1-11.

Nias, R. C., A. A. Burbidge, D. Ball, And R. L. Pressey. 2010. Island arks: the need for an Australian national island biosecurity initiative. Ecological Management \& Restoration 11:166-167.

O'donnelt, S., J. K. WebB, And R. Shine. 2010. Conditioned taste aversion enhances the survival of an endangered predator imperilled by a toxic invader. Journal of Applied Ecology 47:558-565.

OAкwood, M. 2000. Reproduction and demography of the northern quoll, Dasyurus hallucatus, in the lowland savanna of northern Australia. Australian Journal of Zoology 48:519-539.

Oakwood, M., and D. Pritchard. 1999. Little evidence of toxoplasmosis in a declining species, the northern quoll (Dasyurus hallucatus). Wildlife Research 26:329-333.

Oakwood, M., and D. M. Spratt. 1999. Parasites of the northern quoll, Dasyurus hallucatus (Marsupialia : Dasyuridae) in tropical savanna, Northern Territory. Australian Journal of Zoology 48:79-90.

Palmer, C., R. Taylor, and A. Burbidge. 2003. Recovery plan for the Golden Bandicoot Isoodon auratus and Golden-backed Tree-rat Mesembriomys macrurus 2004-2009. Northern Territory Department of Infrastructure Planning and Environment. Darwin.

Pardon, L. G., B. W. Brook, A. D. Griffiths, And R. W. Braithwaite. 2003. Determinants of survival for the northern brown bandicoot under a landscape-scale fire experiment. Journal of Animal Ecology 72:106-115.

Parr, C. L., and A. N. Andersen. 2006. Patch mosaic burning for biodiversity conservation: a critique of the pyrodiversity paradigm. Conservation Biology 20:1610-1619.

Parr, C. L., J. C. Z. Woinarski, And D. J. Pienaar. 2009. Cornerstones of biodiversity conservation? Comparing the management effectiveness of Kruger and Kakadu National Parks, two key savanna reserves. Biodiversity and Conservation 18:3643-3662.

Pastro, L. A., C. R. Dickman, And M. Letnic. 2011. Burning for biodiversity or burning biodiversity? Prescribed burn vs. wildfire impacts on plants, lizards, and mammals. Ecological Applications 21:3238-3253.

Pavey, C. 2006. National Recovery Plan for the Greater Bilby Macrotis lagotis. Northern Territory Department of Natural Resources, Environment and the Arts. Alice Springs.

Pepper, M., And J. S. Keogh. 2014. Biogeography of the Kimberley, Western Australia: a review of landscape evolution and biotic responses in an ancient refugium. Journal of Biogeography 41:1443-1455.

Plowright, R. K., H. E. Field, C. Smith, A. Divljan, C. Palmer, G. Tabor, P. Daszak, and J. E. Foley. 2008. Reproduction and nutritional stress are risk factors for Hendra virus infection in little red flying foxes (Pteropus scapulatus). Proceedings of the Royal Society B: Biological Sciences 275:861-869.

Potter, S., R. L. Close, D. A. Taggart, S. J. B. Cooper, and M. D. B. Eldridge. 2014a. Taxonomy of rockwallabies, Petrogale (Marsupialia: Macropodidae). IV. Multifaceted study of the brachyotis group identifies additional taxa. Australian Journal of Zoology 62:401-414.

Potter, S., S. J. B. Cooper, C. J. Metcalfe, D. A. Taggart, and M. D. B. Eldridge. 2012a. Phylogenetic relationships of rock-wallabies, Petrogale (Marsupialia: Macropodidae) and their biogeographic history within Australia. Molecular Pylogenetics and Evolution 62:640-652. 
Potter, S., M. D. B. Eldridge, D. A. Taggart, and S. J. B. Cooper. 2012b. Multiple biogeographic barriers identified across the monsoon tropics of northern Australia: phylogeographic analysis of the brachyotis group of rock-wallabies. Molecular Ecology 21:2254-2269.

Potter, S., D. Rosauer, J. S. Doody, M. J. WebB, And M. D. B. Eldridge. 2014b. Persistence of a potentially rare mammalian genus (Wyulda) provides evidence for areas of evolutionary refugia within the Kimberley, Australia. Conservation Genetics 15:1085-1094.

Price, O. F., A. C. Edwards, And J. Russell-Smith. 2007. Efficacy of permanent firebreaks and aerial prescribed burning in western Arnhem Land, Northern Territory, Australia. International Journal of Wildland Fire 16:295-307.

Price, O. F., B. Rankmore, D. Milne, C. Brock, C. Tynan, L. Kean, and L. Roeger. 2005. Regional patterns of mammal abundance and their relationship to landscape variables in eucalypt woodlands near Darwin, northern Australia. Wildlife Research 32:435-446.

Prowse, T. A. A., C. N. Johnson, P. Cassey, C. J. A. Bradshaw, and B. W. Brook. 2014. Ecological and economic benefits to cattle rangelands of restoring an apex predator. Journal of Applied Ecology doi:10.1111/1365-2664.12378:

RADFord, I. J. 2010. Fire regimes and regional biodiversity declines in north-west Australian tropical savannas? Review of knowledge and recommendations for future research. Conservation Science Western Australia 7:469-479.

RADFORD, I. J. 2012. Threatened mammals become more predatory after small scale prescribed fires in a high-rainfall rocky savanna. Austral Ecology 37:926-935.

Radford, I. J., C. R. Dickman, A. N. Start, C. Palmer, K. Carnes, C. Everitt, R. Fairman, G. Graham, T. Partridge, And A. Thomson. 2014. Mammals of Australia's Tropical Savannas: A Conceptual Model of Assemblage Structure and Regulatory Factors in the Kimberley Region. PloS one 9:e92341.

Rankmore, B. R., A. D. Griffiths, J. C. Z. Woinarski, B. L. GanambarR, R. Taylor, K. Brennan, K. Firestone, and M. CARDoso. 2008. Island translocation of the northern quoll Dasyurus hallucatus as a conservation response to the spread of the cane toad Chaunus (Bufo) marinus in the Northern Territory, Australia. Darwin.

Reardon, T. B., N. L. Mckenzie, S. Cooper, B. Appleton, S. Carthew, and M. Adams. 2014. A molecular and morphological investigation of species boundaries and phylogenetic relationships in Australian free-tailed bats Mormopterus (Chiroptera: Molossidae). Australian Journal of Zoology 62:109-136.

Reardon, T. B., S. K. A. Robson, J. G. Parsons, and T. Inkster. 2010. Review of the threatened status of microchiropteran bat species on Cape York Peninsula. South Australian Museum. Adelaide.

Reside, A. E., J. Vanderwal, A. Kutt, I. Watson, and S. Williams. 2012. Fire regime shifts affect bird species distributions. Diversity and Distributions 18:213-225.

Ritchie, E. G. 2010. Ecology and conservation of the antilopine wallaroo: an overview of current knowledge. Pp. 179-186 in Macropods: The Biology of Kangaroos, Wallabies, and Rat-kangaroos. (Coulson, G. and M. D. B. Eldridge, eds.). CSIRO Publishing. Melbourne.

Ritchie, E. G., And E. E. Bolitho. 2008. Australia's savanna herbivores: bioclimatic distributions and an assessment of the potential impact of regional climate change. Physiological and Biochemical Zoology 81:880-890.

Ritchie, E. G., C. J. A. Bradshaw, C. R. Dickman, R. Hobbs, C. N. Johnson, E. L. Johnston, W. F. Laurance, D. Lindenmayer, M. A. Mccarthy, D. G. Nimmo, H. H. Possingham, R. L. Pressey, D. M. Watson, and J. C. Z. Woinarskı. 2013. Continental-scale governance and the hastening of loss of Australia's biodiversity. Conservation Biology 27:1133-1135.

Ritchie, E. G., C. R. Dickman, M. Letnic, and A. T. Vanak. 2014. Dogs as predators and trophic regulators. Pp. in Free-Ranging Dogs and Wildlife Conservation (Gompper, M. E., ed.). Oxford University Press. Oxford.

Ritchie, E. G., B. Elmhagen, A. S. Glen, M. Letnic, G. Ludwig, and R. A. Mcdonald. 2012. Ecosystem restoration with teeth: what role for predators? Trends in Ecology and Evolution 27:265-271. 
Ritchie, E. G., And C. N. Johnson. 2009. Predator interactions, mesopredator release and biodiversity conservation. Ecology Letters 12:982-998.

Ritchie, E. G., J. K. Martin, C. N. Johnson, And B. J. Fox. 2009. Separating the influences of environment and species interactions on patterns of distribution and abundance: competition between large herbivores. Journal of Animal Ecology 78:724-731.

Ritchie, E. G., J. K. Martin, A. K. Krockenberger, S. Garnett, and C. N. Johnson. 2008. Large-herbivore distribution and abundance: Intra-and interspecific niche variation in the tropics. Ecological Monographs 78:105-122.

Russell-Smith, J., G. D. Cook, P. M. Cooke, A. C. Edwards, M. Lendrum, C. P. Meyer, and P. J. Whitehead. 2013. Managing fire regimes in north Australian savannas: applying Aboriginal approaches to contemporary global problems. Frontiers in Ecology and the Environment 11:55-63.

Russell-Smith, J., A. Edwards, J. Woinarski, A. Fisher, B. P. Murphy, M. Lawes, B. Crase, and N. Thurgate. 2014. North Australian tropical savannas: the three parks savanna fire-effects plot network. Pp. 335-378 in Biodiversity and environmental change: monitoring, challenges and direction (Lindenmayer, D., E. Burns, N. Thurgate, and A. Lowe, eds.). CSIRO Publishing. Melbourne.

Russell-Smith, J., AND A. C. Edwards. 2006. Seasonality and fire severity in savanna landscapes of monsoonal northern Australia. International Journal of Wildland Fire 15:541-550.

Russell-Smith, J., A. C. Edwards, J. C. Z. Woinarski, J. Mccartney, S. Kerin, S. Winderlich, B. P. Murphy, and F. WATT. 2009a. Fire and biodiversity monitoring for conservation managers: a 10-year assessment of the 'Three Parks' (Kakadu, Litchfield and Nitmiluk) program. Pp. 257-286 in Culture, ecology and economy of fire management in north Australian savannas: rekindling the wurrk tradition. (Russell-Smith, J., P. J. Whitehead and P. Cooke, eds.). CSIRO Publishing. Collingwood.

Russell-Smith, J., P. G. Ryan, and D. C. Cheal. 2002. Fire regimes and the conservation of sandstone heath in monsoonal northern Australia: frequency, interval, patchiness. Biological Conservation 104:91-106.

Russell-Smith, J., P. G. Ryan, D. Klessa, G. Waight, and R. Harwood. 1998. Fire regimes, fire-sensitive vegetation and fire management of the sandstone Arnhem Plateau, monsoonal northern Australia. Journal of Applied Ecology 35:829-846.

Russell-Smith, J., P. J. Whitehead, And P. Cooke (eds). 2009b. Culture, Ecology, and Economy of Fire Management in North Australian Savannas: Rekindling the Wurrk Tradition. CSIRO Publishing. Collingwood.

Russell-Smith, J., C. Yates, A. Edwards, G. Allan, G. Cook, P. Cooke, R. Craig, B. Heath, and R. Smith. 2003. Contemporary fire regimes of northern Australia, 1997-2001: Change since Aboriginal occupancy, challenges for sustainable management. International Journal of Wildland Fire 12:283-297.

Russell-Smith, J., A. C. Edwards, And O. F. Price. 2012. Simplifying the savanna: the trajectory of firesensitive vegetation mosaics in northern Australia. Journal of Biogeography 39:1303-1317.

Savolainen, P., T. Leitner, A. N. Wilton, E. Matisoo-Smith, And J. Lundeberg. 2004. A detailed picture of the origin of the Australian dingo, obtained from the study of mitochondrial DNA. Proceedings of the National Academy of Sciences 101:12387-12390.

Schnell, I. B., P. F. Thomsen, N. Wilkinson, M. Rasmussen, L. R. D. Jensen, E. Willerslev, M. F. Bertelsen, and M. T. P. GiLbert. 2012. Screening mammal biodiversity using DNA from leeches. Current Biology 22:262-263.

Schulz, M. And B. Thomson. 2007. National recovery plan for the bare-rumped sheathtail bat Saccolaimus saccolaimus nudicluniatus. Queensland Environmental Protection Agency. Brisbane.

Serena, M. (eds). 1994. Reintroduction biology of Australian and New Zealand fauna. Surrey Beatty and Sons. Chipping Norton.

Setterfield, S. A., N. A. Rossiter-Rachor, M. M. Douglas, L. Wainger, A. M. Petty, P. Barrow, I. J. Shepherd, AND K. B. Ferdinands. 2013. Adding fuel to the fire: The impacts of non-native grass invasion on fire management at a regional scale. PloS ONE 8:e59144. 
Setterfield, S. A., N. A. Rossiter-Rachor, L. B. Hutley, M. M. Douglas, and R. J. Williams. 2010. Turning up the heat: the impacts of Andropogon gayanus (gamba grass) invasion on fire behaviour in northern Australia. Diversity and Distributions 16:854-861.

Shine, R. 2010. The ecological impact of invasive cane toads (Bufo marinus) in Australia. Quarterly Review of Biology 85:253-291.

SkerRatT, L. F. 2005. Sarcoptes scabiei: an important exotic pathogen of wombats. Microbiology Australia 26:79-81.

Slack, A. T., M. L. Symonds, M. F. Dohnt, And L. D. Smythe. 2006. The epidemiology of leptospirosis and the emergence of Leptospira borgpetersenii serovar Arborea in Queensland, Australia, 1998-2004. Epidemiology and Infection 134:1217-1225.

Smith, A., P. Clark, S. Averis, A. J. Lymbery, A. F. Wayne, K. D. Morris, and R. C. A. Thompson. 2008. Trypanosomes in a declining species of threatened Australian marsupial, the brush-tailed bettong Bettongia penicillata (Marsupialia: Potoroidae). Parasitology 135:1329-1335.

Smythe, L. D., H. E. Field, L. J. Barnett, C. S. Smith, M. F. Dohnt, M. L. Symonds, M. R. Moore, and P. F. Rolfe. 2002. Leptospiral antibodies in flying foxes in Australia. Journal of Wildlife Diseases 38:182-186.

St Cloud, S. F. 1966. Observation by J. James at Tinaroo Creek. North Queensland Naturalist 34:6.

Start, A. N., A. A. Burbidge, M. C. Mcdowell, and N. L. Mckenzie. 2012. The status of non-volant mammals along a rainfall gradient in the south-west Kimberley, Western Australia. Australian Mammalogy 34:36-48.

Start, A. N., A. A. Burbidge, N. L. Mckenzie, and C. Palmer. 2007. The status of mammals in the North Kimberley, Western Australia. Australian Mammalogy 29:1-16.

Szabo, J. K., S. H. M. Butchart, H. P. Possingham, and S. T. Garnett. 2012. Adapting global biodiversity indicators to the national scale: a Red List Index for Australian birds. Biological Conservation 148:6168.

Telfer, W., AND M. Garde. 2006. Indigenous knowledge of rock kangaroo ecology in western Arnhem Land, Australia. Human Ecology 34:379-406.

Telfer, W. R., A. D. Griffiths, And D. M. J. S. Bowman. 2006. Scats can reveal the presence and habitat use of cryptic rock-dwelling macropods. Australian Journal of Zoology 54:325-334.

Telfer, W. R., A. D. Griffiths, And D. M. J. S. Bowman. 2008. The habitat requirements of four sympatric rockdwelling macropods of the Australian monsoon tropics. Austral Ecology 33:1033-1044.

Thompson, R. C. A., AND J. V. Conlan. 2011. Emerging issues and parasite zoonoses in the SE Asian and Australasian region. Veterinary Parasitology 181:69-73.

Thompson, R. C. A., A. J. Lymbery, And A. Smith. 2010a. Parasites, emerging disease and wildlife conservation. International Journal for Parasitology 40:1163-1170.

Thompson, R. C. A., A. Smith, A. J. Lymbery, S. Averis, K. D. Morris, And A. F. Wayne. 2010b. Giardia in Western Australian wildlife. Veterinary Parasitology 170:207-211.

Thomson, B., C. Pavey, and T. Reardon. 2001. National recovery plan for cave-dwelling bats, Rhinolophus philippensis, Hipposideros semoni and Taphozous troughtoni 2001-2005. Queensland Environmental Protection Agency. Brisbane.

Tingley, R., B. L. Phillips, M. Letnic, G. P. Brown, R. Shine, And S. J. E. Baird. 2013. Identifying optimal barriers to halt the invasion of cane toads Rhinella marina in arid Australia. Journal of Applied Ecology 50:129-137.

Traill, L. W., K. Perhans, C. E. Lovelock, A. Prohaska, S. Mcfallan, J. R. Rhodes, and K. A. Wilson. 2011. Managing for change: wetland transitions under sea-level rise and outcomes for threatened species. Diversity and Distributions 17:1225-1233.

Tuft, K., T. May, E. Page, and S. Legge. 2014. Translocation of the Pale Field Rat (Rattus tunneyi) to Wongalara (NT) from Mornington (WA). Australian Wildlife Conservancy. Perth.

Ujvari, B., M. Oakwood, and T. Madsen. 2013. Queensland northern quolls are not immune to cane toad toxin. Wildlife Research 40:228-231. 
Van Bommel, L., and C. N. Johnson. 2012. Good dog! Using livestock guardian dogs to protect livestock from predators in Australia's extensive grazing systems. Wildlife Research 39:220-229.

Van Dyck, S., I. Gynther, and A. Baker. 2013. Field companion to the mammals of Australia. New Holland Publishers. London.

Van Dyck, S., And R. Strahan. 2008. The Mammals of Australia. Reed New Holland. Sydney.

Vanderduys, E. P., A. S. Kutt, AND J. E. Kemp. 2012. Upland savannas: the vertebrate fauna of largely unknown but significant habitat in north-eastern Queensland. Australian Journal of Zoology 36:59-74.

Vardon, M. J., S. M. Gaston, J. Niddrie, and G. J. W. WebB. 1999. Wildlife use at Momega, north-central Arnhem Land. Australian Biologist 12:15-22.

Wadley, J. J., J. J. Austin, And D. A. Fordham. 2013. Rapid species identification o eight sympatric northern Australian macropods from faecal-pellet DNA. Wildlife Research 40:241-249.

Warren, K. S., R. A. Swan, U. M. Morgan-Ryan, J. A. Friend, and A. Elloot. 2003. Cryptosporidium muris infection in bilbies (Macrotis lagotis). Australian Veterinary Journal 81:739-741.

Wayne, A. F., M. A. Maxwell, C. G. Ward, C. V. Vellios, B. G. Ward, G. L. Liddelow, I. Wilson, J. C. Wayne, and M. R. Williams. 2013a. Importance of getting the numbers right: quantifying the rapid and substantial decline of an abundant marsupial, Bettongia penicillata. Wildlife Research 40:169-183.

Wayne, A. F., M. A. Maxwell, C. G. Ward, C. V. Vellios, I. Wilson, J. C. Wayne, and M. R. Williams. 2013 b. Sudden and rapid decline of the abundant marsupial Bettongia penicillata in Australia. Oryx 2013:1-11.

Webb, J. K., G. P. Brown, T. Child, M. J. Greenlees, B. L. Phillips, and R. Shine. 2008. A native dasyurid predator (common planigale, Planigale maculata) rapidly learns to avoid a toxic invader. Austral Ecology 33:821-829.

Webb, J. K., D. Pearson, And R. Shine. 2011. A small dasyurid predator (Sminthopsis virginiae) rapidly learns to avoid a toxic invader. Wildlife Research 38:726-731.

Westerman, M., B. P. Kear, K. Aplin, R. W. Meredith, C. Emerling, and M. S. Springer. 2012. Phylogenetic relationships of living and recently extinct bandicoots based on nuclear and mitochondrial DNA sequences. Molecular Phylogenetics and Evolution 62:97-108.

Westoby, M., B. H. Walker, AND I. Noy-Meir. 1989. Opportunistic management for rangelands not at equilibrium. Journal of Range Management 42:266-274.

White, A. W., AND G. Madani. 2014. Ghost bat decline in north-western Queensland and the Northern Territory? Are cane toads implicated? The Australasian Bat Society Newsletter 42:45.

White, A. W., And D. R. Mason. 2011. The modern mammal fauna of Riversleigh and Boodjamullah National Park. Australian Zoologist 35:599-618.

Whitehead, P. J., D. M. J. S. Bowman, N. Preece, F. Fraser, and P. Cooke. 2003. Customary use of fire by indigenous peoples in northern Australia: its contemporary role in savanna management. International Journal of Wildland Fire 12:415-425.

Williams, R. J., R. A. Bradstock, G. J. Cary, N. J. Enright, A. M. Gill, A. C. Liedloff, C. Lucas, R. J. Whelan, A. N. Andersen, D. M. J. S. Bowman, P. J. Clarke, G. D. Cook, K. J. Hennessy, and A. York. 2009. Interactions between climate change, fire regimes and biodiversity in Australia - a preliminary assessment. Report to the Department of Climate Change and Department of the Environment, Water, Heritage and the Arts, Canberra. Darwin.

Williams, R. J., G. A. Duff, D. M. J. S. Bowman, And G. D. Cook. 1996a. Variation in the composition and structure of tropical savannas as a function of rainfall and soil texture along a large-scale climatic gradient in the Northern Territory, Australia. Journal of Biogeography 23:747-756.

Williams, R. J., J. C. Z. Woinarski, and A. N. Andersen. 2003a. Fire experiments in northern Australia: contributions to ecological understanding and biodiversity conservation in tropical savannas. International Journal of Wildland Fire 12:391-402. 
Williams, S. E., E. E. Bolitho, And S. Fox. 2003b. Climate change in Australian tropical rainforests: an impending environmental catastrophe. Proceedings of the Royal Society of London B. Biological Sciences 264:1887-1892.

Williams, S. E., R. G. Pearson, and P. J. Walsh. 1996b. Distributions and biodiversity of the terrestrial vertebrates of Australia's Wet Tropics: a review of current knowledge. Pacific Conservation Biology 2:327-362.

WINTER, J. W. 1997. Responses of non-volant mammals to Late Quateernary climatic changes in the wet tropics region of north-eastern Australia. Wildlife Research 24:493-512.

WoINARSKI, J. C. Z. 2004a. The forest fauna of the Northern Territory: knowledge, conservation and management. Pp. 36-55 in Conservation of Australia's Forest Fauna (Lunnay, D., eds.). Royal Zoological Society of New South Wales. Sydney.

Woinarski, J. C. Z. 2004b. National multi-species recovery plan for the Carpentarian Antechinus Pseudantechinus mimulus, Butler's Dunnart Sminthopsis butleri and Northern Hopping-mouse Notomys aquilo, 2004-2008. Northern Territory Department of Infrastructure Planning and Environment. Darwin.

WoINARSKI, J. C. Z. 2014. The illusion of nature: perception and the reality of natural landscapes, as illustrated by vertebrate fauna in the Northern Territory, Australia. Ecological Management and Restoration 15:30-33.

WoINARSKI, J. C. Z. 2015. Critical-weight range marsupials in northern Australia are declining: a commentary on Fisher et al (2013) The current decline of tropical marsupials in Australia: is history repeating? Global Ecology and Biogeography 24:118-122.

Woinarski, J. C. Z., M. Armstrong, K. Brennan, A. Fisher, A. D. Griffiths, B. Hill, D. J. Milne, C. Palmer, S. Ward, M. Watson, S. Winderlich, AND S. Young. 2010. Monitoring indicates rapid and severe decline of native small mammals in Kakadu National Park, northern Australia. Wildlife Research 37:116-126.

Woinarski, J. C. Z., AND A. J. Ash. 2002. Responses of vertebrates to pastoralism, military land use and landscape position in an Australian tropical savanna. Austral Ecology 27:311-323.

Woinarski, J. C. Z., A. A. Burbidge, and P. L. Harrison. 2014. The Action Plan for Australian Mammals 2012. CSIRO Publishing. Melbourne.

WoinARSkI, J. C. Z., AND A. Fisher. 2003. Conservation and the maintenance of biodiversity in the rangelands. Rangeland Journal 25:157-171.

Woinarski, J. C. Z., J. Green, A. Fisher, M. Ensbey, and B. Mackey. 2013. The effectiveness of conservation reserves: land tenure impacts upon biodiversity across extensive natural landscapes in the tropical savannas of the Northern Territory, Australia. Land 2:20-36.

Woinarski, J. C. Z., C. Hempel, I. Cowie, K. Brennan, R. Kerrigan, G. Leach, and J. Russell-Smith. $2006 a$. Distributional pattern of plant species endemic to the Northern Territory, Australia. Australian Journal of Botany 54:627-640.

Woinarski, J. C. Z., R. Hokkanen, D. Milne, and M. Armstrong. 2008. Long-term vertebrate fauna monitoring Rio Tinto Alcan Gove rehabilitation monitoring. Report to Matrix+. Department of Natural Resources, Environment and The Arts. Darwin.

Woinarski, J. C. Z., S. Legge, J. A. Fitzsimons, B. J. Traill, A. A. Burbidge, A. Fisher, R. S. C. Firth, I. J. Gordon, A. D. Griffiths, C. N. Johnson, N. L. Mckenzie, C. Palmer, I. Radford, B. Rankmore, E. G. Ritchie, S. Ward, AND M. ZIEMBICKI. 2011a. The disappearing mammal fauna of northern Australia: context, cause, and response. Conservation Letters 4:192-201.

Woinarski, J. C. Z., B. Mackey, H. Nix, And B. Traill. 2007. The Nature of Northern Australia: natural values, ecological processes and future prospects. ANU e-press. Canberra.

Woinarski, J. C. Z., J. C. Mccosker, G. Gordon, B. Lawrie, C. James, J. Augusteyn, L. Slater, and T. Danvers. $2006 \mathrm{~b}$. Monitoring change in the vertebrate fauna of central Queensland, Australia, over a period of broadscale vegetation clearance, 1973-2002. Wildlife Research 33:263-274. 
Woinarski, J. C. Z., D. J. Milne, And G. Wanganeen. 2001. Changes in mammal populations in relatively intact landscapes of Kakadu National Park, Northern Territory, Australia. Austral Ecology 26:360370.

Woinarski, J. C. Z., C. Palmer, A. Fisher, R. Southgate, P. Masters, and K. Brennan. 1999. Distributional patterning of mammals on the Wessel and English Company Islands, Arnhem Land, Northern Territory, Australia. Australian Journal of Zoology 47:87-111.

Woinarski, J. C. Z., B. Rankmore, B. Hill, A. D. Griffiths, A. Stewart, and B. Grace. 2009a. Fauna assemblages in regrowth vegetation in tropical open forests of the Northern Territory, Australia. Wildlife Research 36:675-690.

Woinarski, J. C. Z., J. Risler, And L. Kean. 2004. Response of vegetation and vertebrate fauna to 23 years of fire exclusion in a tropical Eucalyptus open forest, Northern Territory, Australia. Austral Ecology 29:156-176.

Woinarski, J. C. Z., J. Russell-Smith, A. Andersen, and K. Brennan. 2009b. Fire management and biodiversity of the western Arnhem Land plateau. Pp. 201-228 in Culture, ecology and economy of fire management in north Australian savannas: rekindling the wurrk tradition (Russel-Smith, J., P. J. Whitehead and P. Cooke, eds.). CSIRO Publishing. Collingwood.

Woinarski, J. C. Z., S. Ward, T. Mahney, J. Bradley, K. Brennan, M. Ziembicki, and A. Fisher. 2011 b. The mammal fauna of the Sir Edward Pellew island group, Northern Territory, Australia: refuge and death-trap. Wildlife Research 38:307-322.

WoinarSKI, J. C. Z., AND S. Winderlich. 2014. Optimising management actions or the conservation of threatened speces in Kakadu National Park. Background paper for Kakadu National ParkThreatened Species Strategy. North Australian Hub of the National Environmental Research Program. Darwin.

Woolproducers Australia. 2014. National Wild Dog Action Plan: Promoting and supporting communitydriven action for landscape-scale wild dog management. WoolProducers Australia. Canberra.

Wyatt, K. B., P. F. Campos, M. T. P. Gilbert, S.-O. Kolokotronis, W. H. Hynes, R. Desalle, S. J. Ball, P. Daszak, R. D. E. Macphee, And A. D. Greenwood. 2008. Historical mammal extinction on Christmas Island (Indian Ocean): correlates with introduced infectious disease. PLoS ONE 3:e3602.

Yates, C. P., A. C. Edwards, And J. Russell-Smith. 2008. Big fires and their ecological impacts in Australian savannas: size and frequency matters. International Journal of Wildland Fire 17:768-781.

Yibarbuk, D., P. J. Whitehead, J. Russell-Smith, D. Jackson, C. Godjuwa, A. Fisher, P. Cooke, D. Choquenot, and D. M. J. S. Bowman. 2001. Fire ecology and Aboriginal land management in central Arnhem Land, northern Australia: a tradition of ecosystem management. Journal of Biogeography 28:325-343.

Ziembicki, M. R., J. C. Z. Woinarski, AND B. Mackey. 2013. Evaluating the status of species using Indigenous knowledge: Novel evidence for major native mammal declines in northern Australia. Biological Conservation 157:78-92.

Summited: September 30, 2014

Review: January 15, 2015

Accepted: January 28, 2015

Associated editor: William Lidicker 